\title{
Geotechnical engineering and frontier resource development
}

\author{
N. R. MORGENSTERN*
}

The traditional concepts that constitute the framework for geotechnical engineering are often insufficient on their own to provide a basis for solving geotechnical problems associated with frontier resource developments. Studies are reported on the creep of permafrost slopes, the mechanics of heave in freezing soils and the behaviour of frozen soils subjected to thaw to illustrate this. These problems are encountered in the exploration and production of hydrocarbon resources in the Arctic. Considerations of ice rheology, fundamental thermodynamics and heat conduction in soils are additional concepts needed to solve these problems. Other examples are drawn from the geotechnical concerns that enter into the development of the Alberta oil sands. Here the geotechnical engineer must deal with gas-saturated, diagenetically-altered sands and with deformability and strength under high temperatures. Illustrations are given of the novel forms of behaviour encountered under these conditions. Initial results are presented of pore pressures developed under undrained heating and of the theoretical relation between the rate of heating and the dissipation of pore pressures.

Rankine is actually better known for his work on themodynamics and properties of fluids and gases than for his work on earth pressure and therefore it seems fitting in a Rankine Lecture to draw attention to the significance of the main body of Rankine's work in many new areas of geotechnical endeavour.

Les concepts traditionnels sur lesquels se base le génie géotechnique ne suffisent souvent pas, à eux seuls, à permettre de résoudre les problèmes géotechniques associés au développement des ressources frontalières. Pour illustrer ce point, il est fait mention d'études sur le fluage de pentes à gel permanent, la mécanique du soulèvement dans des sols en train de geler, et le comportement de sols gelés soumis au dégel. Ces problèmes se posent lors de l'exploration et de la production de ressources hydrocarbonées en Arctique. La rhéologie de la glace, la thermodynamique élémentaire ainsi que la transmission de la chaleur dans les sols sont des concepts supplémentaires nécessaires à la résolution de ces problèmes. D'autres exemples sont tirés des préoccupations d'ordre géotechnique relatives au développement des Sables Pérolifères de l'Alberta. Dans ce cas, l'ingénieur géotechnique a affaire à des sables saturés de gaz diagénétiquement modifiés et qui présentent une certaine déformabilité et une résistance à des températures élevées. Les nouveaux types de comportement rencontrés dans ces

\footnotetext{
* University of Alberta.
}

conditions sont décrits. Des premièrs résultats sont présentés pour les pressions interstitielles engendrées par le chauffage sans drainage, ainsi que pour le rapport théorique entre l'intensité du chauffage et la dissipation des pressions interstitielles. Rankine est, en fait, mieux connu pour ses travaux sur la thermodynamique et les propriétés de fluides et de gaz que pour ses travaux sur la poussée des terres et il semble donc approprié, lors d'une conférence sur Rankine, d'attirer l'attention sur l'essentiel de son oeuvre et son influence dans bien des nouveaux domaines de la recherche géotechnique.

\section{INTRODUCTION}

In selecting the subject of this lecture, I have reflected on my activities since my return to Canada in 1968. Since that time I have had the opportunity of working on and conducting research into a variety of problems related to landslides, dams, foundations, etc. But most of all I have been involved in a series of novel geotechnical problems in remote environments and it is from this experience that $I$ have chosen to draw the material for this lecture. I hope that in so doing I will not convey information of only parochial interest, but will be able to convince you that results have emerged that are of wide scientific and engineering interest. These results have been obtained in attending to special problems associated with geotechnical engineering in frontier resource development with particular reference to the Arctic environment and to the exploitation of the Alberta oil sands. Figure 1 indicates the general region of activity, the location of some of the projects and some place names for guidance.

Geotechnical engineering is remarkable in the variety of materials that are encountered in the practice of it. This is indicated in Fig. 2 which contains a classification of geotechnical materials in terms of origin, composition and consistency. ${ }^{1}$ Figure 2 is not intended to include all earth materials but is meant merely to be illustrative of the range of materials met in professional practice. It is of interest to attempt to isolate those principles of geotechnical engineering that unify the subject and thereby provide a framework whereby activit-

\footnotetext{
1 The first version of this classification was produced by Professor A. W. Skempton in 1964.
} 


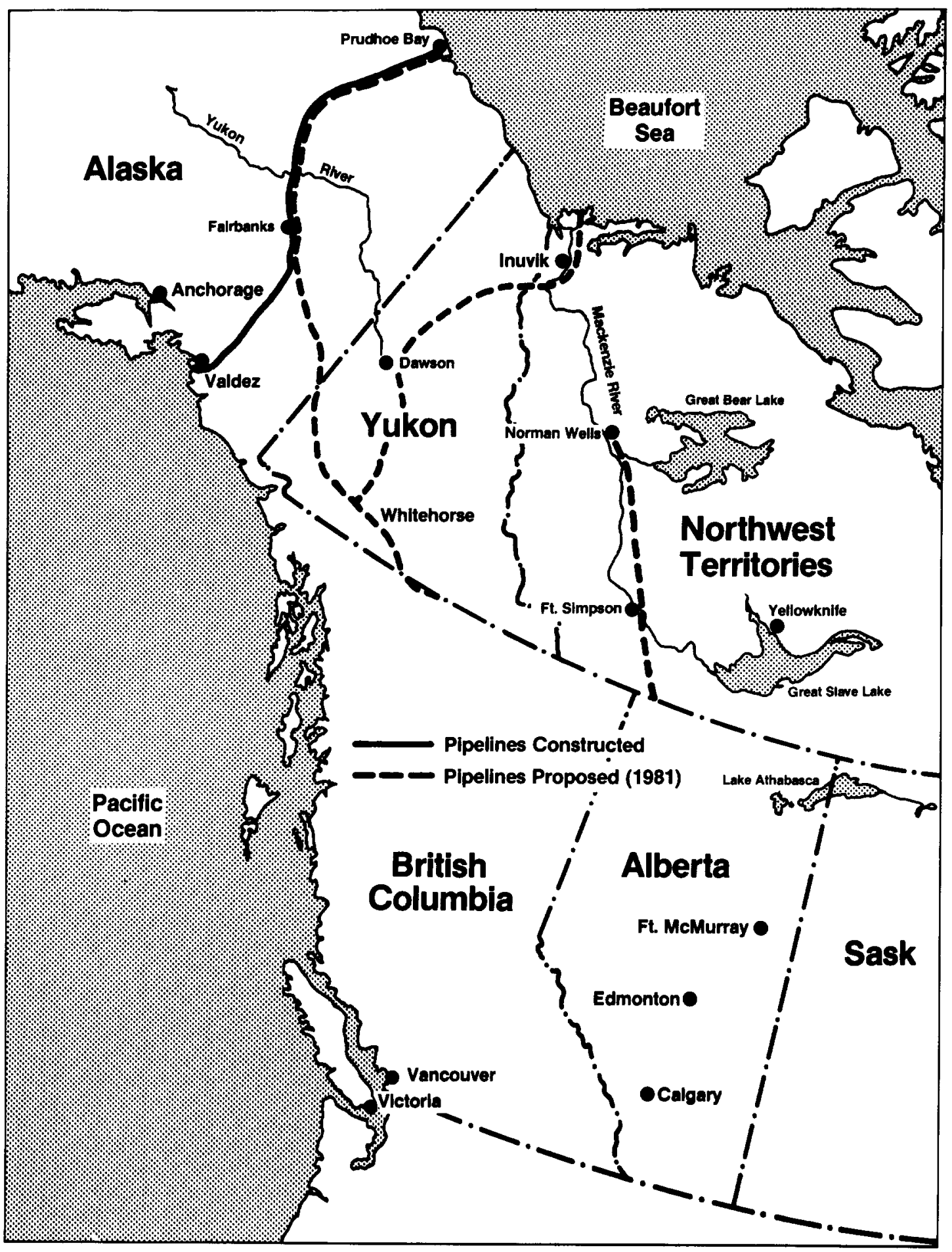

Fig. 1. Region and place names of interest 


\begin{tabular}{|c|c|c|c|c|c|c|c|}
\hline & \multicolumn{5}{|c|}{ Sedimentary } & \multirow{3}{*}{$\begin{array}{c}\text { Igneous } \\
\text { and } \\
\text { Metamorphic }\end{array}$} \\
\hline & & \multicolumn{2}{|c|}{ Clastic } & \multicolumn{2}{|c|}{ Chemical } & \multirow[t]{2}{*}{ Organic } & \\
\hline & & Arenaceous & Argillaceous & Carbonates & Evapourltes & & \\
\hline 둥 & Cohesionless & $\begin{array}{c}\text { Alluvial Sand } \\
\text { and } \\
\text { Gravel }\end{array}$ & Rock Flour & $\begin{array}{l}\text { Calcareous } \\
\text { Sands }\end{array}$ & $\begin{array}{c}\text { Gypsiferous } \\
\text { Sands }\end{array}$ & Topsoil & Talus \\
\hline נש & Cohesive & Oll Sand & $\begin{array}{c}\text { Clay } \\
\text { Clay Shale }\end{array}$ & $\begin{array}{l}\text { Oozes } \\
\text { Mart }\end{array}$ & & Peat & Laterite \\
\hline & Slaking and Soltoning & & & & & & \\
\hline$\div$ & $\begin{array}{c}\text { Soft } \\
\text { Compresuswe Strength }\end{array}$ & $\begin{array}{c}\text { Friable } \\
\text { Sandstone }\end{array}$ & Mudstone & Chalk & Gypsum & Lignite & $\begin{array}{l}\text { Weathered } \\
\text { Granite }\end{array}$ \\
\hline a & $\begin{array}{c}500 \mathrm{kPa} \\
\text { Hard }\end{array}$ & Sandstone & Shale & Limestone & Potash & Coal & Granile \\
\hline
\end{tabular}

Fig. 2. The range of geotechnical materials by origin, composition and consistency

ies over a broad spectrum of earth materials may be undertaken. It seems to me that there are three unifying concepts and they are

(a) the concept of effective stress: a rational explanation of the mechanical behaviour of soils and rocks is best developed in terms of effective stress

(b) the recognition of frictional behaviour: with few exceptions both stiffness and strength of soils and rocks increase with increasing effective normal stress

(c) a continual awareness of the role of structure detail: at one extreme a sample of soil amenable to laboratory testing may adequately characterize the structure of a soil while at the other extreme a discontinuity in otherwise sound rock may be the only element of practical interest; fissured clays and clay shales fall between these two extremes

For an increasing range of problems, these three unifying concepts do not, on their own, provide an adequate basis for the geotechnical engineer to resolve the problems that confront him. $\mathrm{He}$ is obliged instead to extend his considerations to additional physical concepts from thermodynamics, heat conduction and other physicochemical phenomena, in order to meet his obligations. Just as the explorer for resources extends the frontiers of technological activity, so the geotechnical engineer working with him expands the range of our activities.

$\mathrm{My}$ intent in this lecture is twofold: firstly, to bring to this Society a geotechnical perspective of the nature of these undertakings; and secondly, to encourage particularly our younger colleagues to abandon the view that geotechnical engineering is mature, ready for standardization, but instead to adopt the view that the range of natural materials is so great and the contribution of geotechnical engineering to many technological undertakings is so central, that the limits to our profession expand continually.

By way of presentation, firstly the way a particular problem or class of problems has arisen will be identified. Then the specific research undertaken to solve the problem will be discussed. This will be followed by a summary of the results and some comments on their broader applicability. This procedure will be repeated in a discussion of several issues the have arisen in the development of oil and gas resources in the Arctic and in Alberta.

\section{CREEP IN A NATURAL PERMAFROST SLOPE The problem}

There have been several proposals to bring both oil and gas pipelines down the Mackenzie Valley (Fig. 1). In order to contribute to the orderly design of these projects, as well as for fundamental scientific reasons, a series of research studies were undertaken into the nature of mass movements in permafrost terrain (e.g. McRoberts, 1973; McRoberts \& Morgenstern, 1974a,b; Pufahl, 1976). At least for the glaciated terrain of the Mackenzie Valley, it was found that slope failures occurred both through frozen ground and through thawing ground. The latter were far more frequent and were caused by high rates of thaw generating 


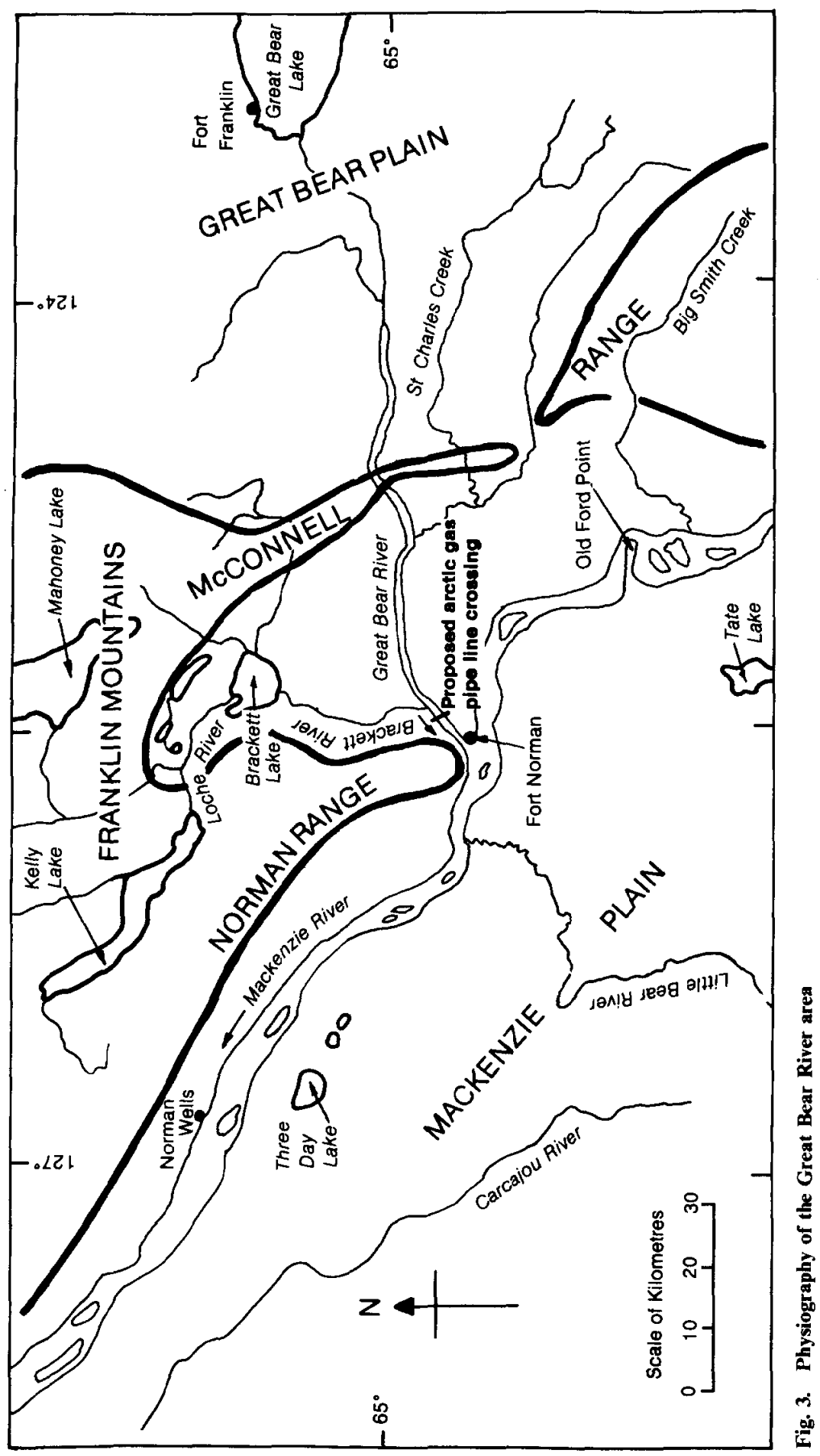


pore pressures, high rates of ablation at ice-rich faces or a variety of more conventional mechanisms in previously thawed material. Failure through frozen ground was a much less frequent occurrence and generally was restricted to large-scale features. The circumstances where failure through frozen ground had occurred or appeared likely could generally be avoided by judicious route location. However, if soil failure had been avoided, the possibility remained for long-term creep deformations, particularly in ice-rich materials, which could result in damage to the pipeline or to any other structure buried in the frozen ground.

Studies of the creep behaviour of frozen ground in the laboratory are not new. The subject is of interest in evaluating the support capacity of artificially frozen ground as well as naturally occurring permafrost. Comprehensive reviews have been published by Andersland \& Anderson (1978) and Vyalov, Dokuchayev \& Sheynkman (1980). However, most studies utilize artificially prepared specimens and experiments have usually been conducted at relatively cold temperatures and for comparatively short times. This is in contrast with the need to evaluate creep in the relatively warm, fine-grained, ice-rich, structurally non-homogeneous permafrost soils of the Mackenzie Valley. There are serious limitations to relying on laboratory tests under these conditions.

Ice is known to exhibit creep behaviour and the rheology of ice has been investigated extensively in both the laboratory and the field by glaciologists. It seems reasonable to assume that the creep of ice will provide a sensible upper bound to the creep of icerich frozen soil. ${ }^{2}$ Therefore, using data available at the time that expressed the secondary creep of soil in a power law relation, McRoberts (1975) adopted an infinite slope analysis to calculate the downslope velocities as a function of depth of ice-rich soil and slope inclination. For relatively warm ice (say, warmer than $-4^{\circ} \mathrm{C}$ ) the analysis indicated that surface velocities of about $10 \mathrm{~cm} /$ year might be expected on a slope with $10 \mathrm{~m}$ of ice-rich soil inclined at $15^{\circ}$ to the horizontal. This is a very aggressive geomorphological process and, if true, would be readily discernible in the field. Casual observation was not in accord with these predictions and it was recognized that the available data on creep of ice were probably of limited value in the range of stress, temperature and duration of testing of geotechnical interest.

The evaluation of creep in a natural permafrost slope is best undertaken in detail in the field and it was this phenomenon that was studied. Additional

\footnotetext{
${ }^{2}$ Actually a small amount soil will accentuate the creep characteristics of ice but adding additional mineral soil will lcad to an attenuation (Hooke et al., 1972).
}

studies were also undertaken to define the flow law of ice in more detail.

\section{Field studies}

The site selected for instrumentation is on the southern flank of Great Bear River, a major tributary of Mackenzie River. The site is about $7 \mathrm{~km}$ upstream from Fort Norman at the confluence of the two rivers and lies within the widespread discontinuous permafrost zone on the permafrost map of Canada. The site shown on Fig. 3 was selected for several reasons.

(a) It was an intended crossing for a proposed major pipeline.

(b) It was among the highest and steepest slopes in fine-grained soils encountered in the Mackenzie Valley.

(c) The stratigraphy was characteristic of extensive areas of Mackenzie Plain.

A cross-section of the Tertiary and Quaternary stratigraphy along this reach of Great Bear River is given in Fig. 4. The location is near the thalweg of a buried valley. This topographic low was preserved after the Wisconsin glaciation and received an anomalously large thickness of fine-grained sediment when glacial lakes became impounded in the area. The sediments are presently within the zone of discontinuous permafrost and characteristically contain ground ice in a reticulate network. They are overlain by a thick deposit of glaciodeltaic sand in the uplands, but only a thin veneer of organic soil is present on the steep slopes of the Great Bear River valley.

The field studies had four main objectives

(a) the installation of borehole inclinometers to measure in situ creep deformation in the icerich soils comprising the slope

(b) the installation of thermistor strings to establish the temperature gradient affecting each inclinometer casing

(c) the installation of piezometers below the base of the permafrost to assess the overall stability of the slope against deep-seated failure

(d) to obtain continuous undisturbed cores from each hole in order to establish the stratigraphy, to determine basic soil properties and to permit detailed laboratory investigation of deformation properties under simulated field conditions

This investigation has been discussed in detail by Savigny (1980) from whom much of this material is drawn.

The logistic difficulties of northern site investigation in remote areas present special problems. Land-use regulations often preclude work in summer months by tracked or wheeled vehicles 


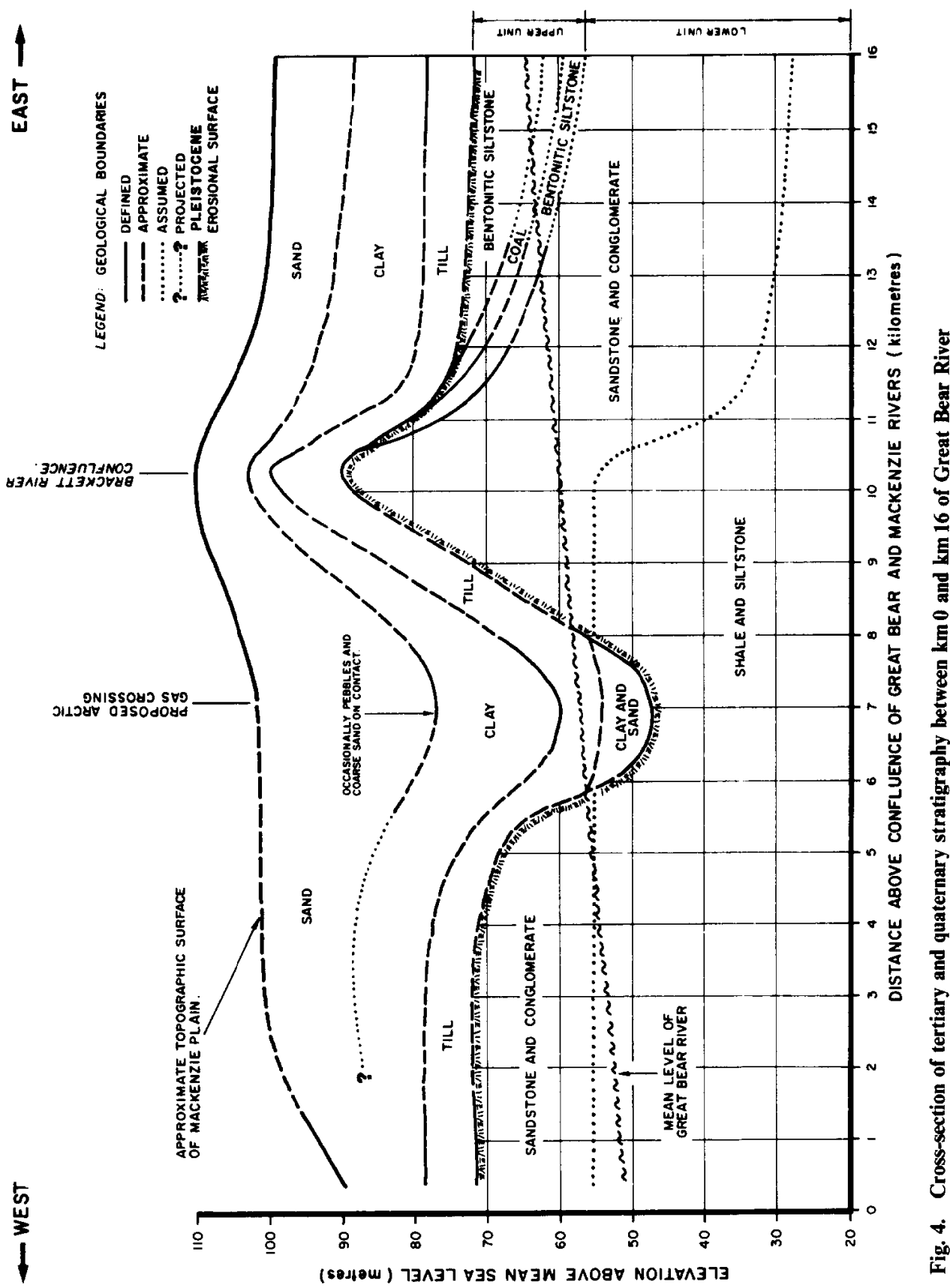




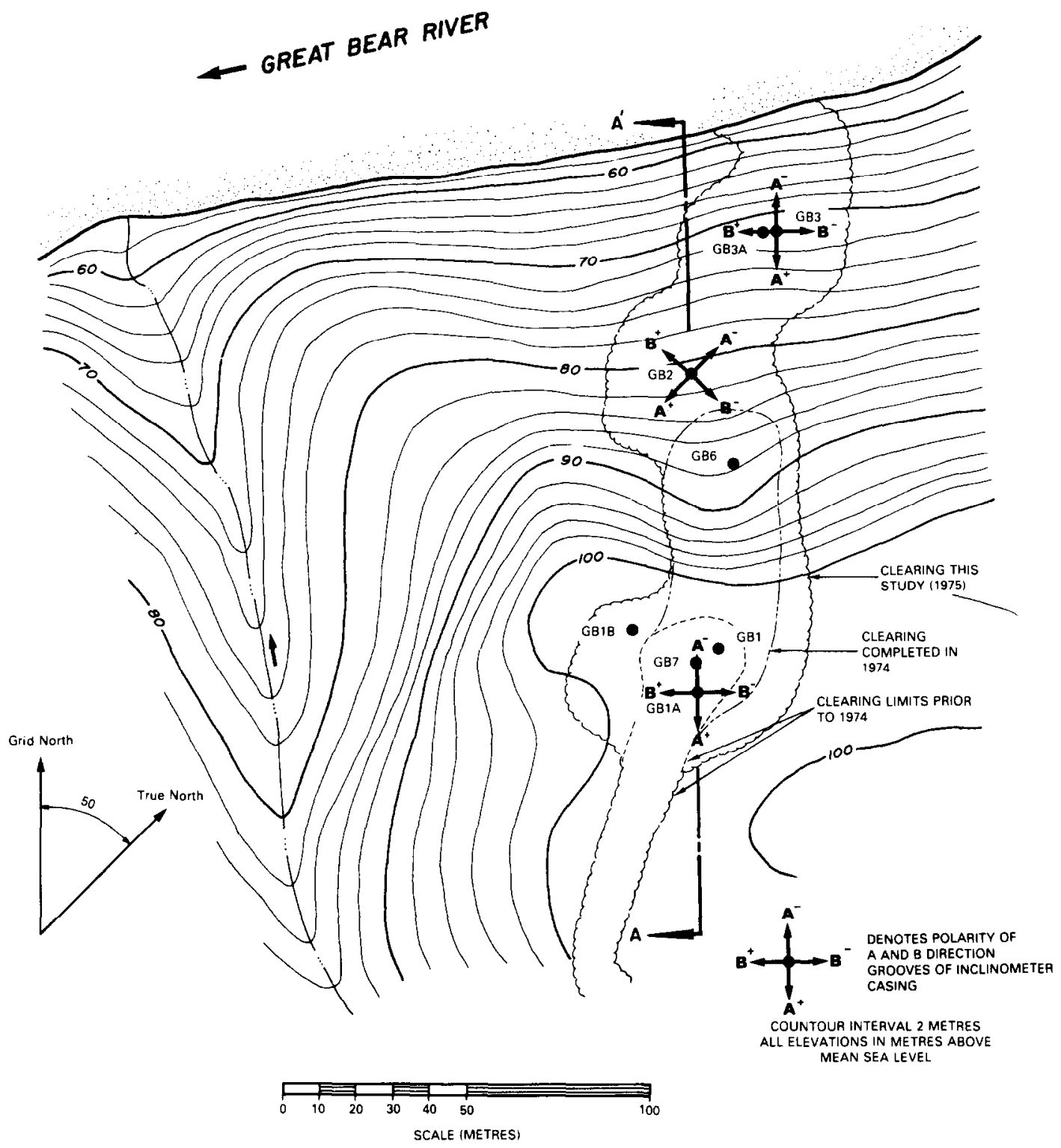

Fig. 5. Site plan, proposed arctic gas crossing of Great Bear River (left bank)

when trafficability is restricted. During parts of the winter, cold is extreme and daylight is limited. Nevertheless we have witnessed a steady stream of innovative solutions to these problems with the development of helicopter-portable drills and selfcontained mobile field camps and laboratories for extended route investigations (Roggensack, 1979).

This investigation which required the installation of accurate instrumentaion of very high quality presented its own special requirements. The programme called for a helicopter-portable wet drilling rig with minimum depth capabilities of $60 \mathrm{~m}$. Dry sampling was to be carried out with modified CRREL ${ }^{3}$ ice augers at least to the limit of fine-grained sediments. Wet sampling was to commence with a PQ wire-line core barrel, if and when the dry auger reached refusal in stony sediments, and was to continue to the desired depth. Stringent environmental and technical regu-

${ }^{3}$ Cold Regions Research and Engineering Laboratory, US Corps of Engineers, Hanover, New Hampshire. 


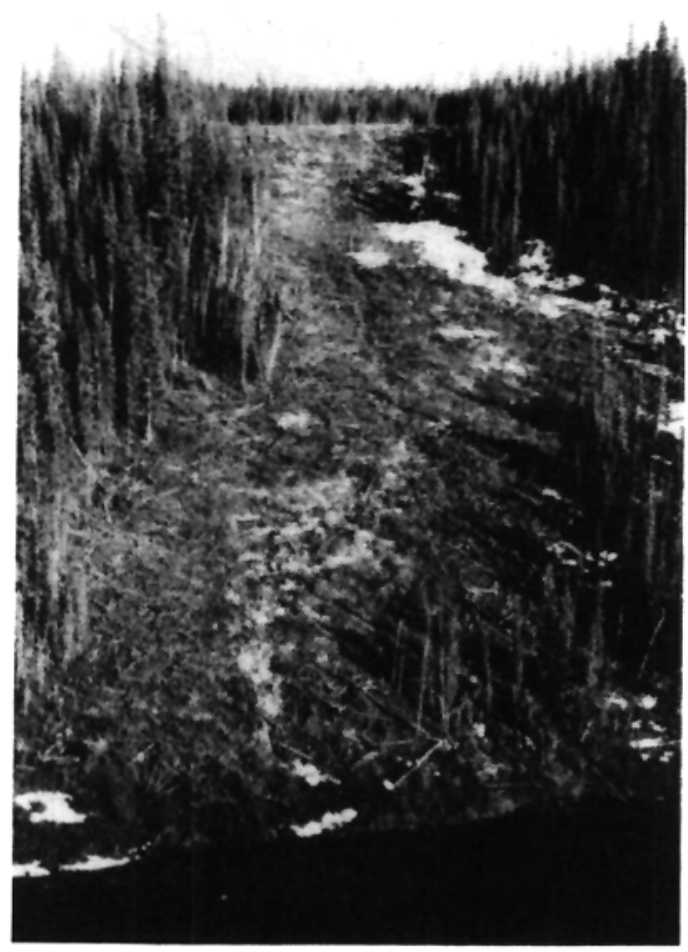

Fig. 6. Great Bear River instrumented slope lations required the drilling fluid to be a non-toxic biodegradable water-based mud which was chillec constantly to at least $-2{ }^{\circ} \mathrm{C}$. Inclinometers were tc be installed well below the deepest ice-rich zone encountered in Quaternary sediments, and grouted to the surface with a chilled, low heat of hydration grout. Piezometers were to be installed in holes advanced by wet-rotary drilling with sampling being limited to grab samples.

Figure 5 is a site plan indicating the location of the boreholes and the orientation of the inclinometer casings. A photograph of the site is given in Fig. 6. Figure 7 is a stratigraphic cross-section based on the boreholes and outcrop mapping. The siltstone and shale bedrock is Tertiary in age. The rocks are laminated, highly arenaceous, weakly cemented and soften only slightly when soaked in water. The bedrock is overlain unconformably by interbedded clay, sand and coal. These strata are mainly alluvial in origin and represent buried river channel deposits probably of Pleistocene age. They are predominantly grey, highly plastic, intensely fissured and slickensided clays. The bedding structures appear to have been highly contorted by ice-thrusting.

Glacial till deposited by the Wisconsin Laurentide ice sheet rest unconformably on the alluvial deposits. The till is comprised of brown, low to medium plastic, fissured, silty clay and

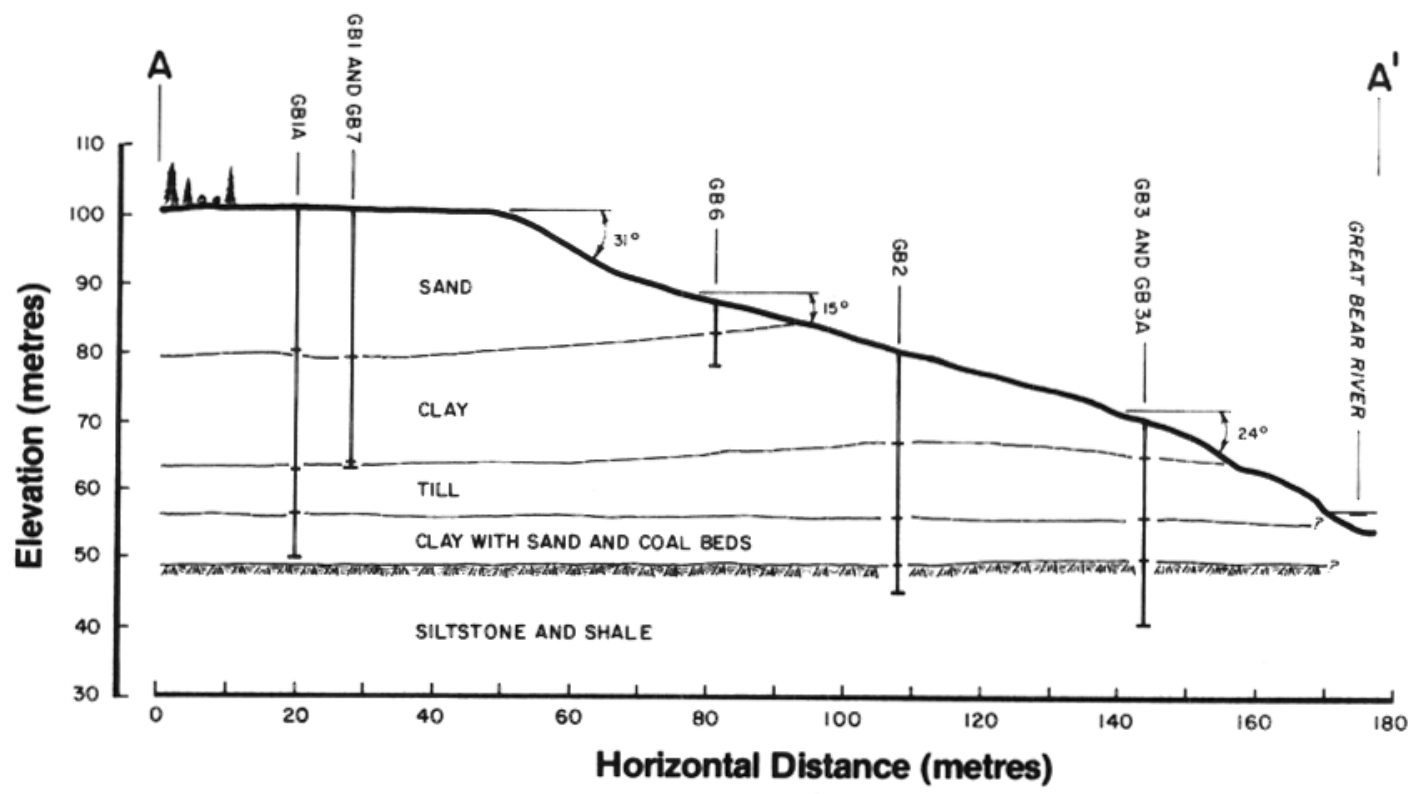

Fig. 7. Stratigraphic cross-section, proposed arctic gas crossing of Great Bear River (left bank) 
contains clasts ranging to boulder sizes. Pockets of medium sand are common and reticulate ice occurs near the upper till contact.

Overlying the till with apparent conformity are thick deposits of glaciolacustrine clay. These sediments are dark grey, rhythmically laminated, medium to highly plastic, silty clay. They are fissured throughout and commonly slickensided in association with ice veins. Reticulate ice is the most common ice form but other more tabular forms are also present. Examples are shown in Fig. 8.

Glaciodeltaic sand, the uppermost unit at the site, lies conformably on the clay. A pebble unit at the bottom testifies to the sudden end of the glaciolacustrine phase. The quartzose sands are varicoloured, medium to fine-grained with horizontally bedded and cross-bedded structures. Pore ice is the most common type of ground ice but occasional steeply dipping ice veins were also noted.

An extensive series of classification and strength tests were performed on both thawed and frozen material. The results are summarized in Table 1 . These results are unexceptional and generally consistent with experience gained from similar Mackenzie Valley soils. However, excluding visible segregated ground ice, the glaciolacustrine clays
Table 1. Properties of glaciolacustrine clay

\begin{tabular}{lc}
\hline Liquid limit; \% & $\sim 50$ \\
Plastic moisture content: $\%$ & $\sim 20$ \\
Natural moisture content: $\%$ & $\sim 22$ \\
Bulk density: $\mathrm{Mg} / \mathrm{m}^{3}$ & $\sim 2.05$ \\
$c^{\prime}: \mathrm{kPa}$ & 10 \\
$\phi^{\prime}$ & $23^{\circ}$ \\
$\phi^{\prime}$ (residual) & $14^{\circ}$ \\
$c$ (frozen): $\mathrm{kPa}$ & 232 \\
$\phi$ (frozen) & $24^{\circ}$
\end{tabular}

exist in situ at a liquidity index of about 0 . This is characteristic of heavily overconsolidated clays (Morgenstern, 1967) but there is no evidence that the glaciolacustrine clays have been subjected to greater overburden than exists at this time. It is likely that the clays have been consolidated by the pore water suctions set up during freezing and the formation of reticulate ice (Mackay, 1974). If this clay were to thaw, most of the water liberated would escape through the fissure network, leaving in place a heavily overconsolidated, fissured and slickensided clay. As a result attempts to reconstruct past overburden loads from consolidation behaviour or infer high horizontal stresses due to preconsolidation history would be in error. Caution must be exercised when applying tradi-
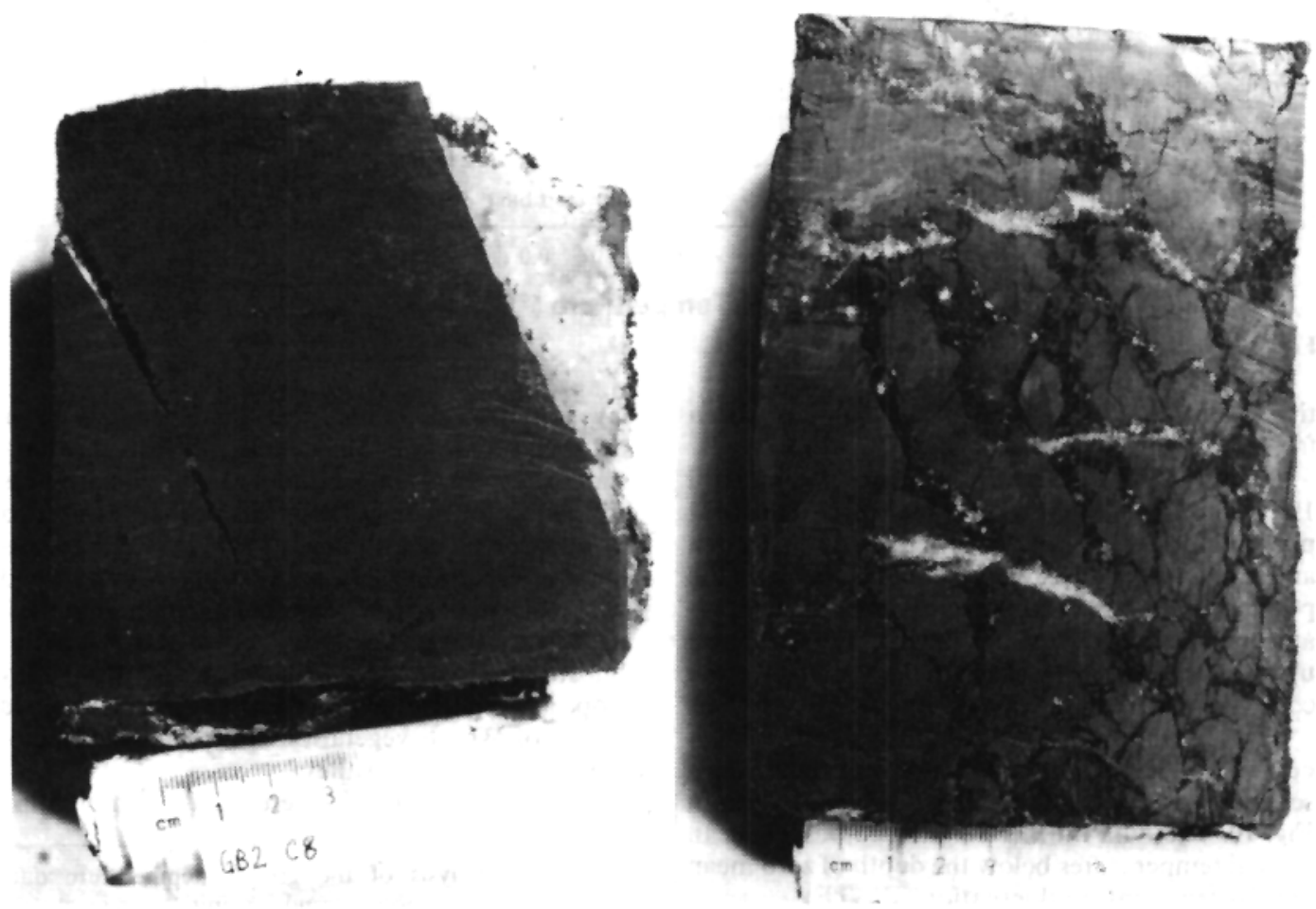

Fig. 8. Ground ice structures 


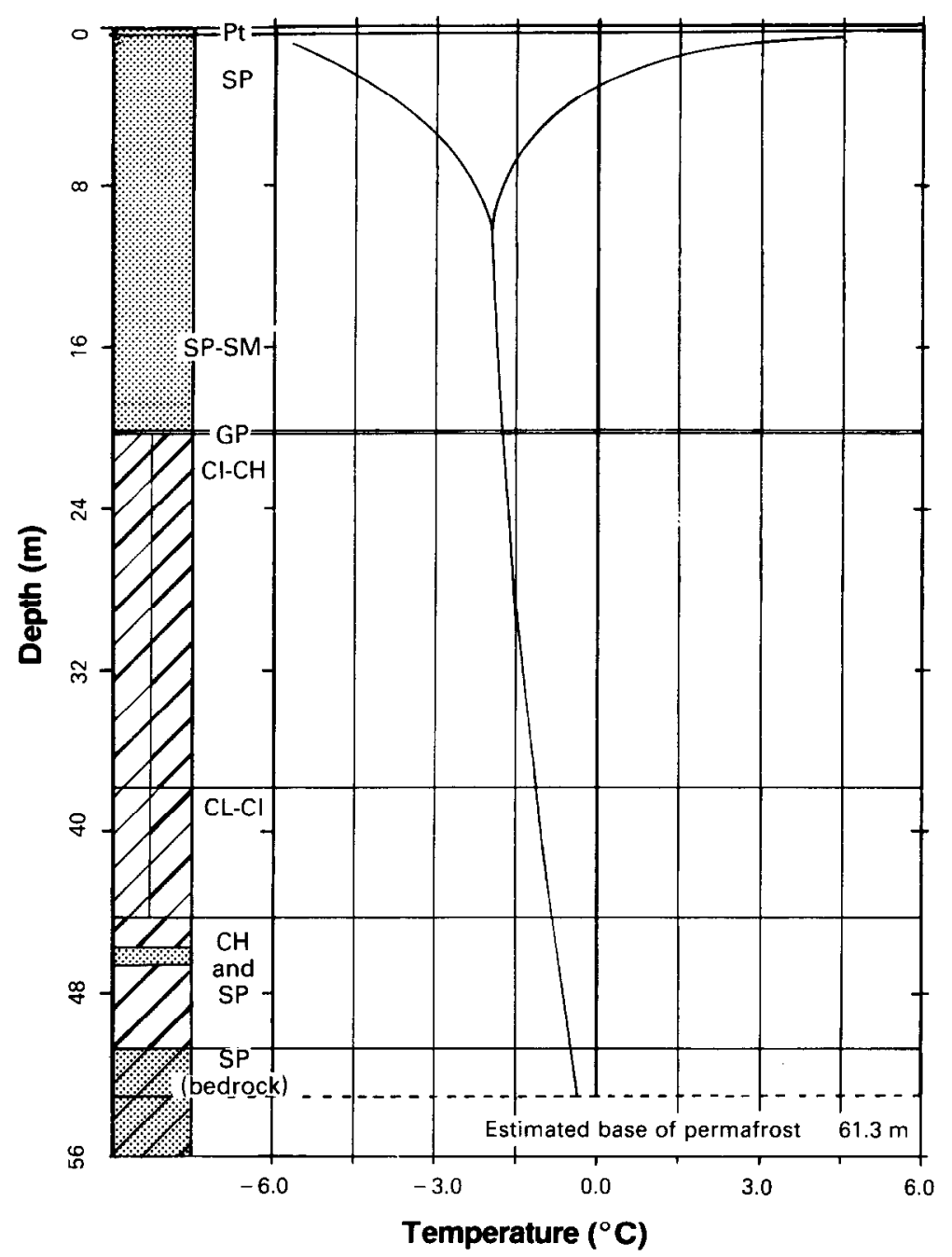

Fig. 9. Temperature gradient for hole GB1A

tional geotechnical concepts to soils that have been frozen in their geological past.

Readings were taken on 12 occasions from April 1975 to June 1977 following completion of the field programme. Most trips were scheduled in March and October of each year to coincide with the periods of coldest and warmest ground temperature respectively. In the following, data from the uppermost hole GB1A will be presented. More complete information is available in Savigny (1980).

The ground temperature profiles or trumpet curve for GB1A are presented in Fig. 9 and a crosssection showing isotherms in the slope is given in Fig. 10. The data on this diagram represent mean annual temperatures below the depth of zero mean annual temperature fluctuation (ZMTF).

In the sandy area at the top of the slope the active layer is $3 \mathrm{~m}$ thick and the depth of ZMTF is between 9 and $10 \mathrm{~m}$. The detailed temperature data show that a warming trend has been in progress since monitoring began and was probably initiated by widespread clearing in 1974 . This recent adjustment is superimposed on an earlier cooling trend which began in approximately 1950 and is manifest in the steep thermal gradient between 28 and $34 \mathrm{~m}^{4}$ Subsurface thermal conditions within the valley slope are slightly different because of the combined effects of aspect, vegetation cover and the microclimate of the river valley.

The piezometers were a combination

\footnotetext{
${ }^{4}$ Detailed analysis of the ground temperature data suggests that this cooling trend was initiated by a change in mean annual air temperature of approximately $0 \cdot 6^{\circ} \mathrm{C}$.
} 


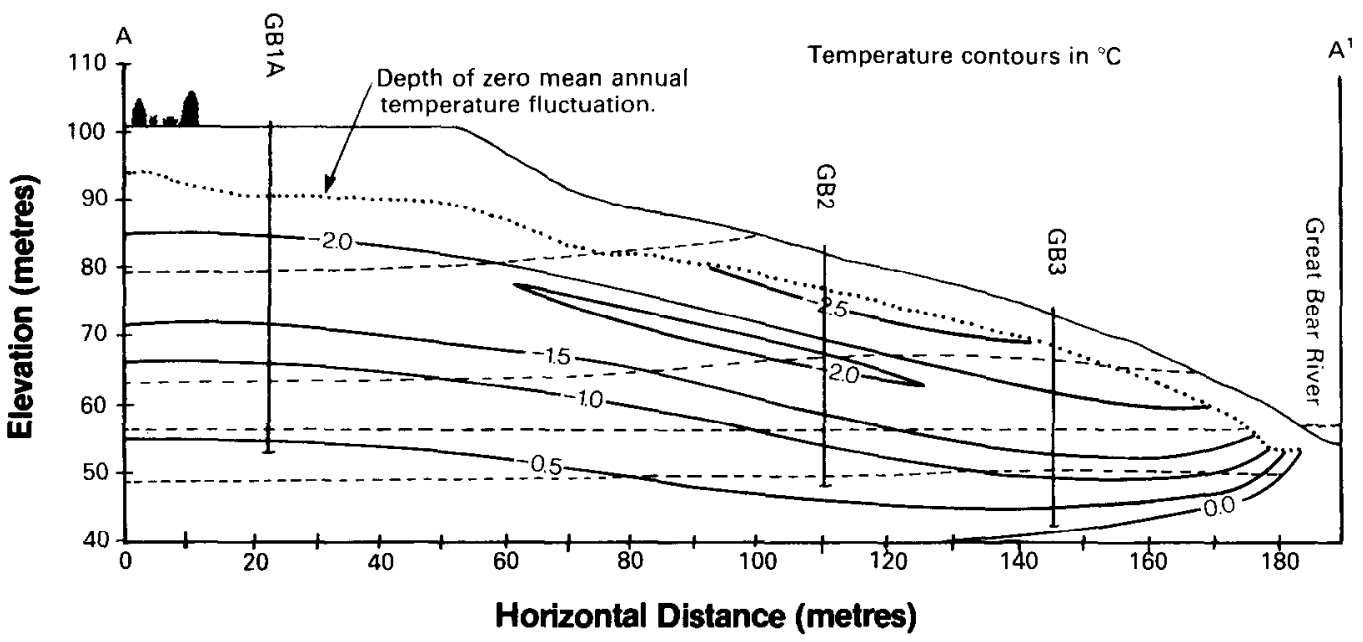

Fig. 10. Thermal cross-section, proposed arctic gas crossing of Great Bear River (left bank)

pneumatic/hydraulic type chosen primarily because of the back-up hydraulic system in which light oil or ethylene glycol could be used in the event that the pneumatic leads became damaged or if verification of the pneumatic reading was $\mathrm{rc}$ quired. Only the piezometer at GB3A operated successfully and it indicated that the piezometric elevation at the base of permafrost in the vicinity of Great Bear River corresponded closely with the river level. The presence of sandy zones, joints and thin sandstone laminae in the bedrock provide a means of rapid pore water communication.

It was recognized that if meaningful observations of creep were to be obtained in a reasonable length of time it would be necessary to rely on the limiting accuracy of the inclinometer system. A servoaccelerometer type (SINCO Digitilt Model) was selected as the most suitable for the following reasons

(a) adequate accuracy and precision

(b) negligible non-linearity, hysteresis, temperature stability and zero drift

(c) proven reliability

A variety of special precautions and reading sequences were adopted, particularly after it was cstablished that lateral movements were marginally inside the resolution of the Digitilt system. The parallel-to-slope results from GB1A are shown in Fig. 11 while the transverse-to-slope results are given in Fig. 12. The very complex pattern of movement is a result of the degree to which deformations of the casing approach the limits of resolution of the inclinometer system. A comprehensive testing programme was undertaken to assess the repeatability, resolution and temperature-drift characteristics of the measuring system. In addition, consideration was given to casing spiral and sensor rotation error.

In situ repeatability tests showed that the average performance exceeded by 10 times the manufacturer's specifications. Resolution tests to determine accuracy in a specially constructed calibration frame revealed that errors were negligible. Large temperature changes were found to have an effect on the sensing elements and approximately $20 \mathrm{~min}$ were required to achieve stable readings. This gave guidance for field practice. The sensor also displayed a linear temperature drift but it was of no significance to this study because of the small differences in temperature observed throughout the installation profile. An evaluation of casing spiral and sensor axis rotation error due to shifting of sensing elements indicated neither to be of concern.

Several external factors related to the installation procedure and site conditions have affected the readings. These include recovery of thermal equilibrium around the casing, the effect of stratigraphy, and settlement and heave of the casing. They are not peculiar to this study but are particularly important because the magnitude of associated movements is significant in relation to the lateral deflexions measured. A statistical analysis of the inclinometer results revealed that recovery of temperature and stress equilibrium around inclinometer casings cause erratic local deformations, and it was possible to establish an instrument response above which erratic deformations dominate the measurements to the extent that net ground movement at the scale of creep deformations are obscured. In the case of GB1A this occurred for about 75-100 days after the placement of grout.

A correlation exists between deformations and ice-rich zones, especially those with pervasive ice lenses more than $25 \mathrm{~mm}$ thick. Where single ice 


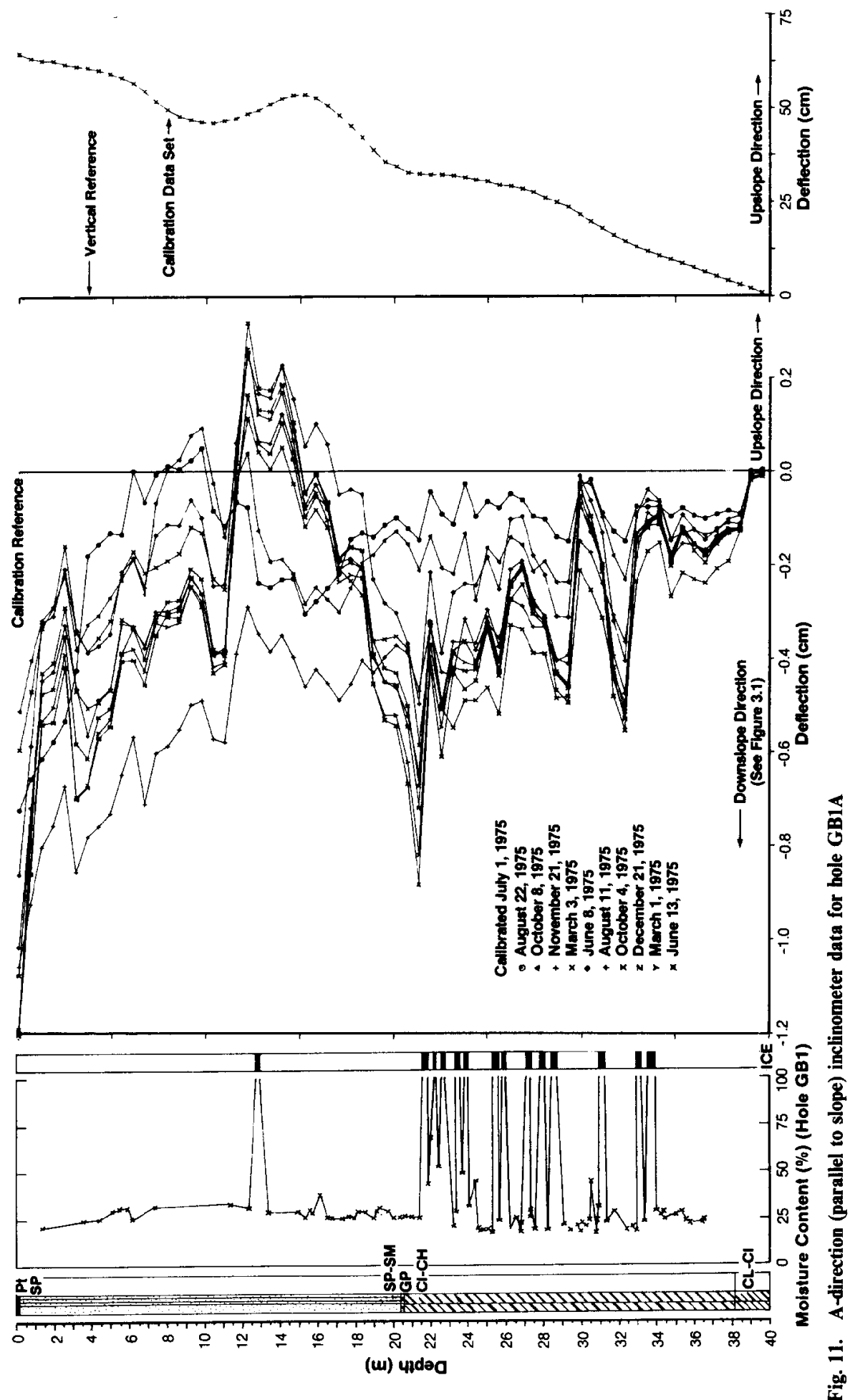




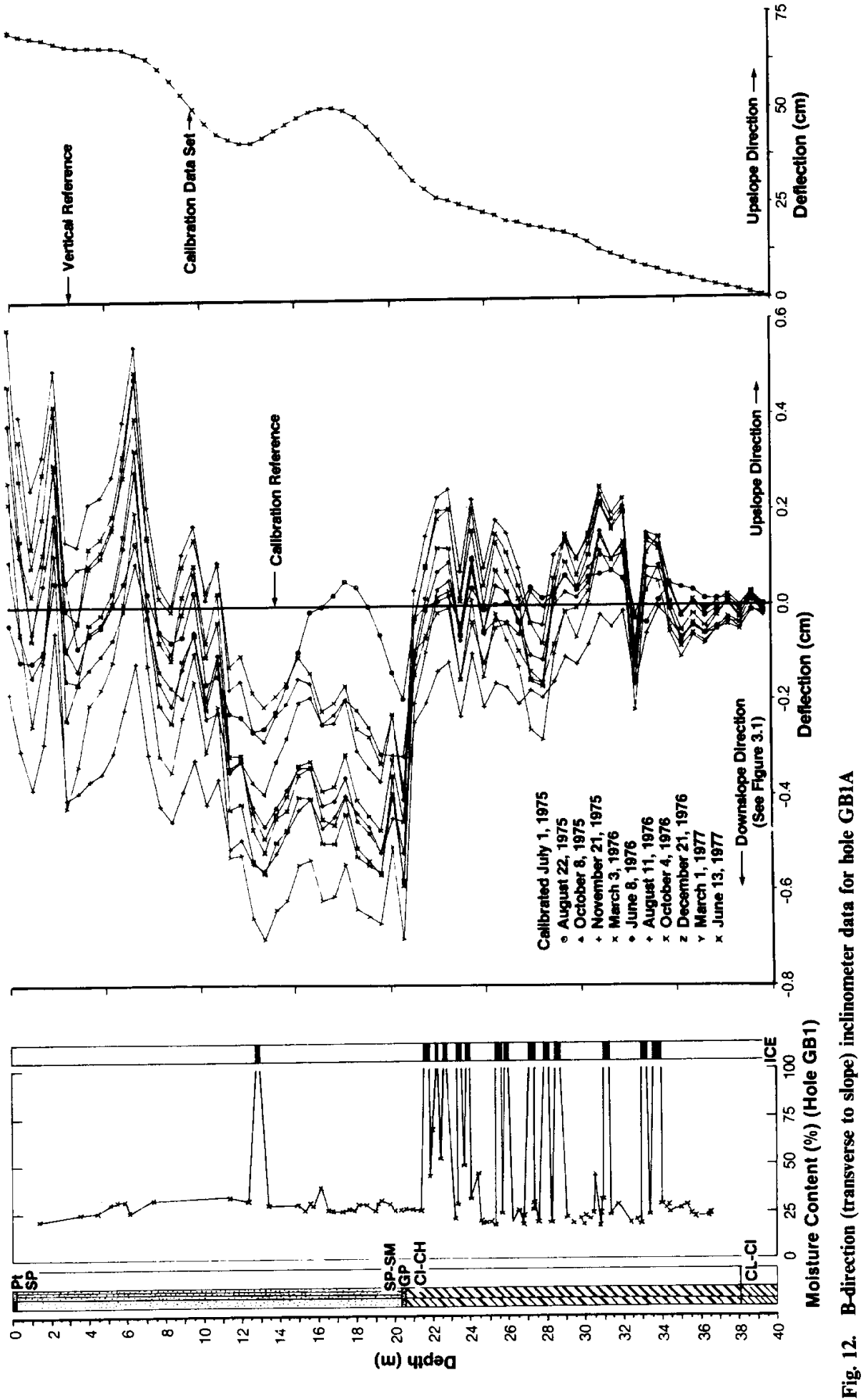




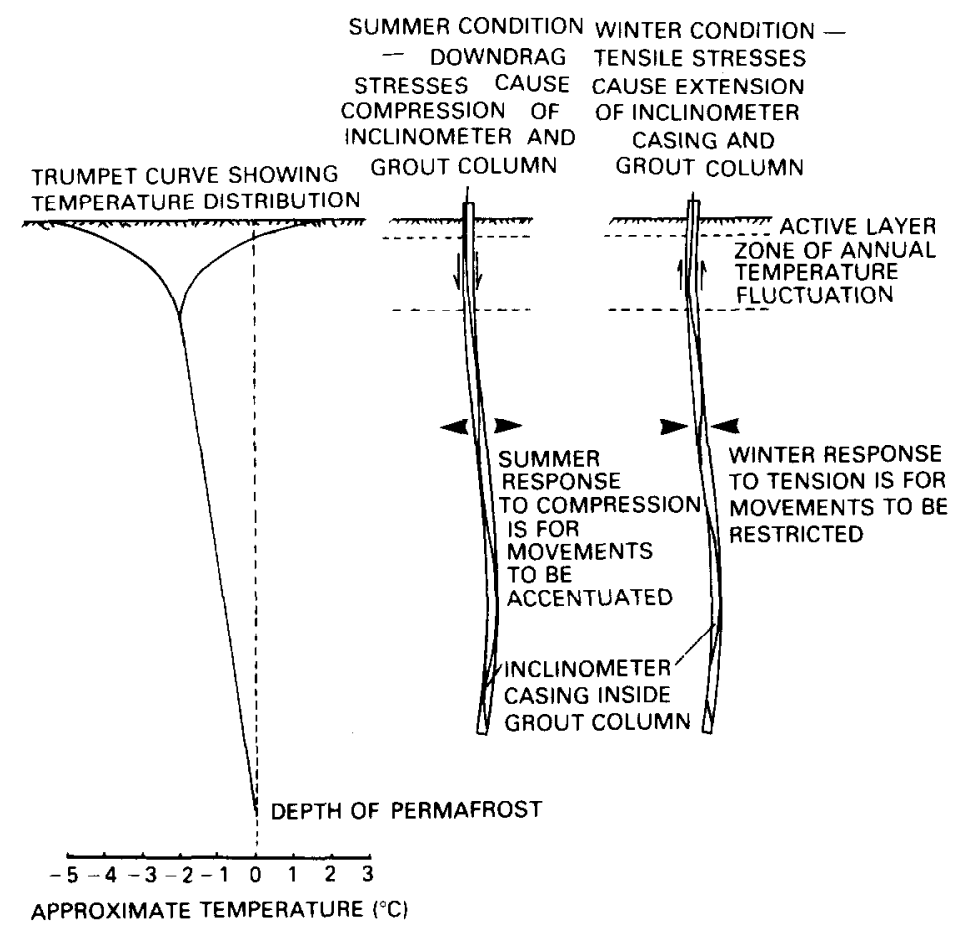

Fig. 13. Schematic representation of heave and settlement of inclinometer casing and grout column

lenses or zones containing closely spaced ice lenses are separated by $2 \mathrm{~m}$ or more, relative movements are typically large and cause very sharp deflexions. Examples of this occur at the $15 \mathrm{~m}$ depth and between 29 and $34 \mathrm{~m}$ in GB1 A (see Fig. 11). Where single ice lenses or zones containing closely spaced ice lenses are separated by less than $1 \mathrm{~m}$, and the natural moisture content of soil between the ice lenses is at least $25 \%$ to $30 \%$, movements are typically smaller and much less abrupt. These movements are generally progressive with time in the downslope direction, although the pattern is occasionally interrupted by a reversal in the sense of movement. Net downslope deflexion occurs between $20 \mathrm{~m}$ and $25 \mathrm{~m}$ in GB1A. While the data indicate a correlation between movement and ice lenses, the resulting deflexion pattern approximates simple shear in terms of homogeneous strain through any ice-rich section of the overall soil profile.

The large annual variations in near-surface ground temperatures induce both settlement and heave of the casing as illustrated in Fig. 13. It is probable that compressive and tensile stresses seated in both the active layer and the zone of annual temperature fluctuation are transmitted through the inclinometer casing and grout column. Through the summer season, and up to the approximate culmination of warming, lateral movement outward in response to settlement is progressive, while through the winter season, lateral movements are progressively inward in response to heave. This is supported by Fig. 14 which shows typical plots of deflexion as a function of time for the A (downslope) and B (cross-slope) directions at four discrete measuring depths together with mean velocities determined from least-squares linear regression analysis. In the B direction, which is assumed to be unaffected by downslope net overall ground deformations, each data set has a sinusoidal distribution about its mean velocity with a wave length of approximately 365 days. Lateral movement associated with settlement and heave is progressive, but occurs in the opposite direction during periods of ground warming and cooling respectively, and the net lateral movement after one year is small. In the A direction, conditions are identical, although the sinusoidal distribution is distorted because lateral movements resulting from settlement and heave are superimposed on natural ground deformations associated with creep. This type of plot provides a means for discriminating net ground deformation from seasonal fluctuations.

Velocity data obtained in this way for GB1A are shown in Fig. 15. Although the results are scattered and vary with ice distribution, the velocity at the top of the clay layer is between 0.25 and 0.30 


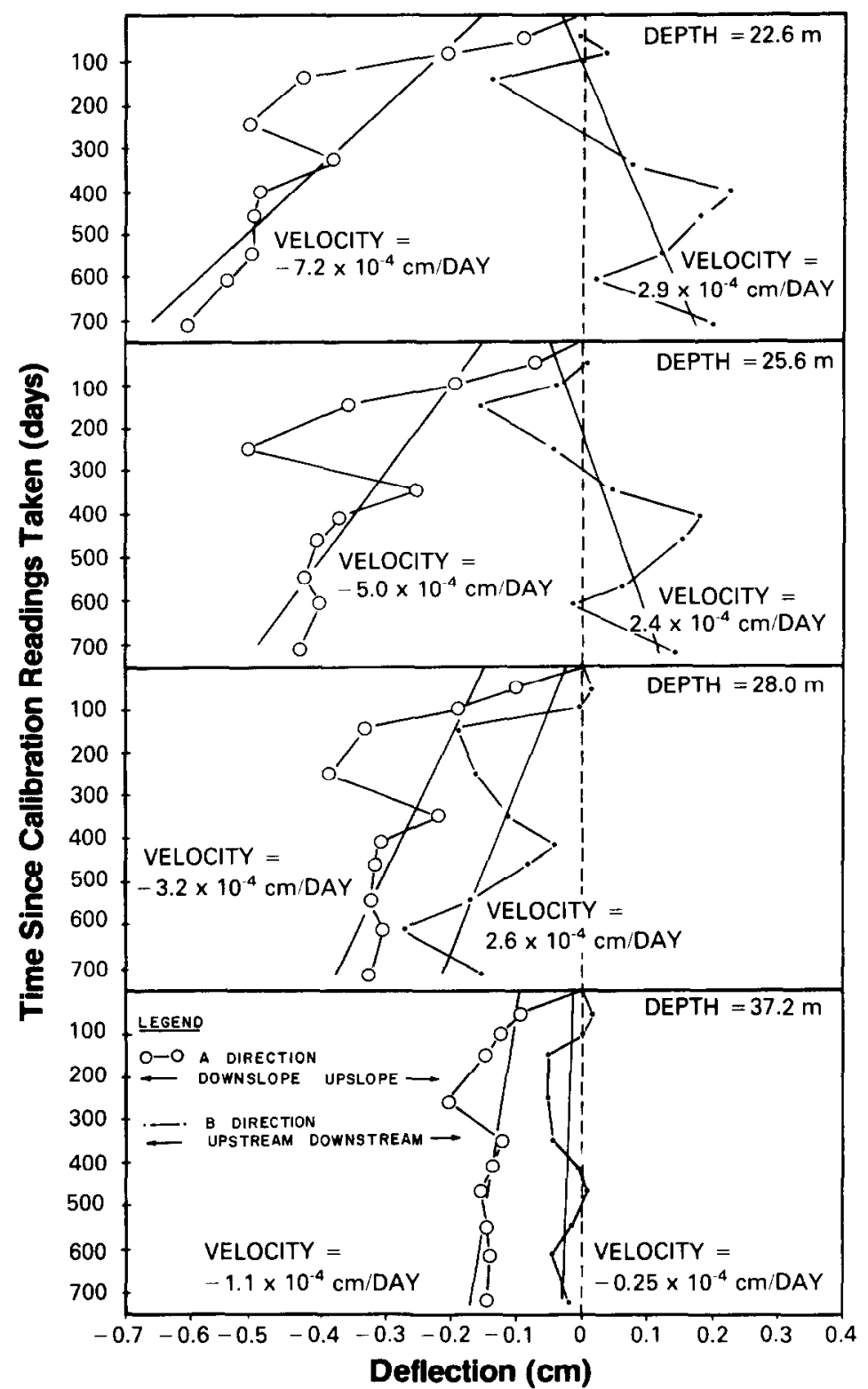

Fig. 14. Typical plots of deflexion against time at different depths in glaciolacustrine clay in hole GB1A

im/year. Above the $29 \mathrm{~m}$ depth where ice lenses are arge and closely spaced, the velocity gradient is llmost uniform. The shear strain rate through this :one is approximately $2.0 \times 10^{-4} /$ year. At depths rom approximately 29 to $34 \mathrm{~m}$, where large ice enses are more widely separated, the velocity is rratic, with proportionally more movement Issociated with the large ice lenses. Below the $34 \mathrm{~m}$ lepth, where only small ice lenses are present, the relocity gradient becomes more uniform with a hear strain rate of about $0.4 \times 10^{-4} /$ year. B- direction deflexions in the clay oscillate about approximately zero net deformation with a small but insignificant downstream velocity. No creep deformations are evident in the sand. This does not preclude the possibility of creep in frozen sand but the data obtained are judged to be less reliable because of more drilling and grouting difficulties experienced during installation.

\section{Laboratory studies}

In order to undertake numerical analyses of the 


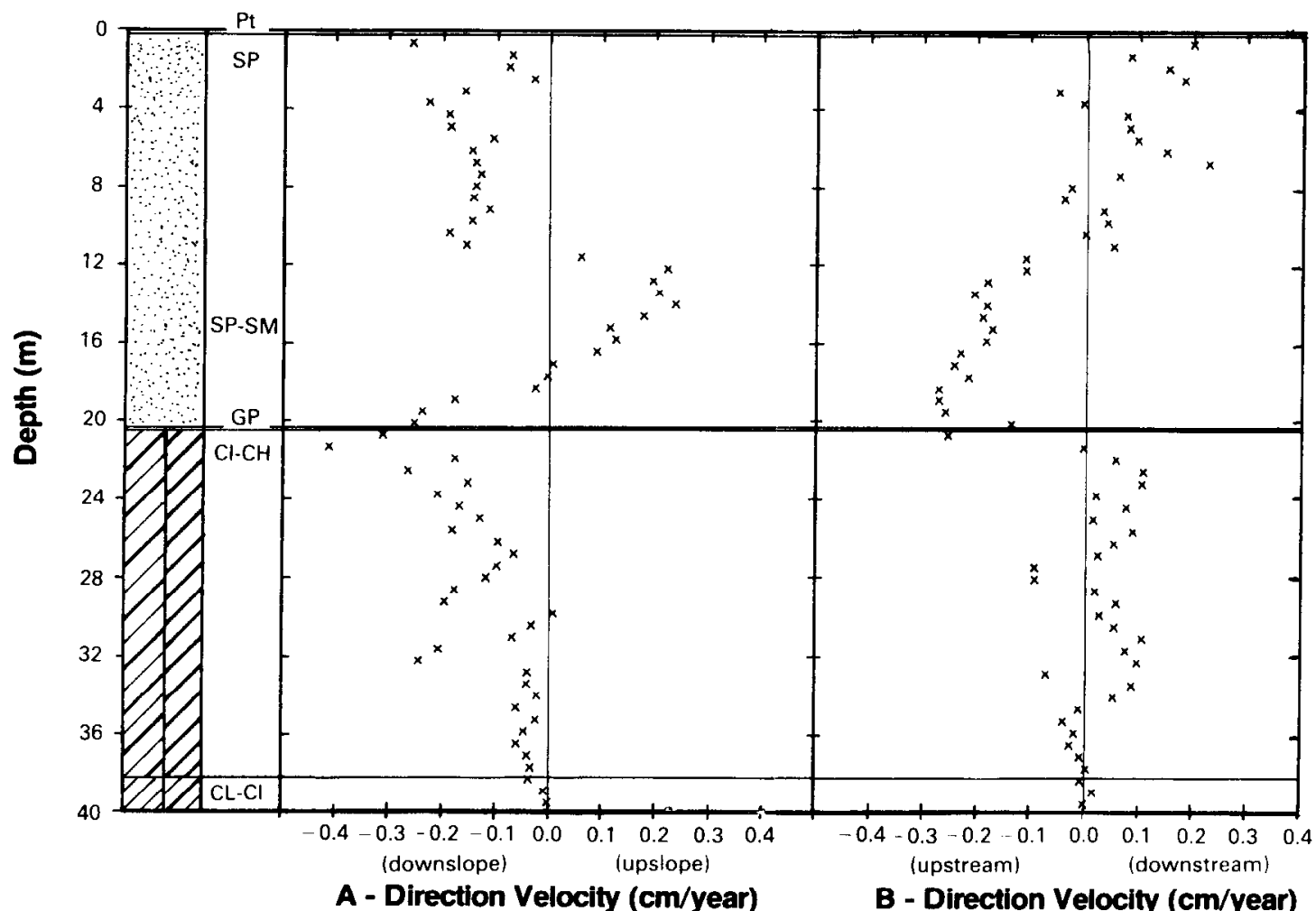

Fig. 15. Velocity profiles for bole GB1A

apparent steady state creep deformation in the slope it is necessary to determine constitutive equations which describe the stress-strain-time behaviour of the materials. There are serious limitations to relying on laboratory tests alone and long-term data on the creep of undisturbed finegrained permafrost soils are difficult to obtain. Nevertheless, it is still of interest to relate the field creep behaviour to a body of laboratory test data.

The creep of ice is known to follow a power law relation between strain rate and stress at temperatures and stresses of geotechnical interest (Morgenstern, Roggensack \& Weaver, 1980; Sego, 1980 ) and the creep of ice-rich permafrost has been interpreted within the same framework. A plot of the variation of minimum strain-rate with stress observed in creep tests for Great Bear River area glaciolacustrine soils is given in Fig. 16. Recent suggested flow laws for polycrystalline ice and other fine-grained permafrost soils are also shown for purposes of comparison. From the experimental data there is no clear relation between minimum strain rate and stress. Many specimens failed prematurely and the failure mechanism seemed closely related to specific ground ice features (see Fig. 17) where shear developed principally along the soil-ice interface of pervasive primary ice veins.
Samples subjected to higher confining pressures generally failed sooner than unconfined specimens. It appears that local stress concentrations are set up at ice-soil interfaces in response to confining pressures and that at least some time should be allowed for creep to dissipate high stress gradients. Systematic procedures are not yet in place to lead to reliable long-term test data on heterogeneous icerich soils. However, several tests did display longterm steady state behaviour after about 6 months of sustained loading. The data cluster about the flow law for ice but the scatter is substantial.

\section{Finite element simulation}

A visco-elastic finite element analysis of steady state deformation occurring in the slope was undertaken to assess the validity of the power law for describing the creep of ice-rich permafrost. It was assumed that

(a) creep strain causes no volume change

(b) the hydrostatic state of stress has no effect on creep rate

(c) the principal strain rate and stress tensors are coaxial

(d) the stress-strain relation for multiaxial states of stress reduces to the uniaxial power law for uniaxial loading 


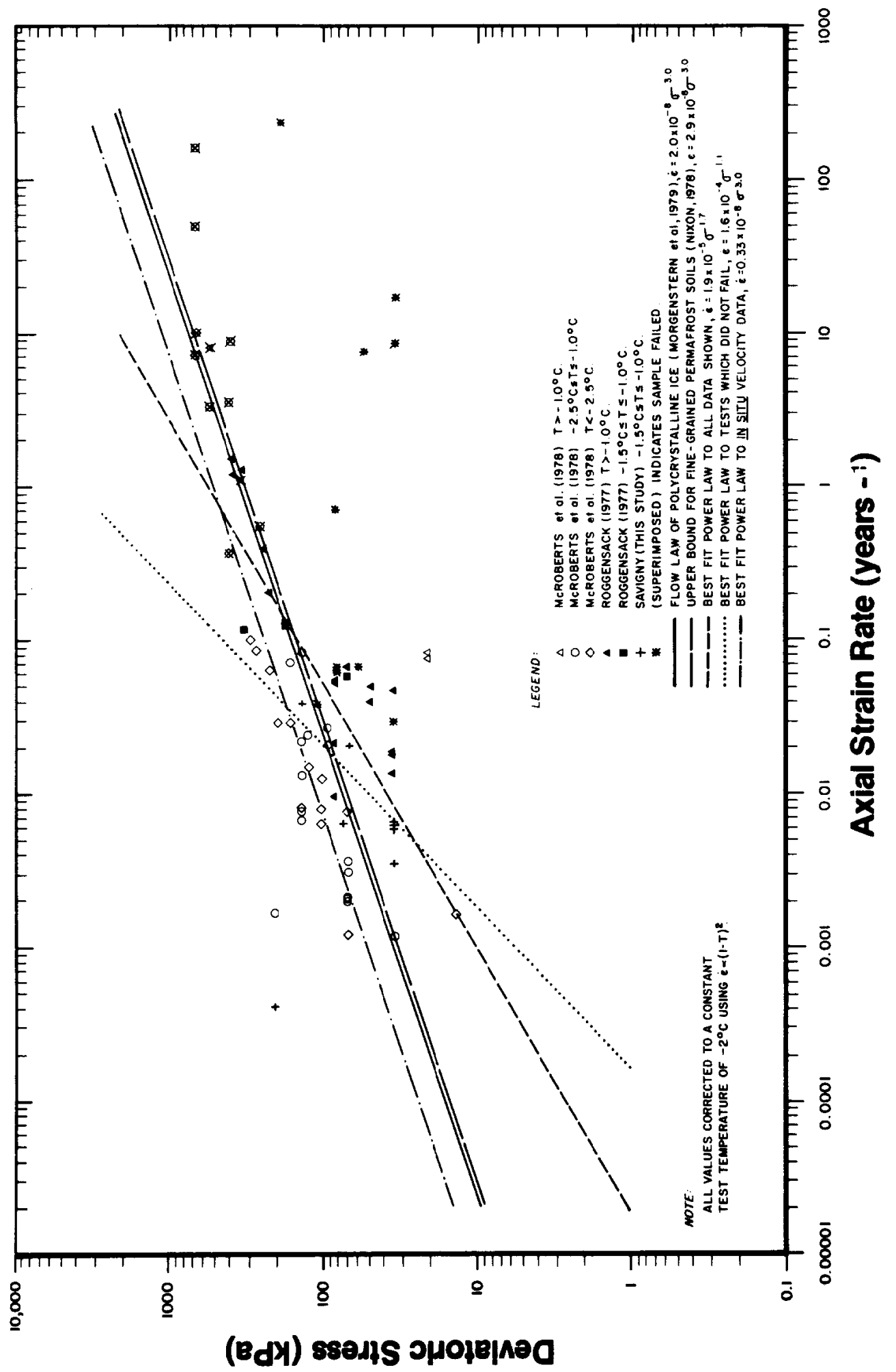

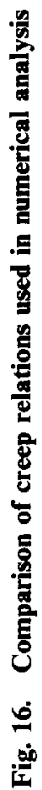




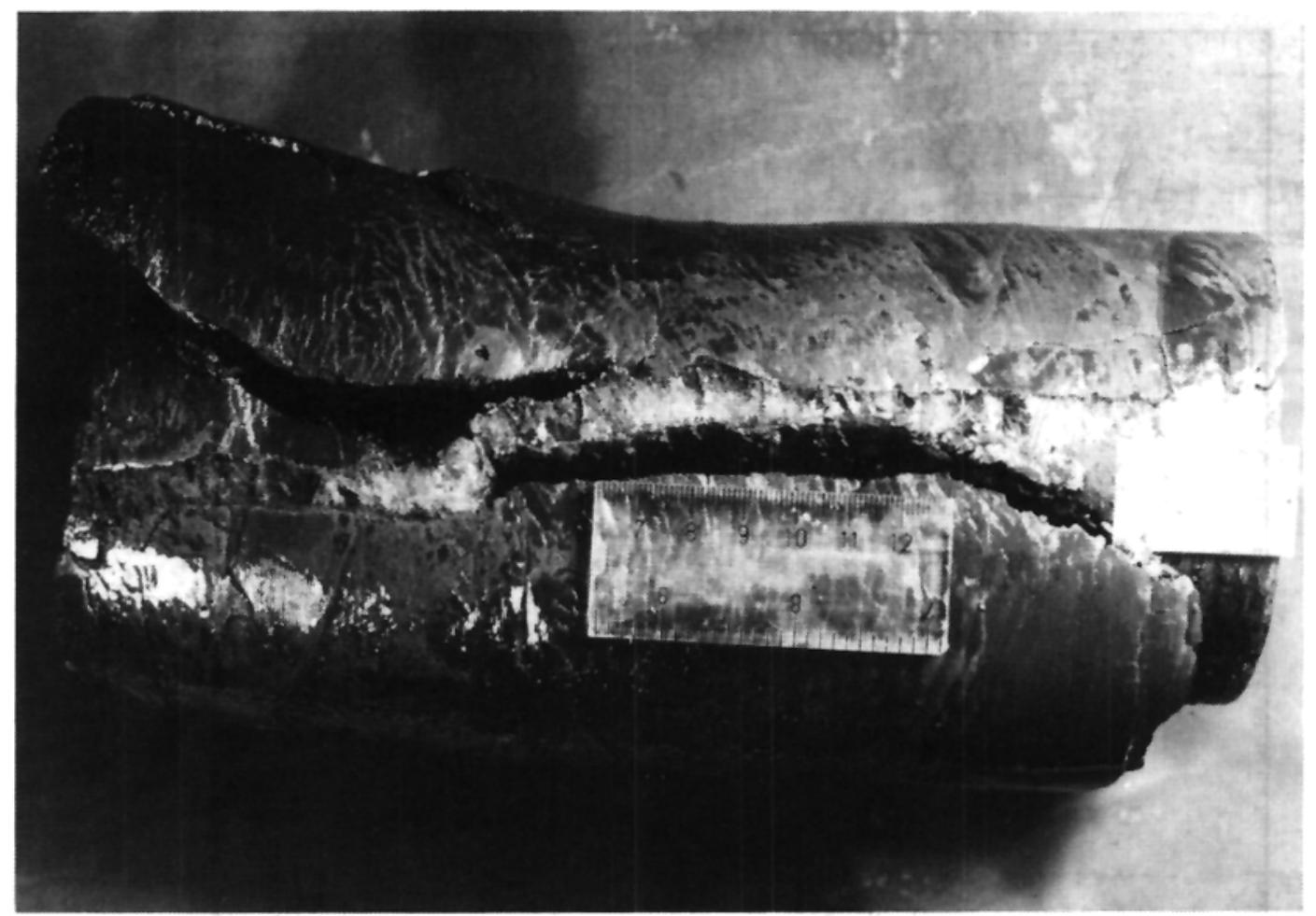

Fig. 17. Failure along ice structure

In the first formulation it was assumed that frozen sand will creep in a manner similar to that exhibited by the clay, particularly if tension develops in the sand. Figure 18 shows the comparison between measured and predicted velocities. If the flow law for ice is used, velocities are grossly overestimated. It is necessary to reduce the modulus in the flow law by 6 times in order to achieve reasonable correspondence with observations in the clay. If the frozen sand is not allowed to creep, the creep of the underlying clay is also restrained but very high horizontal tensile stresses develop in the sand which could not be sustained in the long term. This illustrates the tendency in some instances for tensile cracks to develop in material overlying creeping frozen ground.

\section{Commentary}

Despite the remote and hostile conditions, it has been possible to install and monitor instrumentation thereby demonstrating that natural slopes in ice-rich soils do creep. Shear strain rates of the order of $10^{-4} /$ year have been detected. The movements are in part associated with localized shear in widely separated, pervasive ground ice features. The process is more subdued than predictions based on the flow law of ice alone and the flow law that matches the field behaviour can be used for engineering design in similar soils elsewhere, at least until further data are forthcoming. Special limitations to the use of laboratory tests for evaluating the deformation behaviour of heterogeneous ice-rich permafrost have been indicated.

While the results of the Great Bear study are of direct use for frozen ground engineering in the Mackenzie Valley, they are also of more general interest. Students of the mechanics of periglacial phenomena will have noticed that the creep observed at the slope may be indicative of the process of valley bulging that so far lacks a satisfactory quantitative explanation.

The antecedents to the discovery and description of valley bulging and related phenomena may be found in Horswill \& Horton (1976) which now constitutes the definitive description. Salient features are shown in Fig. 19. Briefly, clay has been squeezed upwards into the valley bottom resulting in thinning of the clay layers and forward rotation (cambering) of the overlying strata. The upper portion of the clay is brecciated but the limit of brecciation reflects closely the overlying valley topography. Hence the process which resulted in brecciation must have extended down from an old valley surface. 


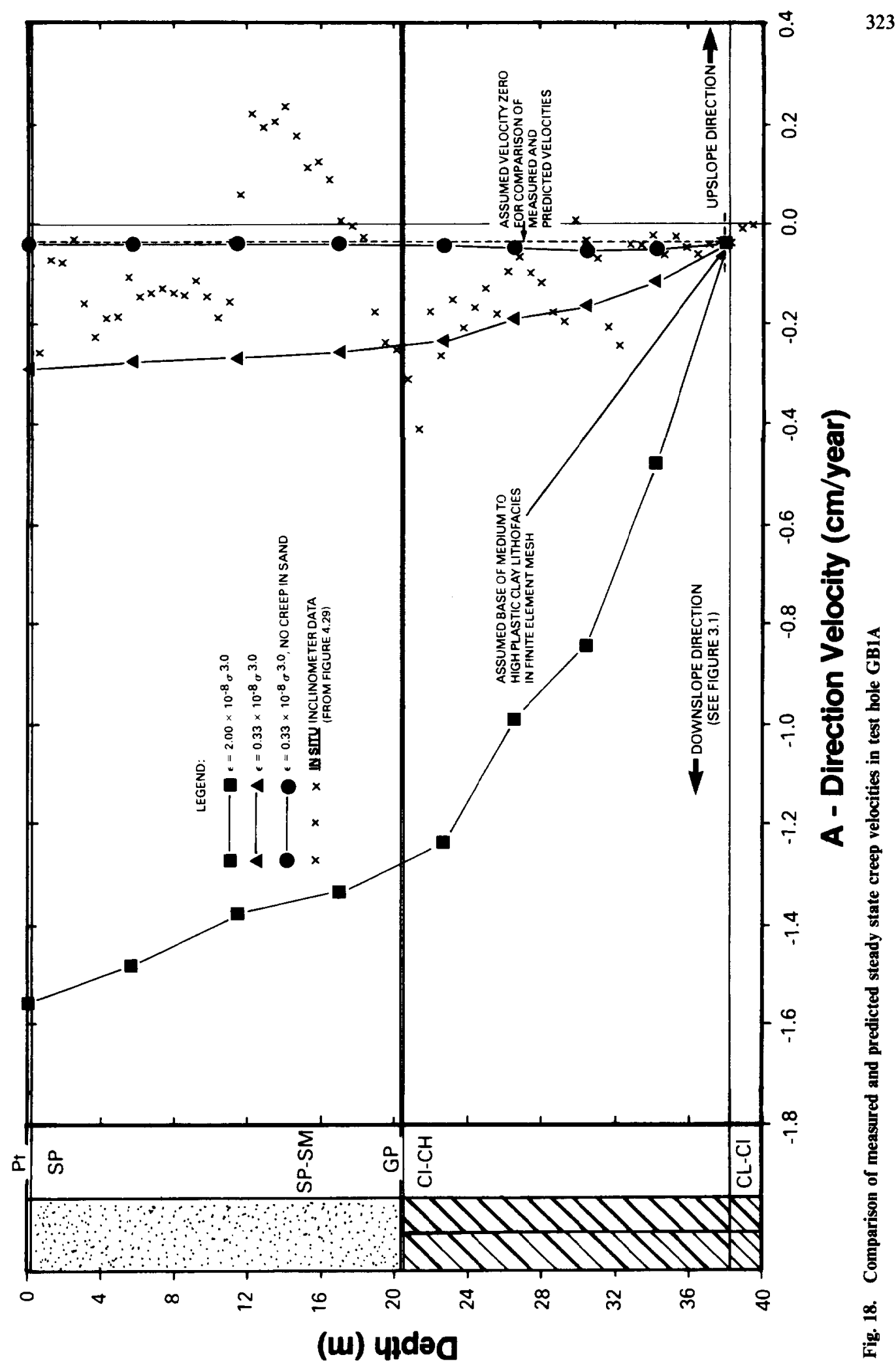




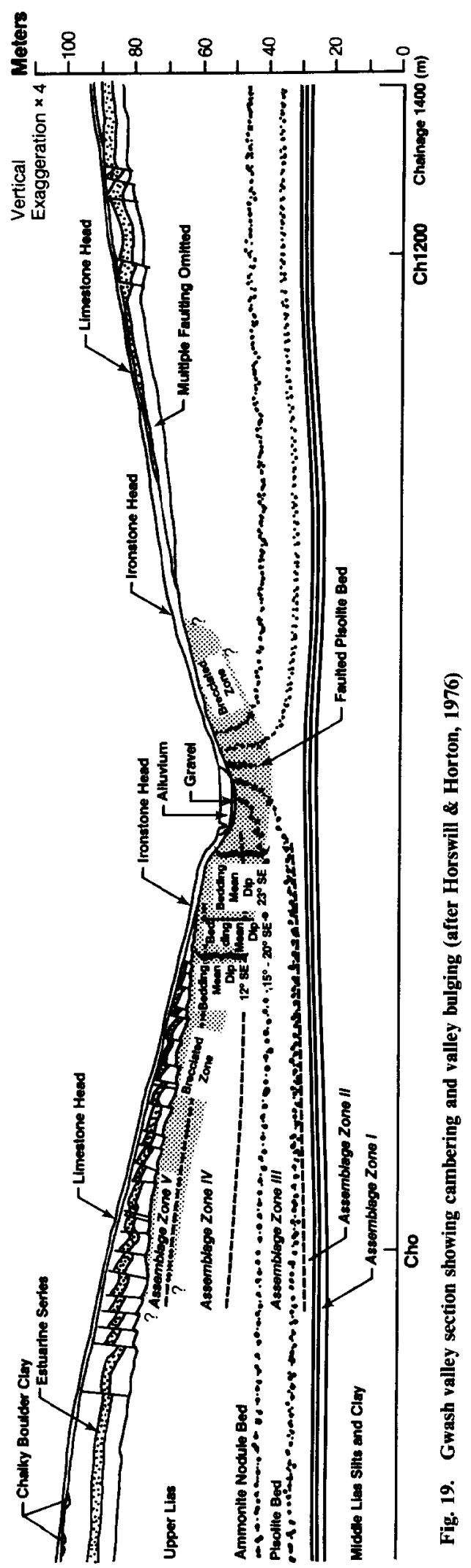


Vaughan (1976) has reconstructed the deformation history of the Empingham Valley slope and offered several alternative mechanisms to account for the strains and displacement implied by the present valley slope morphology. He considered lateral movements due to stress relief, vertical loading due to overlying ice and downslope sliding of frozen ground. None are satisfactory in accounting for the magnitude of the movements, the pattern of the deformations and the minor structures within the underlying clay. Various lines of reasoning developed in these recent studies point to the presence of permafrost as a necessary condition for valley bulge formation and the observations at Great Bear River equally support this hypothesis.

In addition to geometrical considerations, the mechanics of valley bulging should account for the flow-like behaviour of the clay, the limits of brecciation and the distinct change in water content displayed by the brecciated clay. A consistent mechanism may be constructed based on the view that valley bulging is due to sustained creep of icerich clay following enrichment due to cyclic freezing and thawing. It is unlikely that in situ freezing of the Upper Lias clay alone could lead to significant ice segregation because of the low water content of the undisturbed clay. Instead, cyclic freezing and thawing could disrupt the fabric and permit ingress of water from the overlying sands. If the clays were frozen at depth while free water was available during thaw above, substantial ice enrichment could occur. When the ice content became high enough and the ice structures sufficiently pervasive, creep would be initiated and sustained. Flow of frozen ground toward the valley would cause tensile failure of the overlying material, while crosion in the valley would result in progressive thinning of the mobile members. Vaughan (1976) has deduced valleyward displacements at Empingham of $100 \mathrm{~m}$ near the base and $200 \mathrm{~m}$ at the top of the Upper Lias. Simple transfer of the Great Bear observations of approximately $0.3 \mathrm{~cm} /$ year at the top of the layer indicates some 65000 years for the bulge process. If ice-rich Upper Lias crept as fast as ice this might be as little as 10000 years. Finite element modelling is required to explore this explanation in more detail.

\section{FROST HEAVE MECHANICS \\ The problem}

The transfer of oil by pipeline from the Arctic to southern markets has, so far, involved operating at oil temperatures far above $0^{\circ} \mathrm{C}$. When the pipeline is buried in permafrost, thaw results with attendant problems where the ground is ice-rich. These problems are overcome in the delivery of natural gas by pipeline by chilling the gas to below $0{ }^{\circ} \mathrm{C}$.
For the major projects that have been considered to date, the extra throughput attainable by chilling the gas compensates in part for the cost of refrigeration. A chilled gas pipeline can therefore be constructed without serious economic penalties. Burying a chilled gas pipeline in permafrost preserves the frozen state and thereby resolves most of the problems associated with pipeline operation in ice-rich ground. However, permafrost is not continuous. The chilled gas pipeline must traverse streams underlain by unfrozen ground and as the pipeline extends further southward even the subaerial permafrost becomes increasingly discontinuous. At some point, the gas is no longer chilled below $0{ }^{\circ} \mathrm{C}$ and pipeline design beyond this point proceeds on a more or less conventional basis. However, up to the last point of cold flow the pipeline crosses a considerable extent of unfrozen ground which will become frozen if the chilled pipeline is buried in it. The pipeline may then be subjected to frost heave. Two important new design considerations arise. Under these conditions, how much frost heave will occur over the lifetime of the project? In addition, how much differential heave will occur and will it lead to unacceptable strains in the pipe? For example, where the pipeline crosses from frozen to unfrozen and back to frozen ground, it will be restrained from heaving where it is buried in frozen ground but will be subjected to heave across the unfrozen ground. Can this differential heave lead to distress?

The subject of frost action in soils has received considerable attention in the literature. Jessberger (1970) has assembled a bibliography that contains hundreds of citations. Most studies of frost heave have fallen into one of the following classes

(a) index tests to establish the degree of frost susceptibility of various soils

(b) fundamental thermodynamic analyses

(c) empirical studies attempting to relate laboratory investigations to field performance in a quantitative manner

Notwithstanding the considerable research devoted in the past to the frost heave process, there has been no agreement on an engineering theory of frost heave.

It is well known that the propensity of a soil to heave under freezing conditions is affected by grain size distribution, availability of water, rate of heat extraction and applied loads. For a given soil, an engineering theory of frost heave would lead to the predictions of the magnitude and rate of frost heave as a function of certain characteristics of the freezing system and boundary conditions. Prior to freezing, the temperature profile and boundary conditions controlling the availability of water can be established by measurement. A knowledge of the 

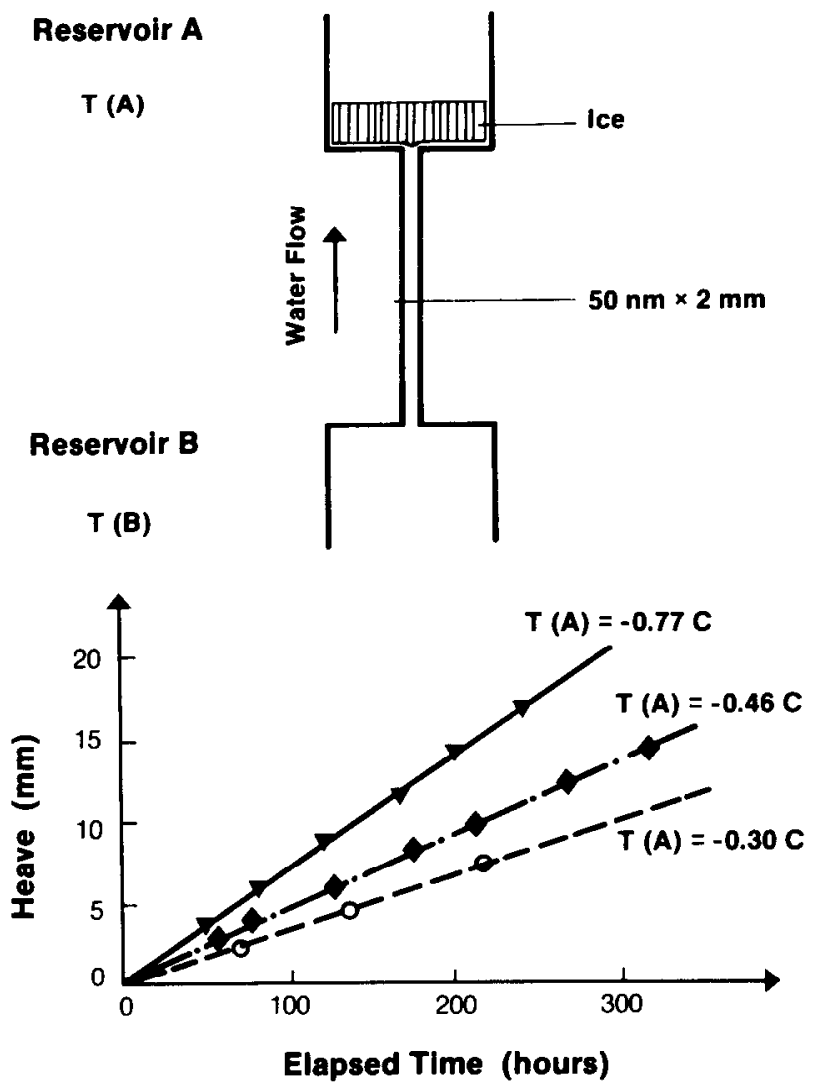

Fig. 20. Experimental results obtained by Vignes \& Dijkema (1974)

soil profile can be translated into the moisture content distribution, the thermal conductivity and the permeability of the soil. A change in heat flux or temperature at a boundary must be specified in order to account for the onset of freezing. As a frost front advances into a fine-grained soil, moisture is drawn to the front. It is this coupling of the heat and mass flow that constitutes the complex element in the theory of frost heave. Recently there have been some attempts to embrace heat and mass flux in a coupled theory but predictive results from these studies have not been convincing.

An understanding of why moisture is attracted to a frost front in a fine-grained soil may be obtained in various ways. We have benefited most by considering the thermodynamic equilibrium between ice and water in porous media. If consideration is given initially only to the conditions where no external loads are applied so that the ice will be at atmospheric pressure and temperature close to that at which phase change takes place $T^{*}$, the requirement that the free energy of the ice equals that of the water leads to a simple form of the Clausius-Clapeyron equation (e.g. Kay \&
Groenevelt, 1974)

$$
P_{\mathrm{w}}=L\left(T^{*}-T_{0}^{*}\right) / V_{\mathrm{w}} T_{0}^{*}
$$

where

$V_{\mathrm{w}} \quad$ denotes the specific volume of water

$P_{\mathrm{w}} \quad$ denotes the water pressure

$L \quad$ denotes the latent heat of phase change per mole

$T^{*} \quad$ denotes the absolute temperature $(\mathrm{K})$

$T_{0}{ }^{*} \quad$ denotes the temperature at the standard state $(273.15 \mathrm{~K})$

For convenience we can write

$$
T=T^{*}-T_{0}^{*}
$$

where $T$ denotes the temperature in ${ }^{\circ} \mathrm{C}$ at which ice and water are considered to be in equilibrium.

Equation (1) indicates that if ice is at atmospheric pressure as the temperature decreases below $T_{0}{ }^{*}$, the water pressure becomes negative, and close to $0{ }^{\circ} \mathrm{C}$ there is a linear relation between the suction and the temperature. Elegant validations of equation (1) have been provided by Vignes \& Dijkema (1974) and Biermans, Dijkema \& de Vries (1978). Vignes \& Dijkema measured water 


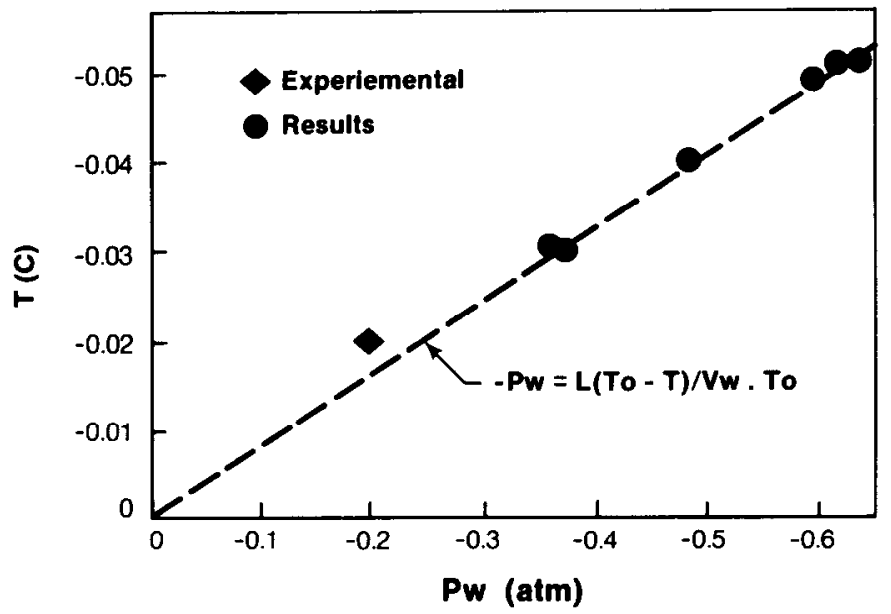

Fig. 21. Experimental results obtained by Biermans et al. (1978)

migration rates using the experimental set-up shown in Fig. 20. Two reservoirs, one containing water either above $0^{\circ} \mathrm{C}$ or super-cooled, the other containing water and ice, were separated by a narrow slit $50 \mathrm{~nm}$ by $2 \mathrm{~mm}$ in cross-section and $50 \mathrm{~mm}$ long. As predicted by equation (1), water flowed toward the ice regardless of the temperature in reservoir B where the water pressure was maintained at atmospheric pressure. The flow rate was constant for a given temperature in reservoir $\mathrm{A}$. Since the hydraulic conductivity of the slit is constant, equation (1) predicts that the flow-rate should be proportional to the temperature of the ice-water interface. The experimental results were in good accord with this prediction.

Using glass filters in order to increase the flow, Biermans et al. (1978) also confirmed the Clausius-Clapeyron relation simplified for atmospheric pressure in the ice. This was achieved by measuring the suction $P_{\mathrm{w}}$ that had to be applied to the water in reservoir $B$ in order to stop the flow to the ice lens and by comparing it with the theoretical prediction. Their results are shown in Fig. 21 and support the theoretical relation to a high degree of accuracy.

Previously Hoekstra (1969) and Radd \& Oertle (1973) had measured the pressure $P_{\mathrm{h}}$ necessary to prevent heave as a function of the temperature in soil freezing with access to water. If one assumes that $P_{\mathrm{w}}=0$ at the ice lens and that the ice pressure is equal to the heaving pressure, the Clausius-Clapeyron relation becomes

$$
P_{\mathrm{h}}=-\left(L / V_{\mathrm{j}}\right) \ln \left(T^{*} / T_{0}^{*}\right)
$$

Their measurements of heaving pressure were in good agreement with this relation, providing further support for the validity of the thermodynamic explanation of the origin of the pore water suction during frost heave.

For frost heave to occur, water must co-exist with ice at temperatures colder than $0^{\circ} \mathrm{C}$. However, if suctions deduced from equation (1) for a possible range of temperatures are applied directly to unfrozen soils of known permeability, flows far in excess of those observed in the laboratory are predicted. Other factors in the frost heave mechanism impede the direct transfer of this suction to the unfrozen soil.

When a fine-grained soil is frozen, not all of the water within the soil pores freezes at $0^{\circ} \mathrm{C}$. In some clay soils up to $50 \%$ of the moisture may exist as a liquid at temperatures of $-2{ }^{\circ} \mathrm{C}$. This unfrozen water is mobile and can migrate under the action of a potential gradient. The characteristics of unfrozen water have been reviewed by Anderson \& Morgenstern (1973) and Tsytovich (1975). Miller (1972) reviewed evidence that water transport to an ice lens takes place through liquid films between ice and mineral matter. This led Miller to propose that an ice lens in a freezing soil grows somewhere in the frozen soil, slightly behind the frost front, i.e. behind the $0^{\circ} \mathrm{C}$ isotherm. The temperature at the base of the ice lens is referred to here as the segregational freezing temperature $T_{\mathrm{s}}$ because the segregational heaving process takes place at that temperature. The temperature at which ice can grow in soil pores $T_{\mathrm{i}}$ depends upon pore size and ice-water interfacial energy through the Kelvin equation. This domain bet ween $T_{\mathrm{i}}$ and $T_{\mathrm{s}}$ is referred to as the frozen fringe. In silty soils, the average pore size is relatively large and $T_{i}$ is close to $0^{\circ} \mathrm{C} . T_{i}$ can also be affected by solute concentration and other factors which are ignored here. Direct evidence for the existence of a frozen fringe has been published by Loch \& Kay (1978) and Penner \& Goodrich (1980).

In addition to these considerations, Mageau \& 

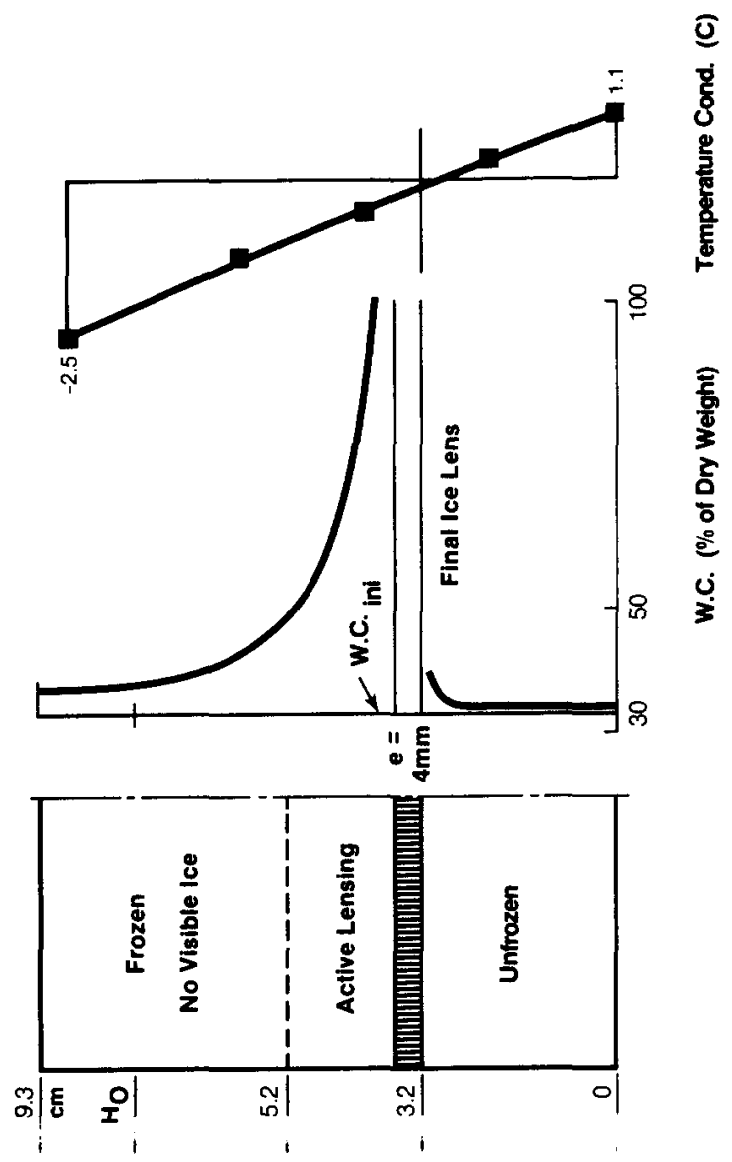

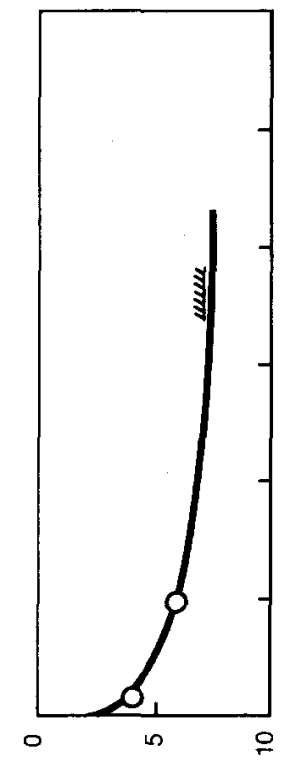

(wo) fuody isost to undea

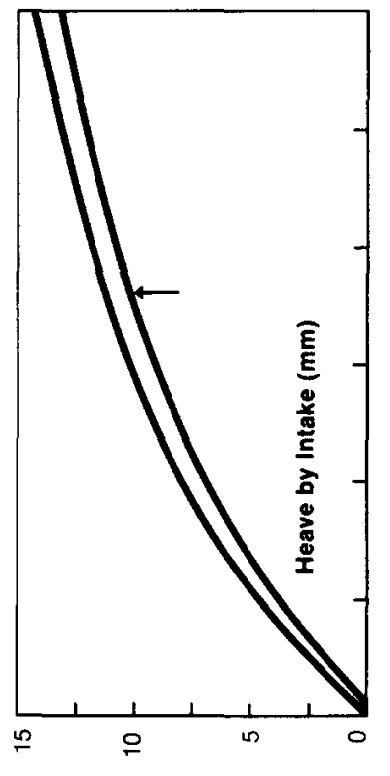

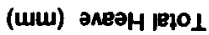

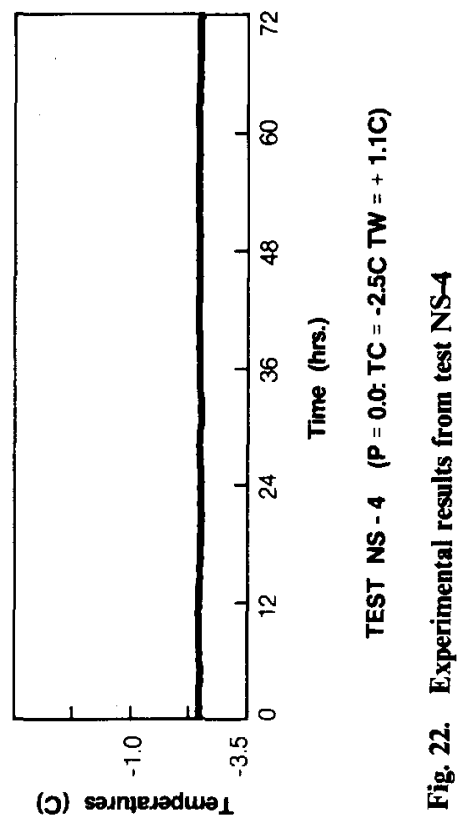




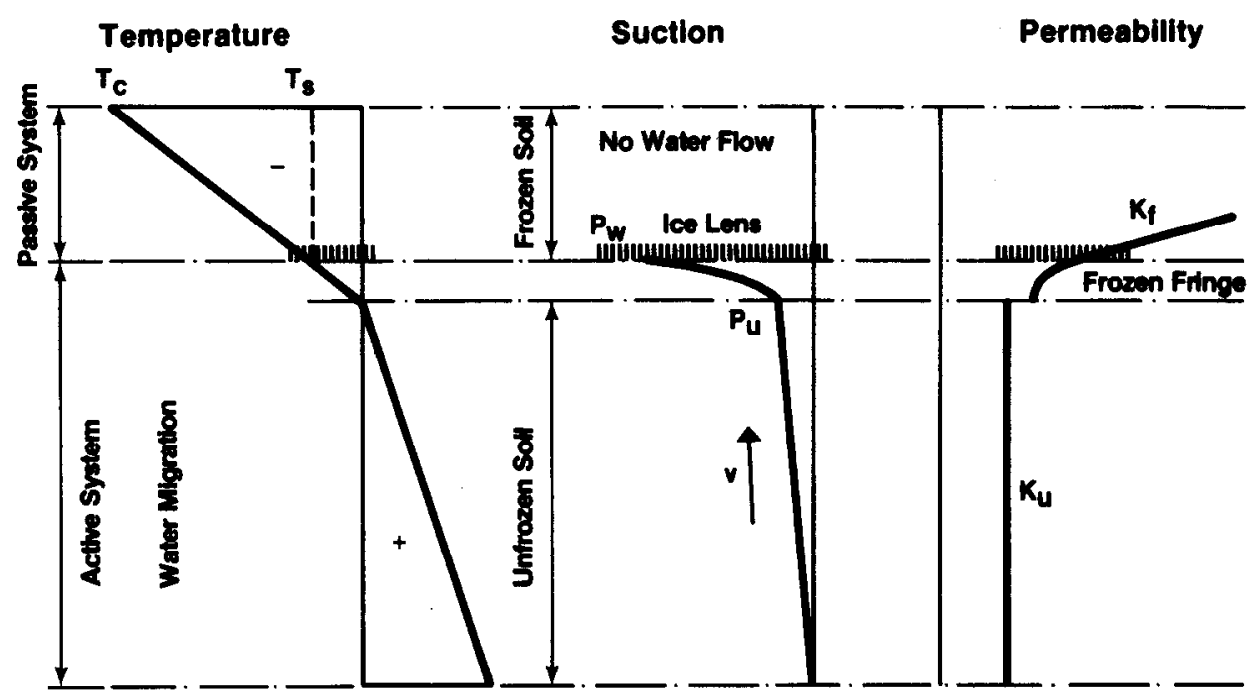

Fig. 23. Schematic representation of a freering soil

Morgenstern (1979) published experimental results indicating that frozen soil on the cold side of the warmest ice lens had little to no effect on the rate of water intake to that lens. That is, an ice lens acts like an impermeable barrier with regard to water migration in the frozen soil. This is confirmed by field studies. The results from a test pipeline designed to study in situ frost heave showed that all the heave occurred near the frost front since heavy gauges installed throughout the soil profile did not exhibit any further relative movement once the frost front had passed them (Slusarchuk et al. 1978).

It appears then that the mechanics of frost heave can be regarded as a problem of impeded drainage to an ice-water interface that exists at the segregation freezing temperature $T_{s}$. Substantial suctions are generated at this interface but the reduced permeability of the frozen fringe impedes the flow of water to the ice lens thereby reducing the suction that acts on the unfrozen soil. In order to understand this process in detail it would be necessary to obtain precise knowledge of the distribution of temperature and permeability within the frozen fringe. Rather than pursue this, we have taken the view that precise point measurements of permeability and temperature would not ultimately be of direct value in a comprehensive theory but that instead the coupling of heat and mass transfer should be deducible from an appropriate laboratory test in the same way that Darcy's law relates mass transfer to potential gradient without local measurements of fluid velocity.

\section{Analytical and laboratory studies}

One-dimensional freezing tests are conducted conveniently in the type of cell described by
Mageau \& Morgenstern (1979). Cold- and warmside temperatures may be controlled and temperature profiles obtained throughout the test. Water inflow and heave may be monitored with time. The test may be performed under a back pressure and, if converted from open flow to a closed system, the pore water suction may be measured.

The results of a typical open system freezing test with constant temperature boundary conditions are shown in Fig. 22. Three distinct phases of frost heave may be recognized

(a) an advancing frost front created by a positive net heat extraction rate

(b) a stationary frost front corresponding to a zero net heat extraction rate

(c) a retreating frost front in which the frozen fringe below the ice lens thaws

It is convenient to analyse first the conditions at the onset of the formation of the final ice lens under zero overburden pressure, which is a simplified case where the effect of frost front advance is almost eliminated (Fig. 23).

At the base of any ice lens, the Clausius-Clapeyron equation (1) relates the pressure in the liquid film to the temperature $T_{\mathrm{s}}$ and can be written

$$
P_{\mathrm{w}}=M T_{\mathrm{s}}
$$

where $M$ is a constant. Neglecting elevation head, equation (4) in terms of total potential becomes

$$
H_{\mathrm{w}}=\left(M / \gamma_{\mathrm{w}}\right) T_{\mathrm{s}}
$$

where

$H_{\mathrm{w}} \quad$ denotes the total potential

$\gamma_{w} \quad$ denotes the bulk density of water 


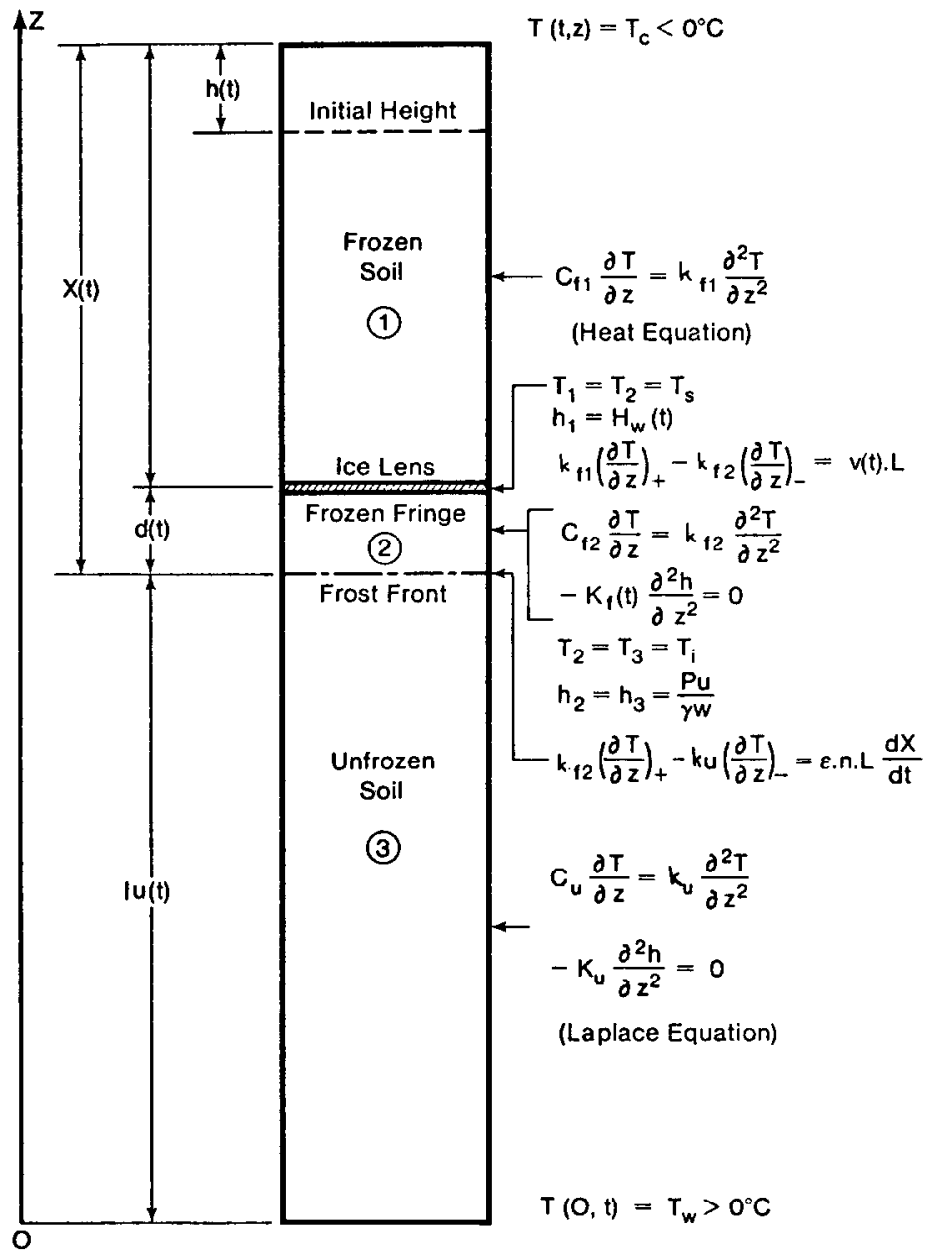

Fig. 24. Equations for the one-dimensional frost heave model, no externally applied load

The soil beneath the ice lens may be treated as a two-layered incompressible system in which there is no accumulation of water or ice and Darcy's law holds. Assuming zero pressure at the base of the system, the velocity of water movement $v(t)$ is given by

$$
v(t)=\frac{\left|H_{\mathrm{w}}(t)\right|}{\left(l_{\mathrm{u}}(t) / K_{\mathrm{u}}\right)+\left[d(t) / \bar{K}_{\mathrm{f}}(t)\right]}
$$

where

$l_{\mathrm{u}}(t) \quad$ denotes the thickness of the unfrozen soil

$d(t)$ denotes the thickness of the frozen fringe

$K_{\mathrm{u}}$ denotes the permeability of the unfrozen soil

$\bar{K}_{\mathrm{f}}(t)$ denotes the overall permeability of the frozen fringe

The heave due to segregational processes $h_{\mathrm{s}}(t)$ is found directly from equation (6) by

$$
h_{s}(t)=1.09 \int_{0}^{t} v(t) d(t)
$$

Routine considerations of heat conduction lead to the equations for temperature $T$ shown in Fig. 24. For one-dimensional heat flow

$$
\frac{\partial}{\partial z}\left(\lambda \frac{\partial T}{\partial z}\right)+Q=C \frac{\partial T}{\partial t}
$$

where

$C \quad$ is the volumetric heat capacity

$\lambda \quad$ is the thermal conductivity

$Q \quad$ is an internal heat generation term per unit area and per unit time

The internal heat is libcrated at two different locations: the segregation-freezing temperature $T_{\mathrm{s}}$ and the in situ freezing temperature $T_{\mathrm{i}}$. At $T_{\mathrm{s}}$

$$
Q=v(t) L
$$




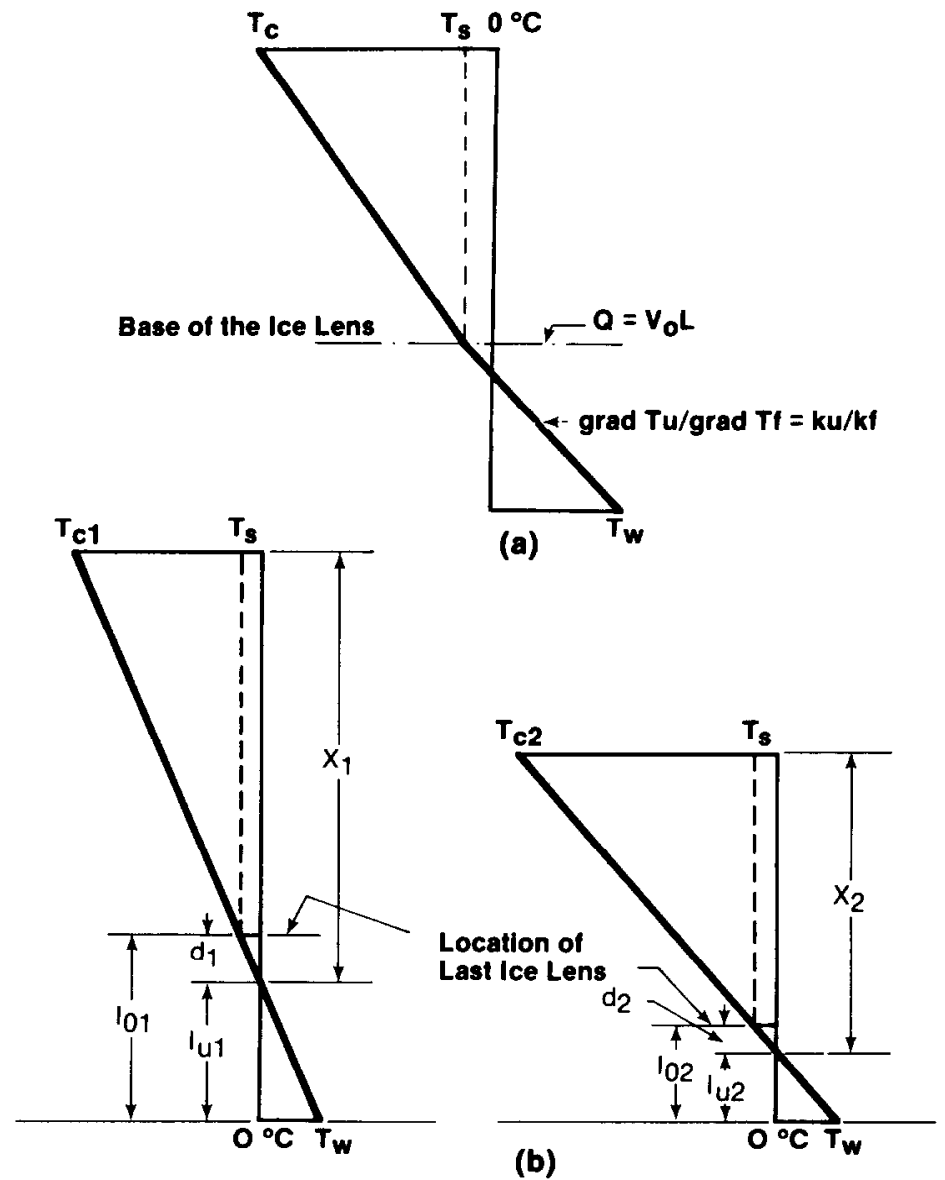

Fig. 25. Conditions associated with the onset of the formation of the final ice lens

and at $T_{\mathrm{i}}$

$$
Q=\varepsilon n L(\mathrm{~d} X / \mathrm{d} t)
$$

where

$\varepsilon$

is a dimensionless factor taking into account the unfrozen water remaining in the sample and lumped at $T_{\mathrm{i}}$

$n \quad$ is the porosity of the soil

$\mathrm{d} X / \mathrm{d} t \quad$ is the rate of advance of the frost front

Konrad \& Morgenstern (1980) have developed a model that avoids the requirement for local measurements of $T_{\mathrm{s}}$ and $\bar{K}_{\mathrm{f}}$ needed to solve the equations given in Fig. 24. They have argued that, since the permeability of frozen soil is influenced by temperature, it is expected that for a given soil the final ice lens should be initiated around the same segregation-freezing temperature $T_{s}$, independent of the temperature gradient across the frozen zone.

Freezing two identical samples with different heights under different cold side temperatures $T_{c}$ and the same warm-side temperature $T_{\mathrm{w}}$ leads to temperature profiles at the beginning of steady state as shown in Fig. 25. From considerations of both geometric similarity and Darcy's law, it can be shown that regardless of $T_{\mathrm{c}}$

where

$$
v=\mathrm{SP} \times \operatorname{grad} T
$$

$$
\begin{gathered}
\mathrm{SP}=\left|\frac{H_{\mathrm{w}}-h_{\mathrm{u}}}{T_{\mathrm{s}}}\right| \bar{K}_{\mathrm{f}} \\
\operatorname{grad} T=\frac{T_{\mathrm{w}}+\left|T_{\mathrm{s}}\right|}{l t}=\frac{T_{\mathrm{w}}}{l_{\mathrm{u}}}
\end{gathered}
$$

$h_{u}$ denotes the suction at the frozenunfrozen interface

SP denotes the segregation potential

Equation (11) states that if the segregation freezing temperature of a soil is unique, the water intake velocity will be proportional to the temperature gradient on the warm side of the ice lens. The constant of proportionality is called the segregation potential , SP; and the prediction of equation (11) 


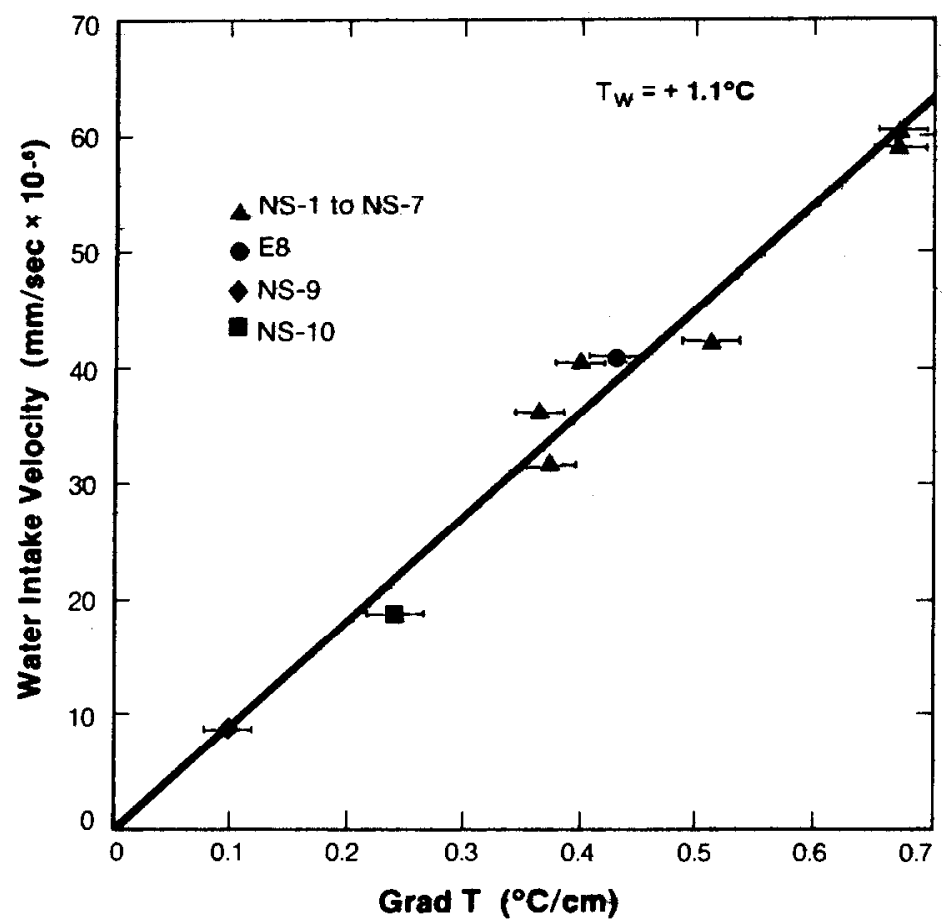

Fig. 26. Relation between water intake velocity and temperature gradient across the frozen fringe at the initiation of the final ice lens

can be tested directly by experiment.

In order to investigate the validity of equation (11) a series of freezing tests on replicate specimens of silt has been conducted at a constant warm-side temperature $T_{\mathrm{w}}$ and different cold-side temperature $T_{c}$. These tests were conducted in such a manner that both $v$ and grad $T$ could be identified at the onset of the last ice lens. Details are given in Konrad (1980). The results are shown in Fig. 26 and support the conceptual development reviewed here.

The segregation potential is itself explicable in terms of the detailed characteristics of the frozen fringe. However, from an engineering point of view it is more important to recognize that equation (11) constitutes the necessary coupling between heat and mass flow required to predict frost heave and that the parameter characterizing the freezing system, SP, is readily found from well-defined laboratory tests. The system of equations summarized in Fig. 24 are readily recast in terms of SP and can be solved by numerical means to predict heave under the specified boundary conditions.

The development of the segregation potential has so far been restricted to conditions of constant $T_{w}$, almost equilibrium cooling and zero external pressure. To be of general value each of these restrictions must be rcmoved.

Konrad (1980) argued on thermodynamic grounds that when water flows through frozen soil, the suction in the frozen medium is no longer related solely to temperature and the unfrozen water content becomes a function of both temperature and suction. Since the unfrozen water content distribution directly affects the permeability of the frozen soil, different average suctions within the frozen fringe will yield different freezing characteristics for a given soil, although the average temperature in the fringe may remain constant.

By recognizing the effect of different temperature boundary conditions on the location of the final ice lens in a laboratory freezing test, and bearing in mind that changes in cold-side step temperature alone do not affect SP, it can readily be shown that the warm-side temperature alone affects the value of the suction at the frost front. Figure 27 presents simplified temperature distributions across a sample for different boundary conditions. The temperature profiles with identical numbers result in identical characteristics of the frozen fringe whereas different warm-end temperatures give different suction profiles in the fringe. From geometrical considerations and considering Darcy's law in the unfrozen soil, assuming for example, a given value of water intake flux for a fringe of thickness unity, it can readily be shown 

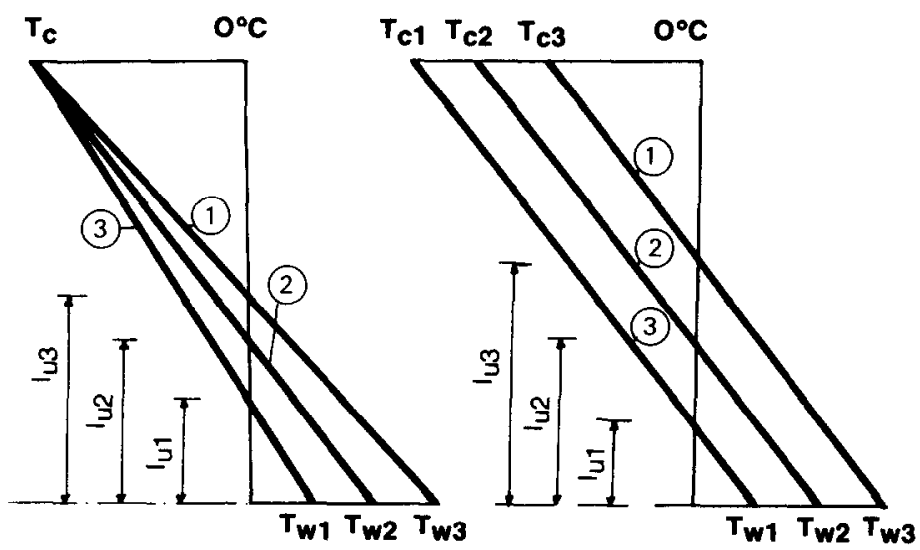

\section{Simplified Conditions at the Inltiation of the Final Ice Lens with Different Thermal Boundary Conditions}

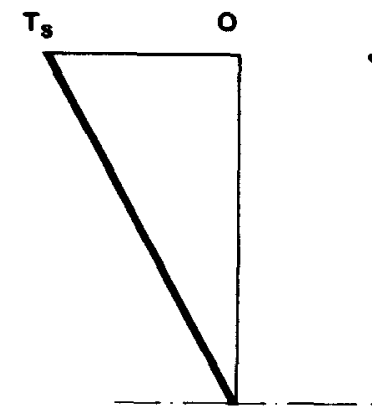

Temperature Profile

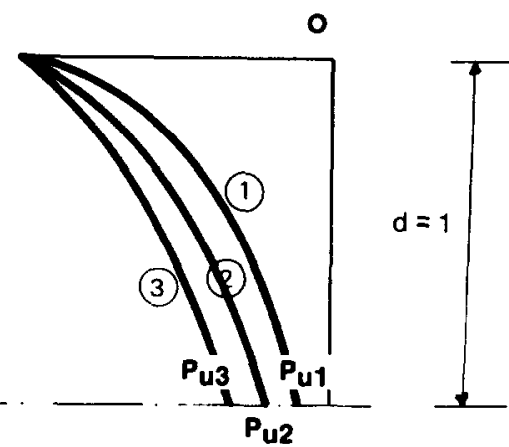

Suction Proffie

Fig. 27. Effect of warm-plate temperature on suction profile in the frozen fringe

that

$$
\frac{\left|l_{\mathrm{u}_{1}}\right|}{T_{\mathrm{w}_{1}}}=\frac{\left|l_{\mathrm{u}_{2}}\right|}{T_{\mathrm{w}_{2}}}=\frac{\left|l_{\mathrm{u}_{3}}\right|}{T_{\mathrm{w}_{3}}}
$$

For $T_{w_{1}}<T_{w_{2}}<T_{w_{3}}$ it follows that

$$
\left|l_{\mathrm{u}_{1}}\right|<\left|l_{\mathrm{u}_{2}}\right|<\left|l_{\mathrm{u}_{3}}\right|
$$

Further, assuming that the segregation temperature $T_{\mathrm{s}}$ does not change drastically with $T_{\mathrm{w}}$, the shape of the suction profile can be drawn schematically as shown in the Fig. 27. Since the average suction is strongly related to the shape of the suction profile which in turn depends on the actual shape of the permeability profile it is impossible to determine with any degree of accuracy the value of that average suction. For a given warm-side temperature the suction profile in the frozen fringe and particularly the suction at the frost front $P_{\mathrm{u}}$ is unique for a given soil. Therefore, $P_{u}$ has been adopted as a reflection of the average suction of the frozen fringe. The advantage of using
$P_{\mathrm{u}}$ lies in the ease with which it can be determined by applying Darcy's law to the unfrozen soil alone.

A variety of tests, including layered systems, were performed to induce different magnitudes of $P_{\mathrm{u}}$ and to measure SP. The relation between SP and $P_{u}$ is illustrated in Figure 28. SP decreases with increasing suction at the frost front. This might be viewed at one level as an experimental finding, but in the Author's view it supports the concept that the average suction in the frozen fringe is a fundamental parameter of a freezing soil. The decrease in SP with increasing suction is accounted for primarily by a reduction in frozen permeability with increasing suction. Both SP and $P_{u}$ can be determined from simple laboratory freezing tests.

\section{Characteristic freezing surface}

The first test of the frost heave theory developed here is the recovery of laboratory freczing test data. The theory has been developed and parameters deduced for conditions of near-stationary frost 


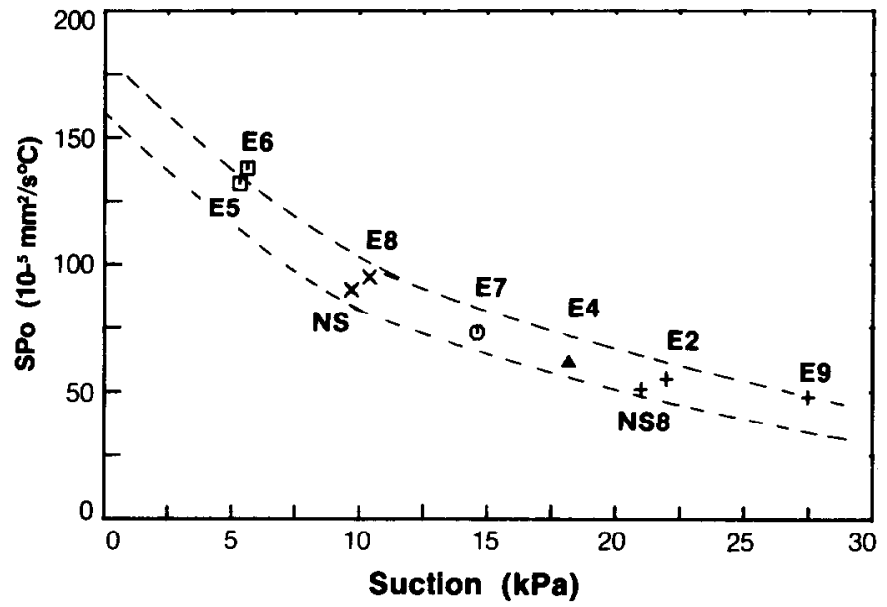

Fig. 28. Segregation potential against suction at the frost front for Devon silt

fronts and additional parameters may be needed to characterize freezing with an advancing frost front. This has proved to be the case (Konrad, 1980).

The governing equations for one-dimensional frost heave summarized in Fig. 24 may be solved numerically using established techniques. Figure 29 compares the total and segregational heave measured in two tests with the predicted values. It appears that good agreement is obtained at the beginning of freezing for about $12 \mathrm{~h}$, after which a substantial difference arises. However, the computed rate of heave compares well with the measured value as steady state conditions are approached. This is not surprising since the input parameters characterizing the freezing system are representative of quasi-steady-state conditions associated with the growth of the final ice lens. Although the predicted heave is about $85 \%$ of the observed value at the onset of the formation of the final ice lens, the simulation is not all that satisfactory. This is illustrated by comparing computed and observed water intake velocities for a particular test (see Fig. 30). Substantial differences are apparent. These differences can be accounted for by the influence of changing suction profiles on the characteristics of the frozen fringe.

During a laboratory freezing test, the suction at the frost front changes continually. Initially, relatively long flow paths in the unfrozen soil associated with high flow velocities indicate quite high suctions at the frozen-unfrozen interface. With time, both flow path and water velocity decrease with a concomitant decrease in suction. While it is possible to account for the changing freezing characteristics in terms of variation in $T_{\mathrm{s}}$ and $K_{\mathrm{f}}$ during rapid freezing, a direct evaluation in terms of SP leads to results that are more readily applicable in practice. However, the relation between SP and $P_{\mathrm{u}}$ obtained at quasi-steady-state conditions cannot be applied to the unsteady heat flow condition with an advancing frost front. This is evident from observations that for a given suction $P_{u}$, different values of SP can be obtained depending on the degree of thermal imbalance in the test.

Many studies have explored the relation between rates of cooling and frost heave but no clear picture has emerged. It is tempting to relate SP to the suction and rate of frost front advance. However, since the frozen fringe is the seat of segregational process, it can be shown that, under certain circumstances, a given frost front penetration over a given time interval does not necessarily induce identical changes in the anatomy of the frozen fringe. This is illustrated in Fig. 31. If two identical samples are subjected to different geometrical and thermal boundary conditions and compared upon reaching a specified rate of frost penetration, there will be differences in temperature gradients in the frozen and unfrozen soil. This in turn affects the thickness of the frozen fringe. If, for simplicity, it is assumed that $T_{\mathrm{s}}$ is the same in both specimens, the dimensions of the frozen fringe are then fully defined at time $t$ in both samples. If the frost front advances in both cases an identical length $\mathrm{d} X$ during an interval $\mathrm{d} t$, the result is a change in temperature distribution in both samples and this is shown in Fig. 31. The ratio of the hatched area and the area defined by the frozen fringe at time $t$ can be interpreted as a measure of the degree of cooling of the fringe. The frozen fringe cooled by a different amount in each case. Therefore the degree of thermal imbalance has been related to the rate of cooling of the frozen fringe during freezing. Hence, a freezing soil subjected to an advancing frost front may be characterized by the segregation 

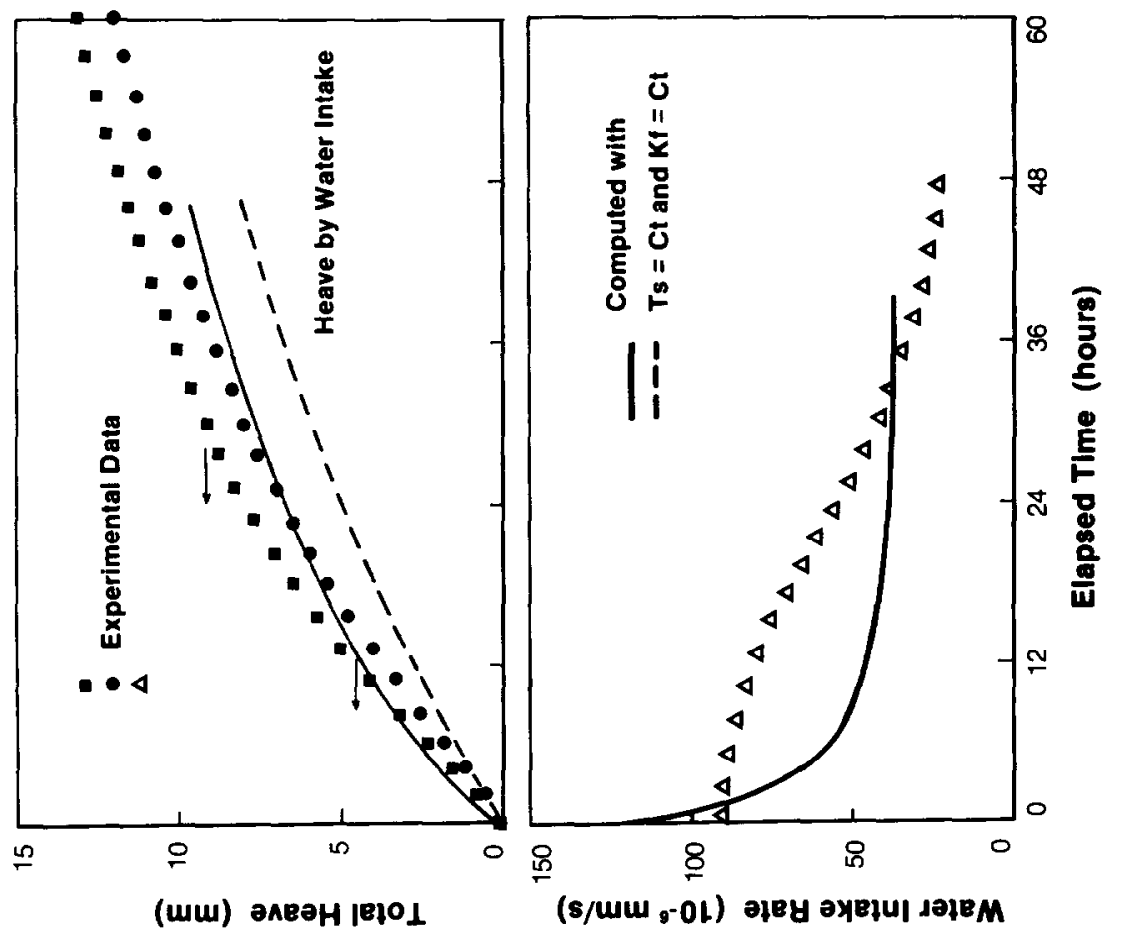



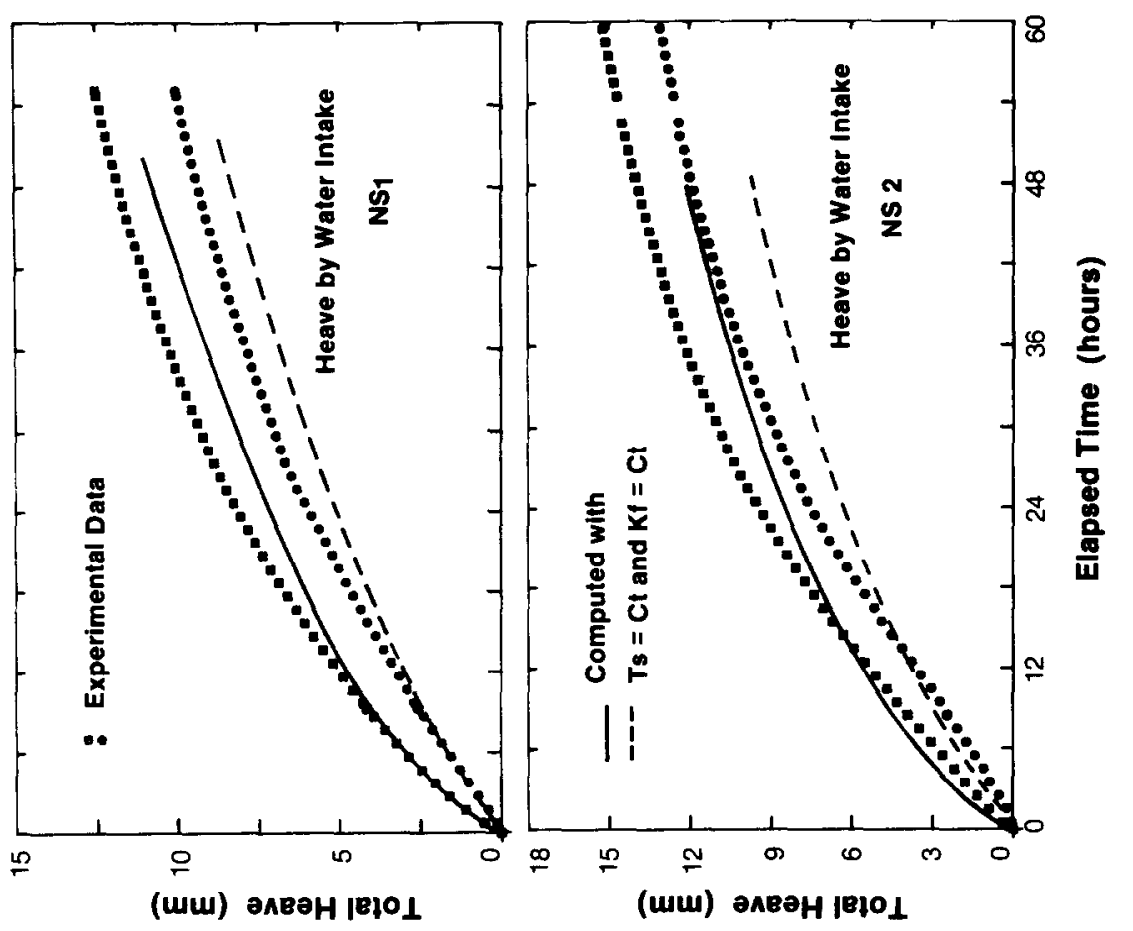

 


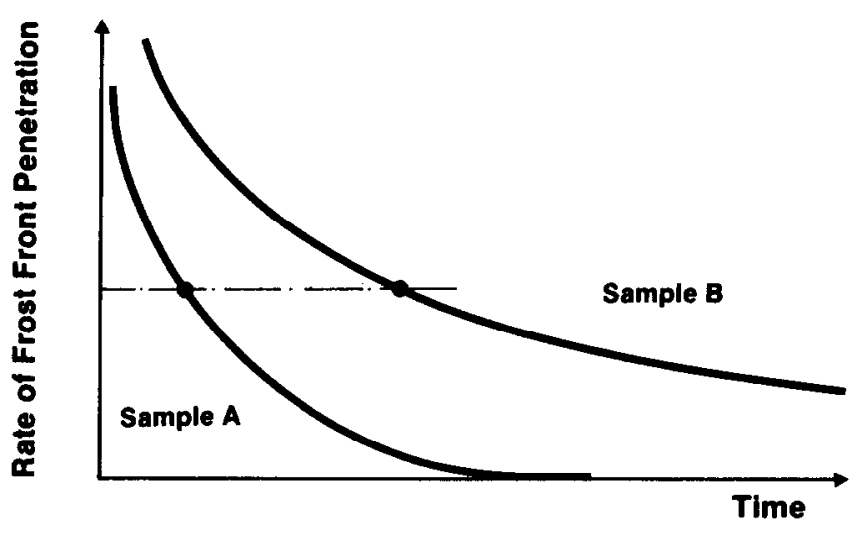

Sample A

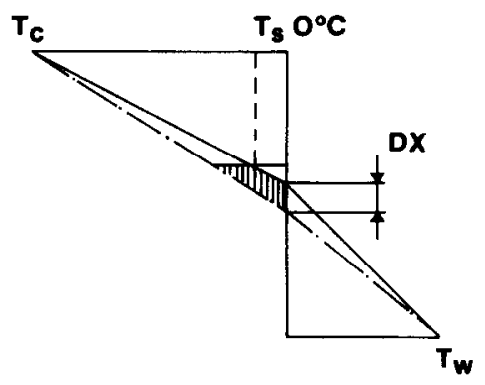

Sample B

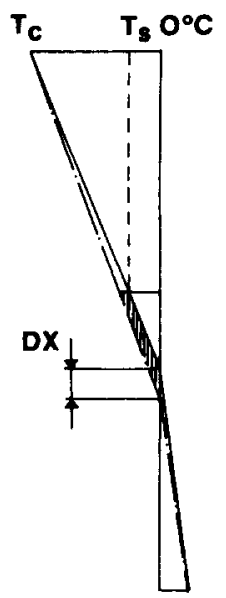

Fig. 31. Changes in frozen fringe at a given rate of frost front advance

potential, which is a function of two independent parameters: the suction at the frost front $P_{\mathrm{u}}$, and the rate of cooling of the fringe $\mathrm{d} T_{\mathrm{f}} / \mathrm{d} t$. This results in acceptable input for frost heave prediction in the more general heat and mass transfer formulation.

The frost heave characteristic surface (SP, $P_{u}$, $\mathrm{d} T_{\mathrm{f}} / \mathrm{d} t$ ) can be determined from controlled freezing tests in which the variation of the length of unfrozen soil at any time is known from temperature measurements. Details of tests and their interpretation are given by Konrad (1980). Figure 32 summarizes results from several different tests and shows that a unique relation between SP and $P_{u}$ exists for a particular value of $d T_{\mathrm{f}} / \mathrm{d} t$. Such a relation has already been established at the onset of the formation of the final ice lens. Results like these can be combined to form the surface shown in Fig. 33. The transients are extreme at high rates of cooling and the surface may not be well defined for these conditions, particularly if the unfrozen soil is compressible. Cavitation also limits the suction. However, this is only of concern for the early stages of laboratory tests and will not be a restriction when applied to field conditions.

By fitting functions to the experimental relations between SP and $P_{\mathrm{u}}$ at different rates of cooling and providing interpolation procedures, the surface can be used to characterize mass transfer in the formulation presented in Fig. 24. Unsteady heat flow is first solved across the whole specimen. The resulting temperature profile can then be used to determine the rate of cooling of frozen fringe. From the current rate of cooling, SP can be fixed as a function of $\boldsymbol{P}_{\mathrm{u}}$. Knowing SP determines the water intake velocity as a function of suction at the frost line. However, for a given length of unfrozen soil the velocity of water flow is related by Darcy's law to the difference in total potential across the unfrozen length. This requirement thus fixes the particular value of SP and $P_{\mathrm{u}}$ at the time under consideration 


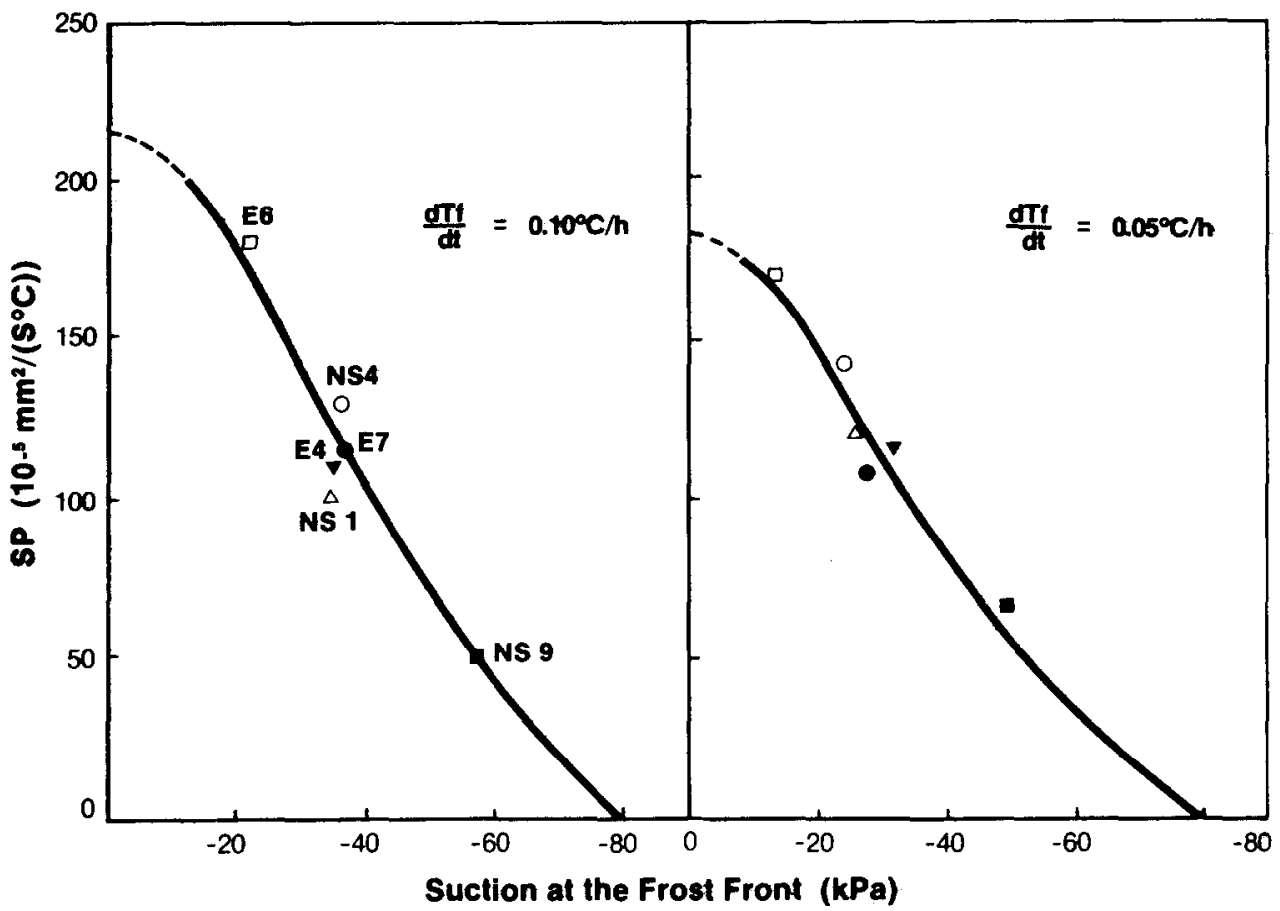

Fig. 32. Freezing characteristics for Devon silt

and the solution process can march forward in time. Comparisons between predicted and measured heaves in a variety of laboratory tests are given in Fig. 34.

All the simulated freezing tests discussed so far have been conducted with fixed temperature boundary conditions during the whole freezing period. It is tempting to conclude that the validity of the proposed characterization of a freezing soil is therefore restricted to those specific thermal conditions. In order to demonstrate that the characteristic freezing surface is independent of freezing path one sample was frozen in two stages. During the first stage, the temperatures at the top and bottom of specimen were maintained constant for $24 \mathrm{~h}$. During that period, the frost front penetrated approximately to the middle of the sample. Then the second stage was initiated by changing the temperatures at both ends in order to force further penetration of the frost front. During the second phase the temperatures were also maintained constant with time. The warm-plate temperature was lowered from $3.5^{\circ} \mathrm{C}$ to $1^{\circ} \mathrm{C}$. This results, in the early stage of the phase, in heat flow to both ends of the specimen since the temperature distribution is at a maximum somewhere within the unfrozen soil. Figure 35 shows the comparison between computed and measured results. The model predicts remarkably well the change in the rate of heaving that occurred as the temperature boundary conditions were changed. Furthermore, the computed frost front penetration is also in agreement with the measured profile and visual observations after the test was completed. In addition, Fig. 36 demonstrates that the model predicts extremely well the actual increase in water content in the frozen soil.

The final parameter that needs consideration in the development of a comprehensive theory for frost heave is applied pressure. It has been known for a long time that applied pressure inhibits frost heave and this can also be illustrated in terms of the SP (see Fig. 37). The influence of applied pressure can be explained in terms of stress-induced changes in unfrozen water content, frozen fringe permeability and segregation freezing temperature; but these are not necessary in order to accept data like Fig. 37 as an experimetal finding of value in predicting the influence of applied stress on frost heave.

\section{Applications}

In order to understand more clearly the chilled gas pipeline problem, both laboratory model and full-scale field studies have been carried out. A model box utilized in one study (Northern Engineering Services Ltd, 1975) is shown in Fig. 38. The tests were intended only to obtain qualitative information; temperature data were not sufficiently complete for analytical purposes. Boundary 

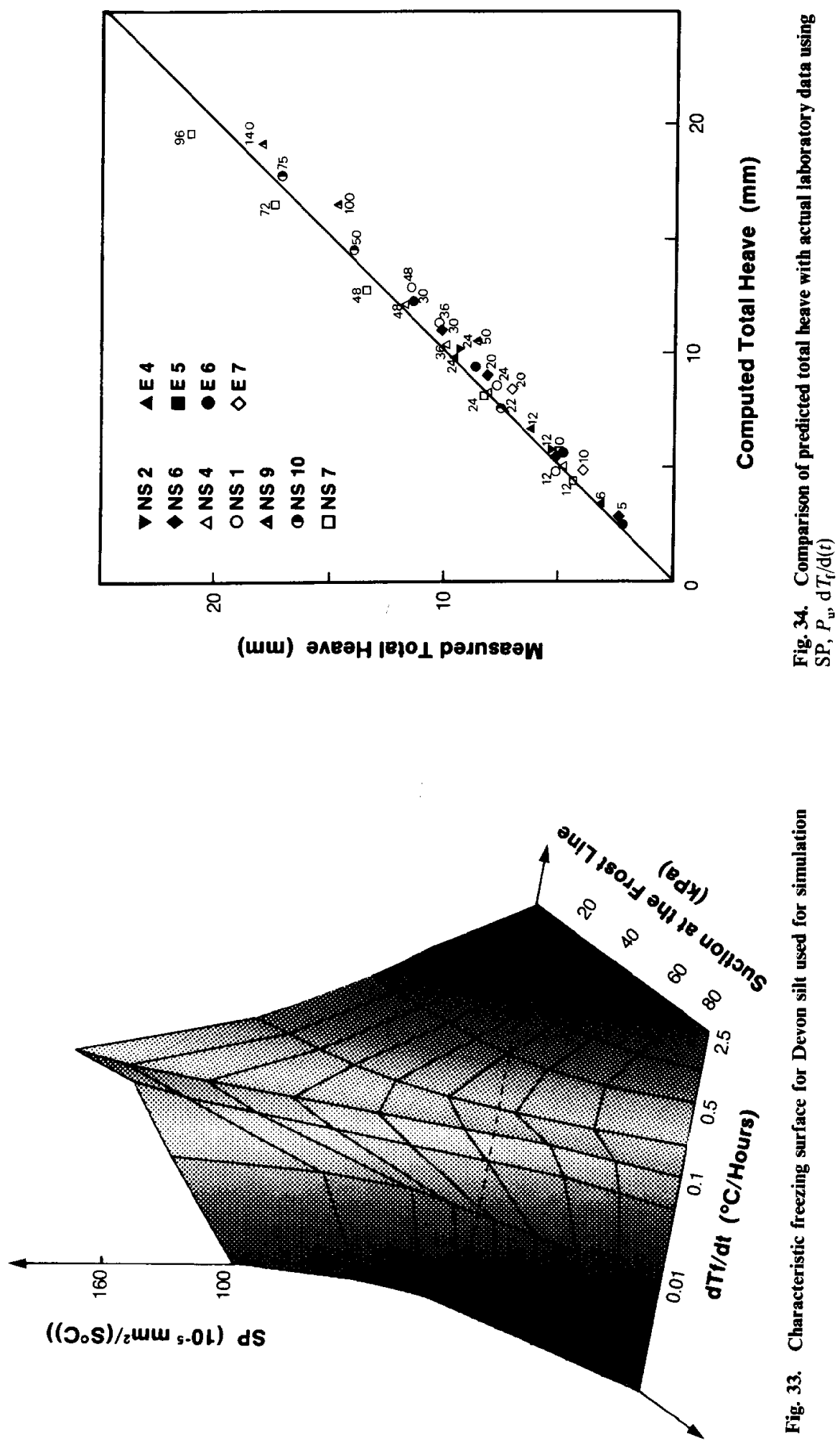

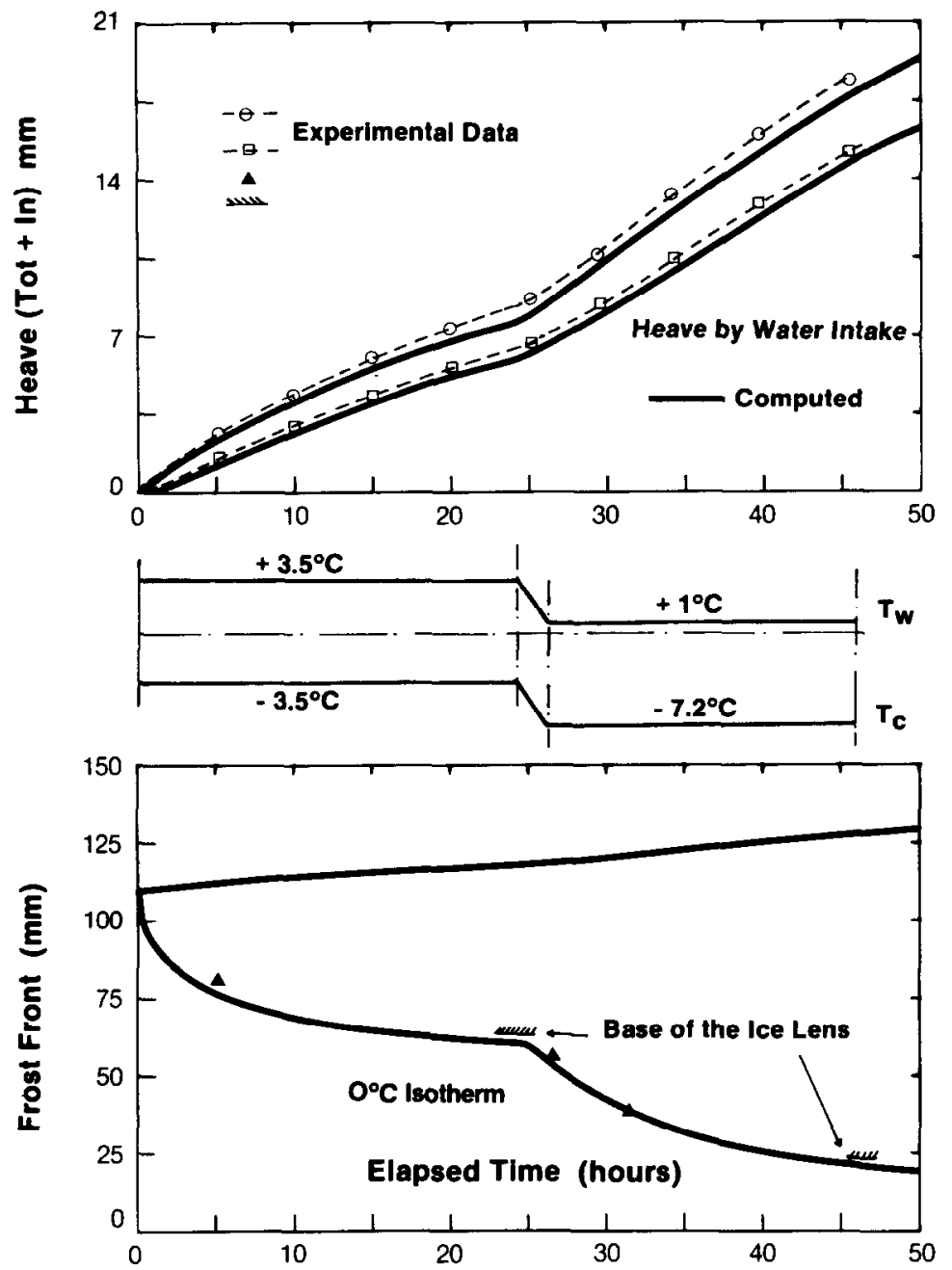

Fig. 35. Comparison of prediction with actual data for test E-1

conditions had to be deduced by back-analysis. Tests U-1, U-2 and U-3 were run consecutively to assess the effect of alternate freezing and thawing on pipeline performance. For tests $U-2$ and $U-3$ the initial conditions corresponded to the final conditions at the end of the thawing cycle for the previous test. The initial ground temperatures below the pipe were therefore warmer than otherwise expected thereby accounting for shallower frost penctration. Tests U-5 and U-6 were essentially duplicate tests and the soil had not been frozen previously in either case. The results of these tests are compared with theoretical predictions in Fig. 39.

The analysis of the model tests reveals that the best fit for tests U-2 and U-3 is obtained with a permeability of the frozen fringe of $1.4 \times 10^{-9} \mathrm{~cm} / \mathrm{s}$ and that tests U-5 and U-6 are fitted best with
$1 \times 10^{-9} \mathrm{~cm} / \mathrm{s}$. These permeabilities are in the range deduced from laboratory freezing tests. The prediction of heave with the matched data is encouraging. It appears that the segregation potential of a soil is increased after a freeze-thaw cycle. This increase, reflected in the permeability of the frozen fringe, is thought to be associated with changes in soil structure. Tests U-5 and U-6 demonstrate that for the same freezing temperature in the model pipe, the dceper the frost front, the smaller the resulting heave. This result, which is not intuitively obvious, confirms that colder ground temperatures which lead to deeper frost penetration are actually more favourable conditions with regard to pipeline heaving than warmer ground temperatures.

A field test facility was constructed in Calgary, Alberta in 1973. Four test sections using $1.22 \mathrm{~m} \mathrm{dia}$. 
pipe were buried in a frost-susceptible silt and have been maintained at a temperature of $-8.5^{\circ} \mathrm{C}$ since that time. Many detailed results have been reported by Slusarchuk et al. (1978). Laboratory freezing tests were performed on undisturbed samples but in a less controlled manner than would be specified today. However, a reasonable fit to the laboratory data provides a relation between SP and applied

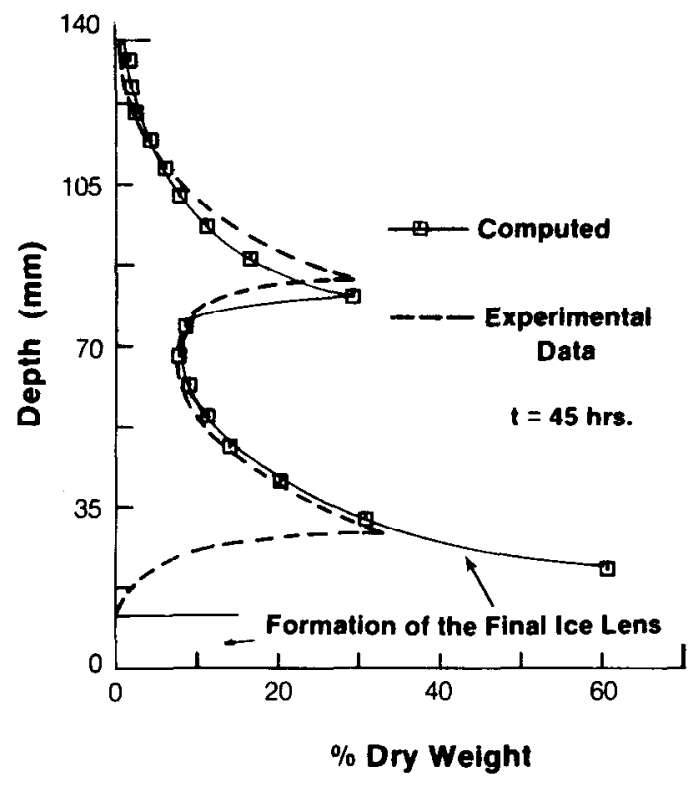

Fig. 36. Water content profile at the end of freezing for test E-1 pressure which can be used in the field prediction to give the results shown in Fig. 40. The good correspondence is encouraging.

In many field freezing conditions $P_{\mathrm{u}}$ will be small enough to ignore. In a laboratory test this would correspond to a warm-plate temperature close enough to $0^{\circ} \mathrm{C}$ to ensure small values of $P_{\mathrm{u}}$. Under these circumstances it is possible to predict natural heaving if the relation between surface freezing temperature and time is known or alternatively to invert the process and deduce SP from observations of natural freeze-back and associated heave. An illustration of this applied to the interpretation of natural freezing in Fairbanks silt (Aitken, 1974) is shown in Fig. 41. By measuring the penetration of the frost front and heave, the in situ magnitude of SP is readily found. If a surcharge is applied to the ground the relation between SP and applied stress can also be determined. This obviates the need to extract samples and conduct laboratory tests to determine frost heave characteristics of many natural soils.

\section{Commentary}

The initial objective of the research programme described here was to develop a procedure for forecasting the heave of a chilled buried gas pipeline both unrestrained and under restrained conditions. The examples cited previously demonstrate that unrestrained heave is predicted in a reasonable manner. Restrained heave may also be predicted by calculating the normal stress required to deform the pipeline encased in frozen soil in a differential manner. This stress can be used as an externally

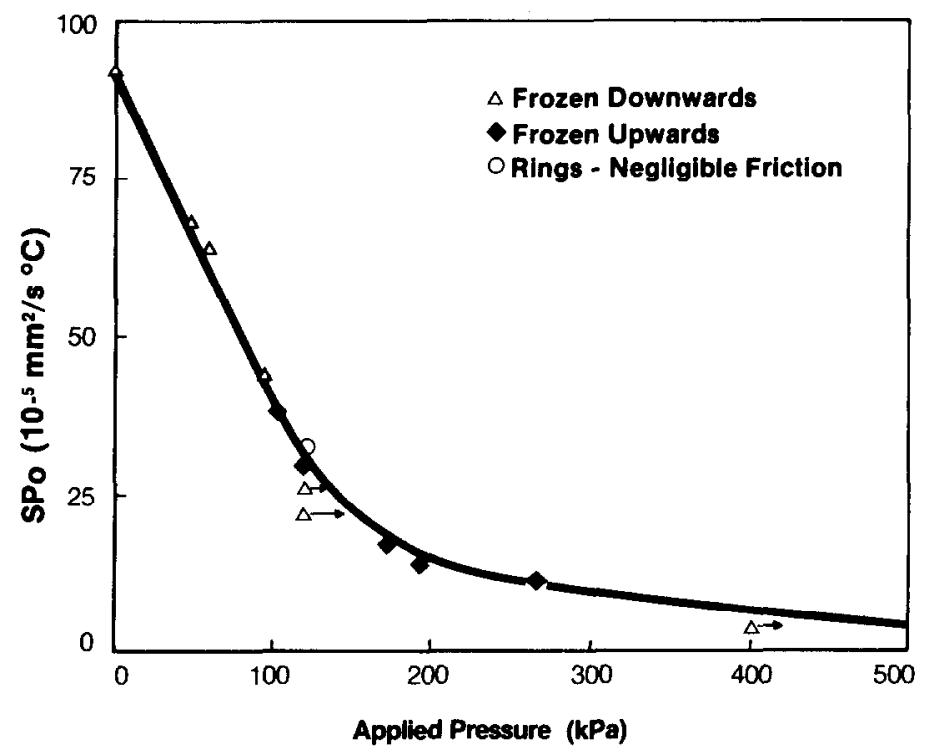

Fig. 37. Segregation potential for Devon silt under different applied loads (series C) 
applied stress in the frost heave calculation to moderate the predicted local heave. In this way, an iterative solution can be developed for soil-structure interaction analyses of differential frost heave.

The segregation potential SP provides a new basis for frost heave classification. Existing procedures are not very effective in discriminating among differing degrees of frost-susceptibility. A standard test can be devised to determine SP under representative boundary conditions and laboratory-based parameters readily correlated with ficld values of SP deduced from natural freezeback tests. Existing classification work has been hampered by a lack of a clear transfer to field conditions.

Experimental studies in terms of the segregation potential or the equivalent parameters $T_{\mathrm{s}}$ and $k_{\mathrm{f}}$ provide a means for exploring in a fundamental manner the influence of mineralogy, pore water solutes and other compositional factors known to influence frost heave susceptibility.

Finally the theory sheds new light on both engineering and geological freezing processes by showing that only ice at less than $0^{\circ} \mathrm{C}$ in a fine- grained soil is needed to attract water whether the ground surface is cooling or not. Segregational processes can even occur under summer conditions as has been observed in the field (Mackay, 1980). Climatic conditions necessary for the accumulation of ground ice do not require sustained neat extraction at the ground surface, although if the ice warms to $0{ }^{\circ} \mathrm{C}$ the segregational process stops.

\section{MECHANICS OF THAWING GROUND The problem}

While it had been recognized for a long time that thawing of ice-rich frozen ground results in large settlements and reduced bearing capacity, procedures for including the effects of thawing permafrost in geotechnical design were virtually nonexistent in North American practice prior to the late 1960s. Possible exceptions to this were the development of hydro-electric facilities along the Nelson River (MacPherson, Watson \& Koropatrick, 1970) and some highway and railroad construction in Alaska and the Canadian north. After the discovery of oil at Prudhoe Bay on the Alaskan North Slope it was finally concluded that the transport of oil from the Arctic coast to an ice-

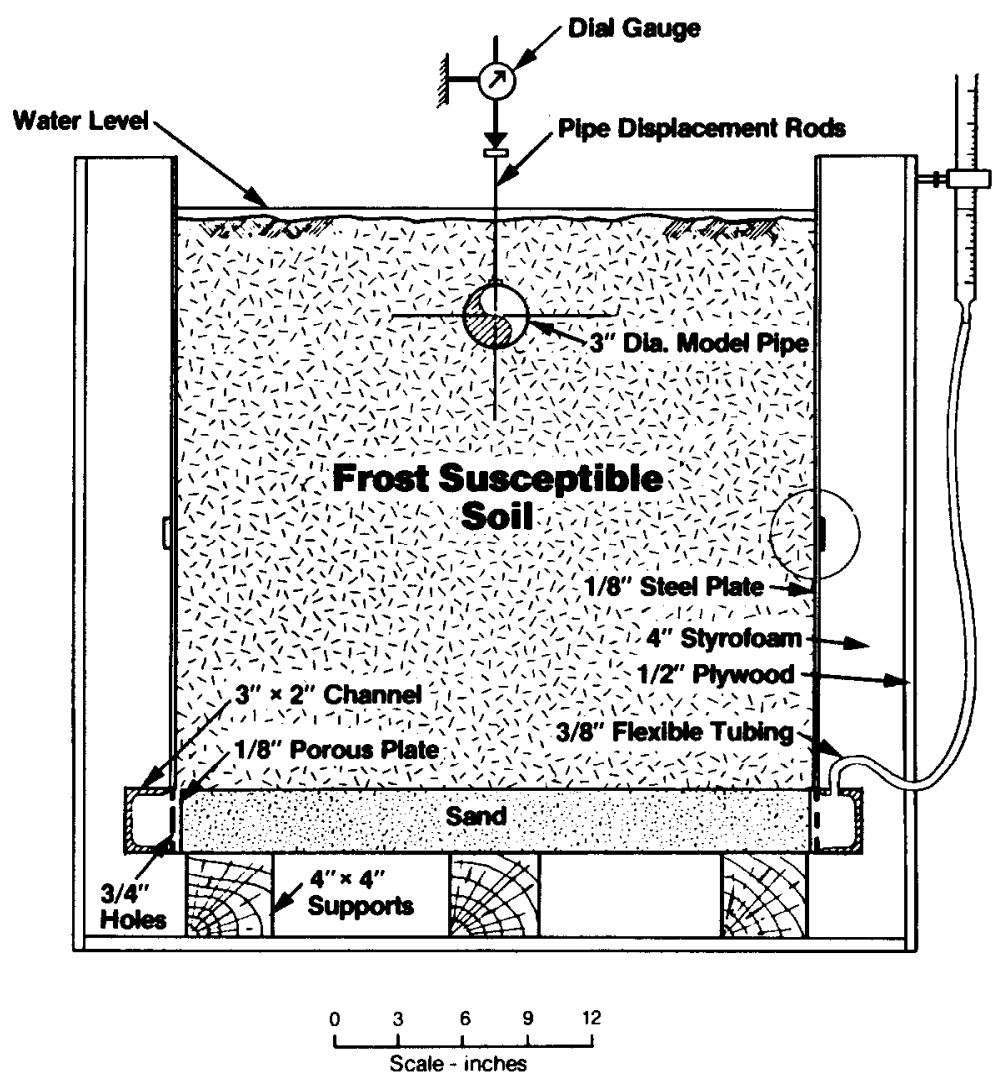

Fig. 38. Dimensions of the model box; after Northern Engineering Services (1975) 


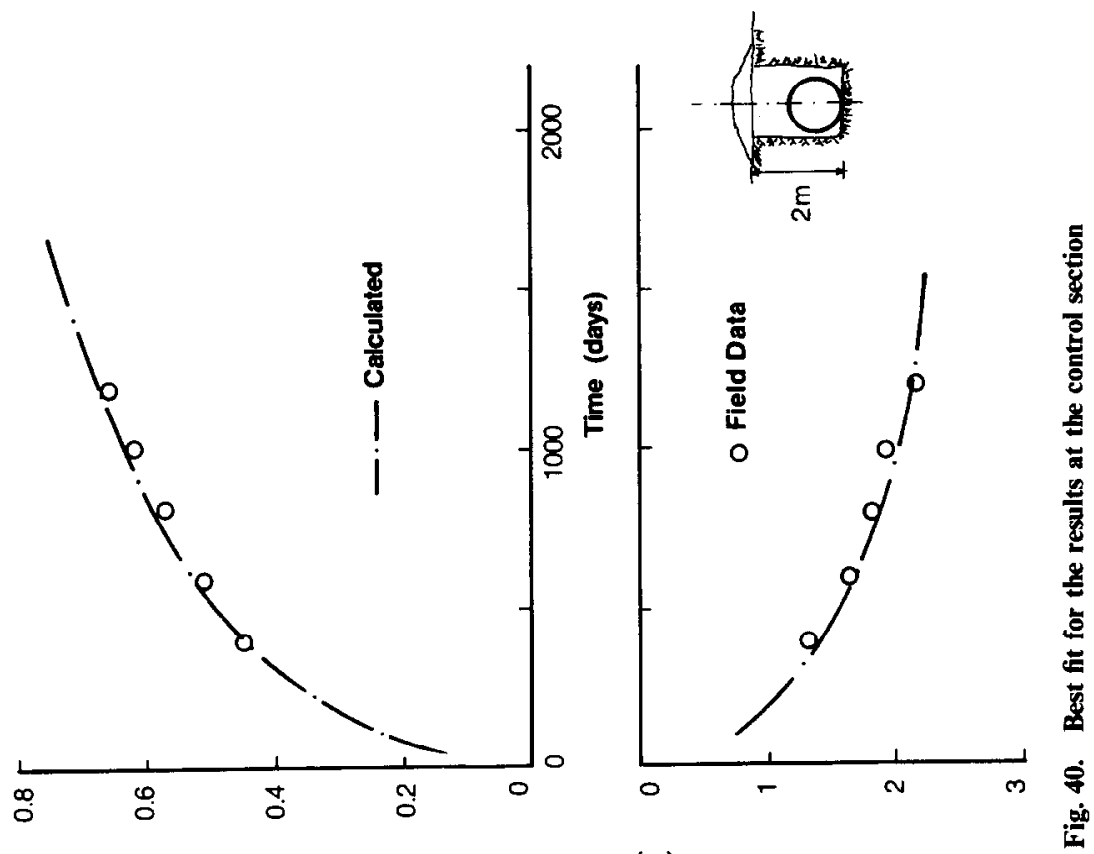

(w) әпеәН

(w) voppenoled tso.t

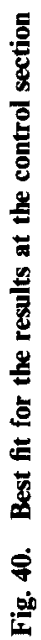
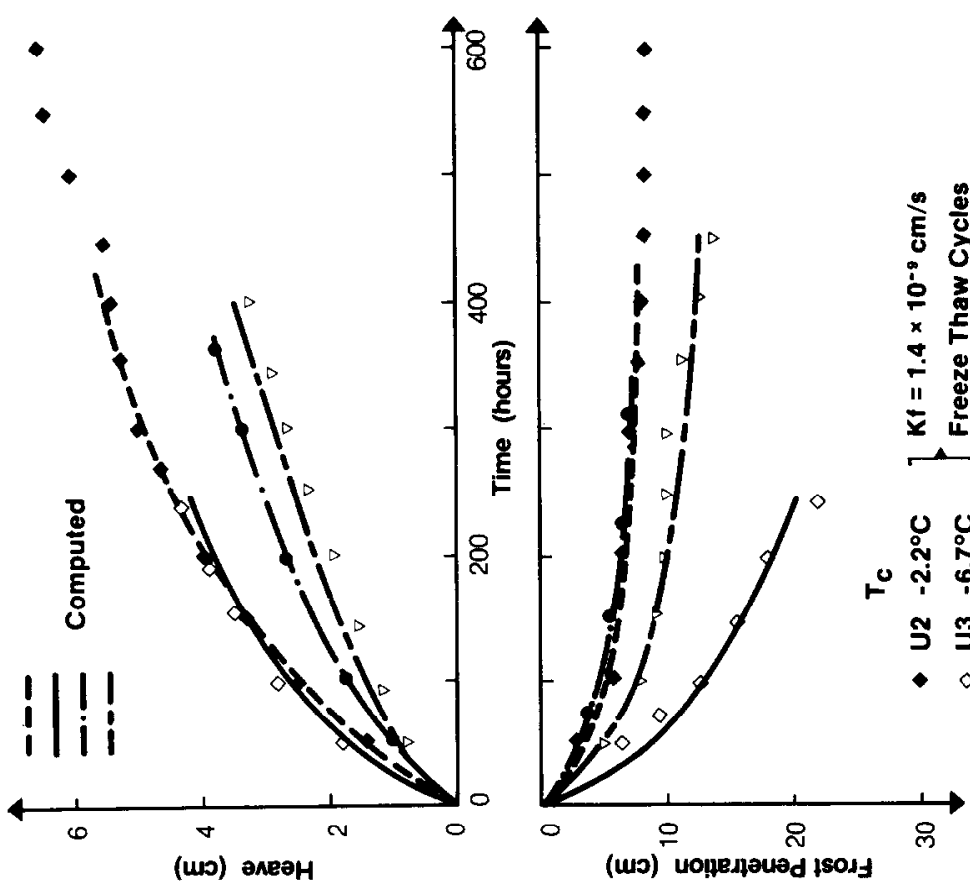

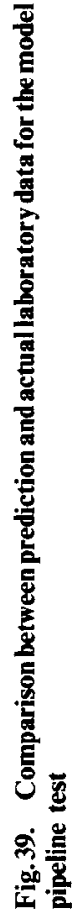



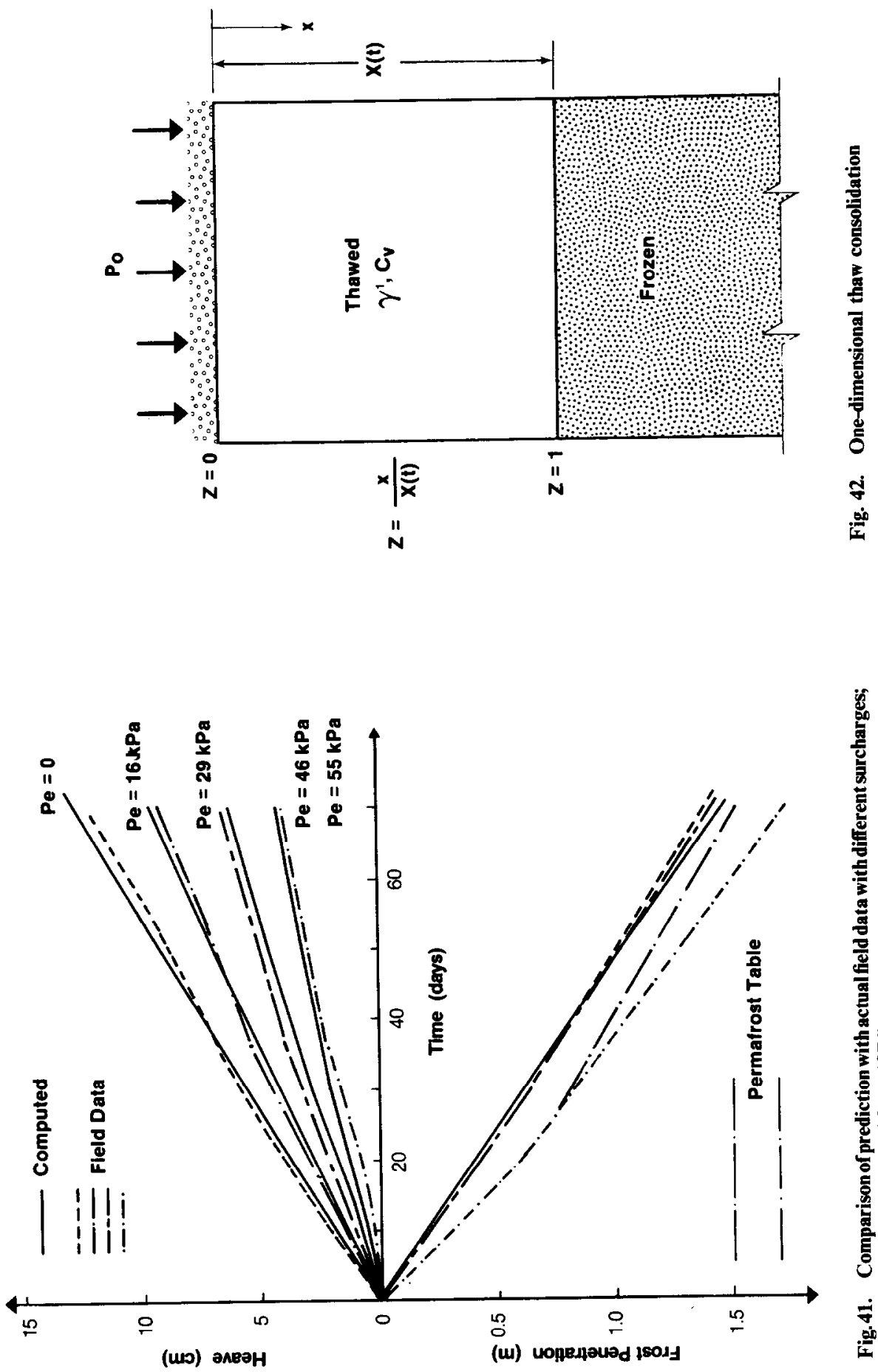

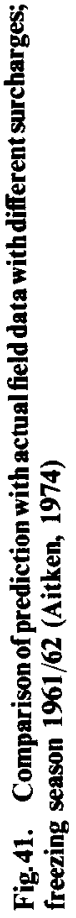




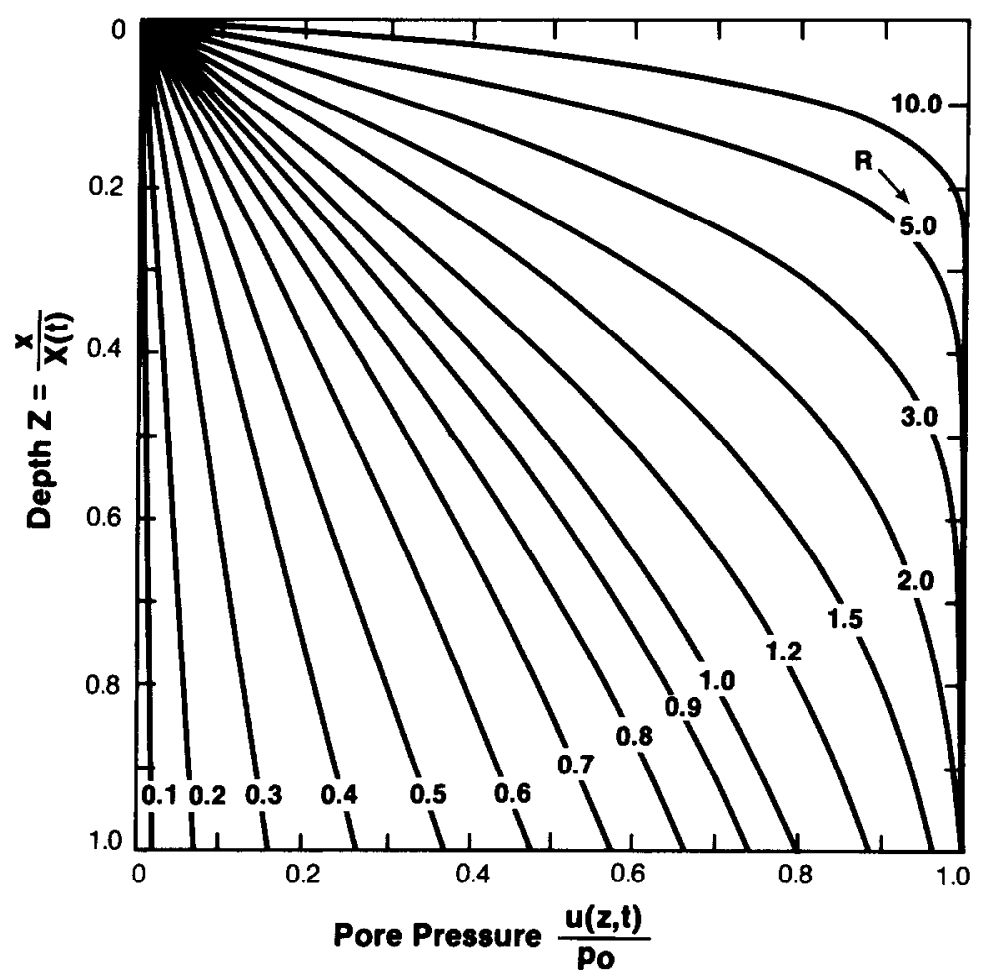

Fig. 43. Excess pore pressures (weightless material)

free port should be accomplished with a 48 in $(1.22 \mathrm{~m})$ dia. pipeline that was originally intended to be buried along most of its route. Since it was necessary to maintain oil temperatures at about $70^{\circ} \mathrm{C}$, this would result in thawing of the surrounding ground wherever the pipeline was buried in permafrost. Lachenbruch (1970) drew attention to the potential problems created by the presence of a hot-oil pipeline in permafrost. Depending upon boundary conditions, it was shown that a thaw bulb some $10-12 \mathrm{~m}$ in diameter might develop over the design life of the pipeline and if the melted soil were considered a viscous fluid, catastrophic slope instability could result. While the conclusions of this study were based on a limited perspective of the mechanical properties of thawed soils, they did serve to draw attentions to the importance of gcotechnical aspects of pipeline design in permafrost.

In the early 1970s investigations into the design and construction of hot-oil pipelines from the Mackenzie delta to southerly markets were initiated and the same geotechnical concerns that had arisen over the Alaskan project became applicable to the developments proposed in Canada. In order to design in a rational manner it was essential to establish the effective stress changes in a soil consequent upon thaw. If thaw led to low effective stresses, the thawed soil would indeed be unstable on slopes and disposed to large settlements as pore pressures dissipated. However, if during and after thaw substantial effective stresses resulted, design could proceed in a more or less conventional manner without undue concern for the presence of permafrost. The problem of thaw-consolidation was therefore systematically attacked.

Determining the actual settlement of soil subjected to thaw is conceptually a straight-forward matter. When thawed under fully drained conditions components of total settlement arise from phase change considerations, settlement under selfweight, and settlement due to additional applied load. The parameters characterizing this behaviour can be studied in the laboratory and used in conventional procedures to estimate onedimensional settlement. The difficulty in practice arises from the extreme variability of the magnitude of thaw-strain parameters over short distances (Speer, Watson \& Rowley, 1973). If thawing proceeds under fully drained conditions the time-settlement relation is simply proportional to the progress of the thaw front with time. However, if thaw proceeds too quickly for the pore pressures generated to dissipate, excess pore pressures are set up, settlement is impeded and the shear strength is reduced accordingly. In order to determine the 


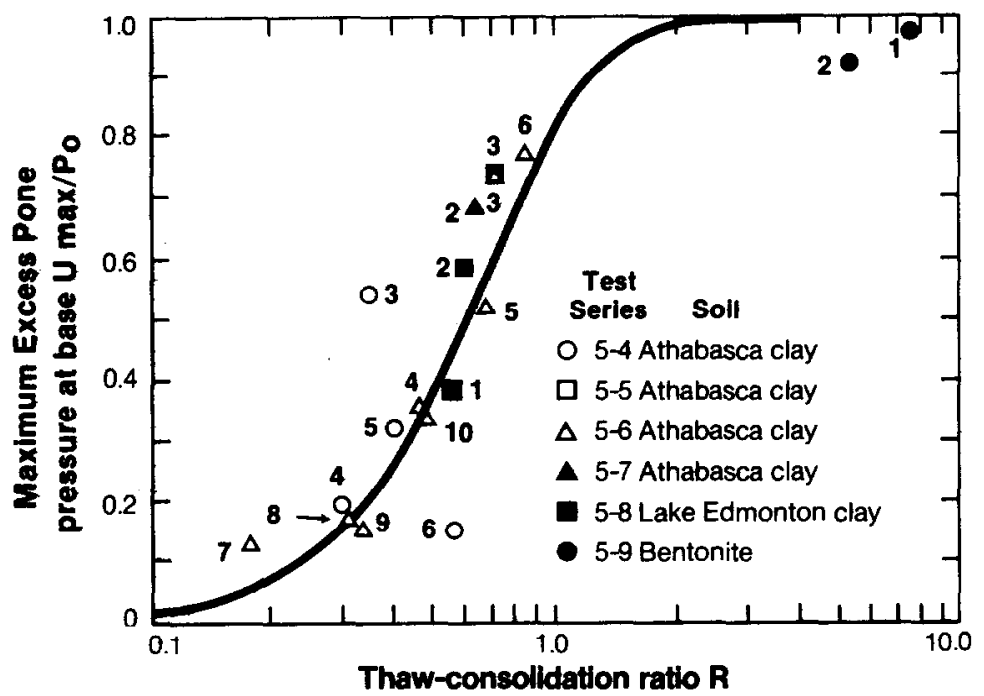

Fig. 44. Maximum excess pore pressures measured for reconstituted soils

extent of drainage that occurs during thaw it is necessary to couple the analysis of the process of thaw with the process of consolidation.

\section{Theoretical and experimental studies}

Figure 42 illustrates a uniform layer of frozen soil of semi-infinite extent subjected to a step increase in temperature at the surface. The solution to this type of heat conduction problem is well known and the movement of the thaw plane is given by

$$
X(t)=\alpha t^{1 / 2}
$$

where

$\alpha \quad$ is a constant that depends upon the thermal properties of the soil, its water content and the thermal boundary conditions

$X \quad$ is the distance from the thaw plane to the surface

$t \quad$ is time

The thawed soil is compressible and in the simplest development the Terzaghi theory of consolidation is assumed to hold. For a saturated soil a continuity condition can be written at the thaw front by noting that any flow from the thaw front is accommodated by a change in volume of the soil. Details of the solution to this moving boundary problem have been given by Morgenstern \& Nixon (1971) and need not be repeated here. Similar but not identical results were obtained by Zaretskii (1968).

This solution permits calculation of pore pressure distributions in thawing layers loaded by both externally applied stresses and self-weight. It cmerges from the analysis that the excess pore pressure distributions and the degree of consoli- dation in thawing soils are dependent upon the thaw-consolidation ratio $R$

$$
R=\alpha / 2 \sqrt{ } C_{v}
$$

where $C_{v}$ is the coefficient of consolidation. This ratio expresses the relative rate at which water is generated and dissipated at the thaw front. Drainage is enhanced at low values of $R$, while at very high values of $R$ the process is essentially undrained. It was also assumed in the simplest theoretical development that, if the soil were to thaw under undrained conditions, the initial effective stress would be zero. This assumption is appropriate for the more fine-grained soils.

The thaw-consolidation ratio $R$ served to clarify the accuracy with which soil thermal properties had to be known for geotechnical purposes. Experiments showed that even for natural soils (excluding organic soils) the published data for conductivity and specific heat were adequate to predict $\alpha$ within about $10 \%$ which is far superior to the accuracy with which $C_{\mathrm{v}}$ is generally known. The confidence with which $R$ can be evaluated is therefore dominated by traditional geotechnical concerns.

The pore pressure distribution anticipated in an oedometer is shown in Fig. 43. Morgenstern \& Smith (1973) described the development of a permafrost oedometer suitable for remoulded soils to assess the validity of the one-dimensional thawconsolidation theory. As shown in Fig. 44, the observed dependence of the maximum excess pore pressure upon $R$ is in good agreement with the theoretical relation.

The linear theory of thaw-consolidation can be extended to layered systems, other temperature 


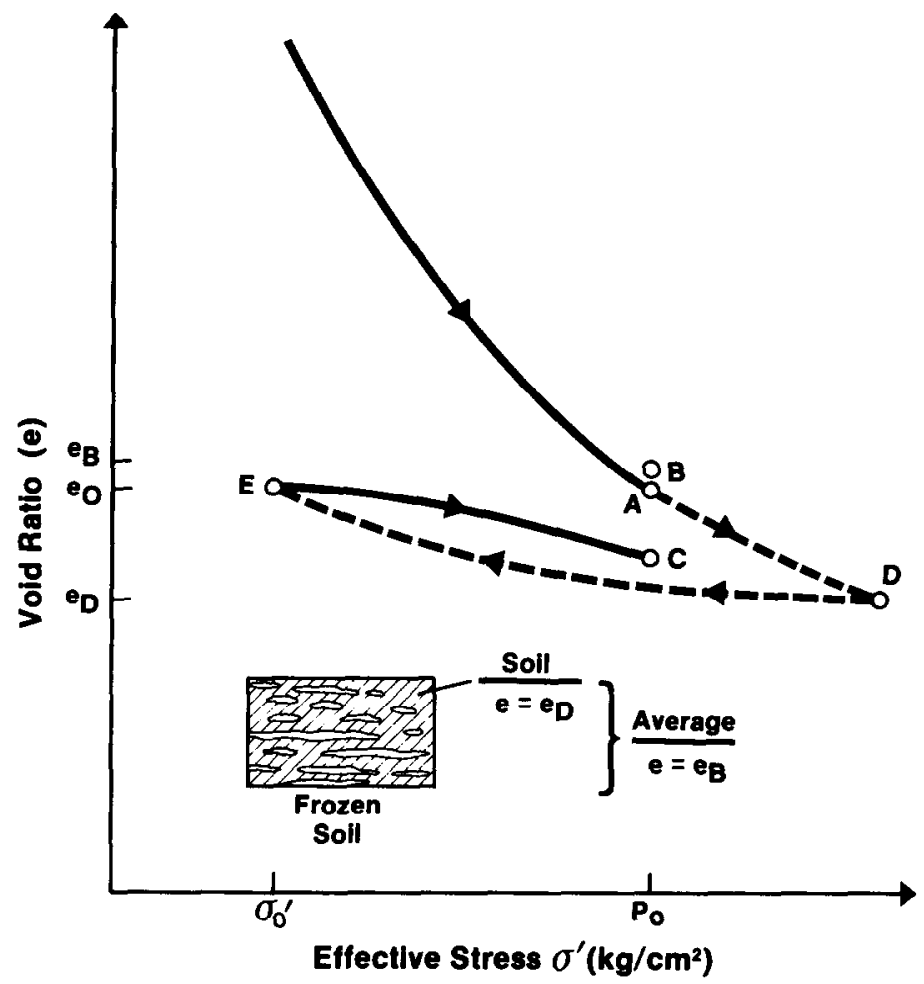

Fig. 45. Stress path in a close-system freeze-thaw cycle (schematic)

boundary conditions and non-linear material formulations. Nixon \& Ladanyi (1978) provide a convenient summary of these extensions.

The non-linear theories require a starting point on the relation between void ratio and effective stress. This led Nixon \& Morgenstern (1973) to the recognition of the significance of the residual stress which is the initial effective stress in soil thawed under undrained conditions. In addition to phase change effects, it is the departure from the residual stress that results in volume change. While it is reasonable to set the residual stress equal to zero in ice-rich soils with high void ratios, this will not necessarily be the case when the stress and thermal histories associated with the formation of a permafrost soil have caused the void ratio of the soil to be reduced prior to thawing.

The origin of the residual stress can be explained by referring to the experiment illustrated in Fig. 45. A sample of unfrozen soil was normally consolidated to an effective stress $P_{0}$ at $\mathrm{A}$. The sample was then frozen with zero drainage and the void ratio increases to $\mathrm{B}$ in order to accommodate the volume change associated with phase change as most of the water in the pores turns to ice. If the sample is now allowed to thaw with no drainage, the void ratio returns to $A$. However, this is accompanied by an increase in pore water pressure which, in the limit, may reduce the effective stress to zero. Now, if drainage is permitted under $P_{0}$, the specimen will consolidate to $C$.

Externally, thc freezc-thaw cycle under constant external stress has brought about a net decrease in volume represented by $\mathrm{AC}$. Internally the stress path has been different. Suction develops when finegrained soils freeze and this can result in an internal redistribution of moisture even under conditions of no overall drainage. At some locations the soil will become highly stressed as water is extracted from it while at other locations segregated ice will form.

Upon thawing, the overconsolidated elements in the soil may sustain effective stresses greater than $P_{0}$ but free water is made available locally from the thaw of segregated ice. The soil will swell by absorbing this water and the local stress path taken by freezing and thawing may then follow ADE. If the soil can absorb all of the free water it will come to equilibrium at the residual stress $\sigma_{0}{ }^{\prime}$. If not, excess free water will remain with the residual stress being zero. When drainage is permitted the soil will reconsolidate to $P_{0}$ along $\mathrm{EC}$ in a manner characteristic of an overconsolidated soil and exhibit thaw-strain.

Permafrost, when thawed, is influenced by the 


\section{$\sigma_{0}^{\prime}$ Residual Stress $\left(\mathrm{lb} / \mathrm{ln}^{2}\right)$}

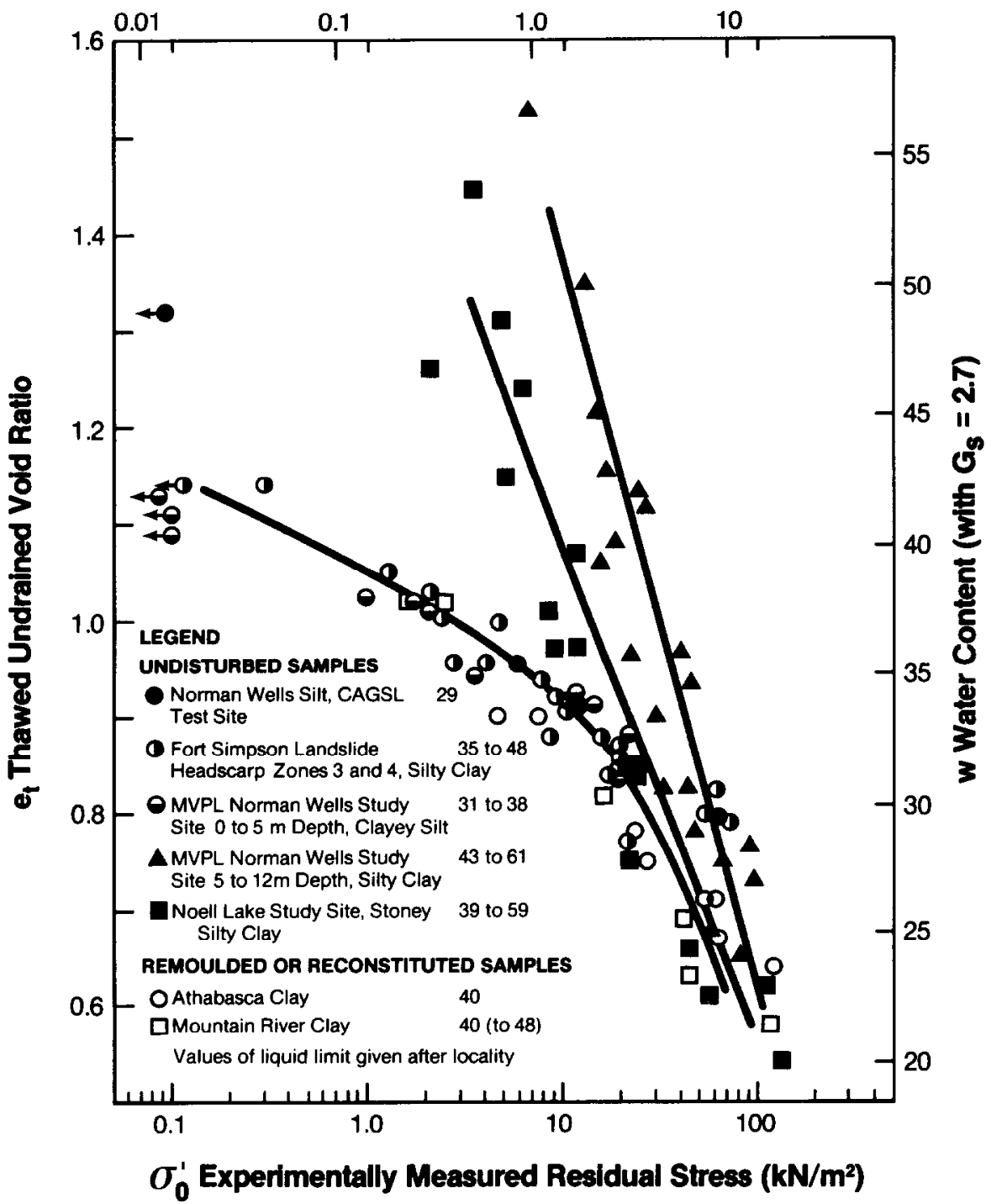

Fig. 46. Relation between residual stress and thawed, undrained void ratio

stress history and thermal history, as well as the hydrogeologic conditions that prevailed prior to the onset of freezing. In some instances $\sigma_{0}{ }^{\prime}$ will be greater than $P_{0}$ and frozen ground might even swell when thawed (Crory, 1973). The residual stress will affect pore pressures, settlements associated with thaw and the undrained strength of the soil mass. For example, if a permafrost were thawed under undrained conditions, the undrained shear strength $C_{\mathrm{u}}$ would be given by

$$
C_{\sigma_{0}^{\prime}}=\frac{\left[K_{0}+A\left(1-K_{0}\right)\right] \sin \phi^{\prime}}{1+(2 A-1) \sin \phi^{\prime}}
$$

where

$K_{0}$ denotes the ratio between lateral and vertical effective stress under conditions of zero lateral yield

$A$ denotes the pore pressure parameter

$\phi^{\prime} \quad$ denotes the effective angle of shearing resistance

The first measurements of residual stress were reported by Nixon \& Morgenstern (1973) who tested reconstituted specimens in an oedometer modified for freezing, thawing and pore pressure 


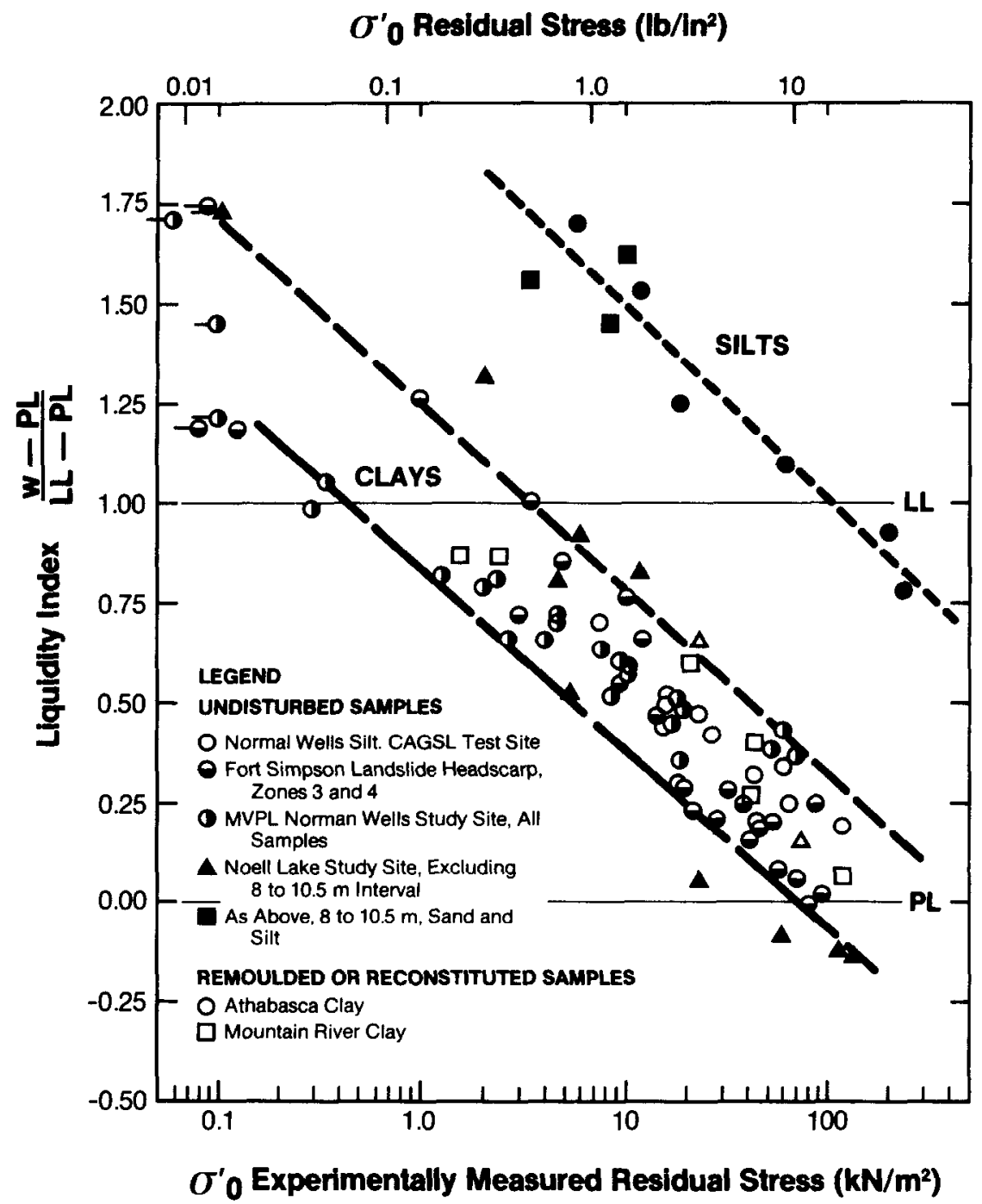

Fig. 47. Relation between liquidity index and residual stress

measurements. The tests revealed a linear relation between thawed undrained void ratio et and the logarithm of the effective stress, that is essentially independent of stress path, at least for a limited exploration. Nixon \& Morgenstern (1974) also measured residual stress in a number of undisturbed samples of silt and showed that the nonlinear theory of thaw consolidation accounting for $\sigma_{0}{ }^{\prime}$ correctly predicted measured pore pressures, that again the thawed undrained void ratio et varied linearly with the logarithm of the residual stress, and that there was a tendency for $\sigma_{0}{ }^{\prime}$ to increase with depth.

The study of the behaviour of undisturbed finegrained permafrost soils from a variety of locations has been pursued in more detail by Roggensack
(1977). As illustrated in Fig. 46, the existence of linear relation between et and $\log \sigma_{0}^{\prime}$ was confirmed. The slope of this relation appears to be related to soil plasticity. Higher plasticity is usually associated with an increased clay content which, in turn, creates greater compressibility and a potential for larger negative pore pressures during freezing. The combination of these two features produces a steeper curve for the $e t-\log \sigma_{0}{ }^{\prime}$ relation.

When experimentally determined residual stresses are replotted in terms of the liquidity index instead of void ratio, as shown in Fig. 47, the points for clay soils fall in a distinct band. This correlation is useful to extrapolate to the conditions when frozen ground is thawed at great depth such as arises in some oil well casing stability problems. 


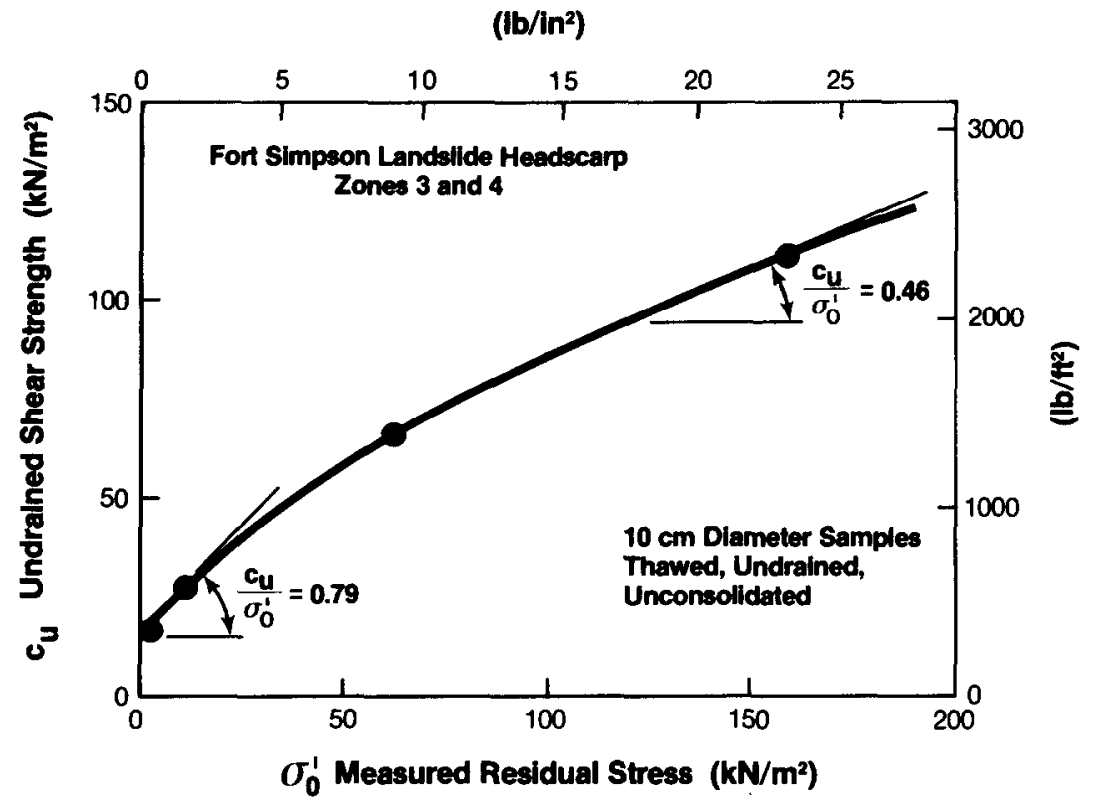

Fig. 48. Undrained strength as a function of residual stress; Fort Simpson site

The slope of the band is essentially identical to that for the sedimentation compression of clays reported by Skempton (1970). However, at any particular liquidity index residual stresses fall significantly below corresponding effective overburden pressures usually anticipated for normal consolidation. The difference between the two is related to the stress path followed to reach each condition. Freeze-thaw action brings about a large decrease in void ratio under conditions of constant applied stress. To obtain the same void ratio or liquidity index along the virgin compression line would require much larger effective stresses. This emphasizes once again the dominant effect that freezing history can have on stress history and the caution that should be exercised before attributing apparent overconsolidation to ice-loading, erosion or drying.

Roggensack (1977) also performed undrained compression tests to investigate the applicability of equation (17). In terms of effective stress, thawed clays display curved strength envelopes and $A$ values that increase with increasing $\sigma_{0}{ }^{\prime}$. Both features can be attributed to the cryogenic texture found in thawed fine-grained permafrost soils. Experimentally measured undrained strengths (Fig. 48) compare well with $C_{\mathrm{u}} / \sigma_{0}{ }^{\prime}$ values computed by substituting appropriate values for $\phi^{\prime}, A$ and $K$ as found in the laboratory into equation (17). In situ values will likely be less unless $K_{0}$ is equal to unity. Neither the in situ value for $A$ nor $K_{0}$ for soils subjected to freezing and thawing have been studied.

\section{Applications}

Recognition of the consolidation of fine-grained soils during thaw and of the presence of a residual stress even if thawed under undrained conditions provides two mechanisms to account for the strength of thawing ground. As a result, thawed soil will not generally behave like a viscous fluid and problems such as the stability of the thaw bulb around a buried warm-oil pipeline will therefore be less acute than might otherwise be anticipated. The opportunity for validation was provided by the study of an instrumented test section installed near Inuvik, NWT.

The test section consisted of a $27 \mathrm{~m}$ length of $610 \mathrm{~mm}$ buried pipe through which hot oil at $71^{\circ} \mathrm{C}$ was circulated. The field test was started on $22 \mathrm{July}$, 1971, and the ice-rich permafrost in which the pipeline segment was founded began to thaw. The soil around the pipe was instrumented to measure settlements, temperatures and pore water pressures. Undisturbed samples of the permafrost were collected in advance for laboratory testing. The field instrumentation has been described by Slusarchuk, Watson \& Speer (1973), the experimental data have been presented by Watson, Rowley \& Slusarchuk (1973) and a comparison between observed and predicted results has been given by Morgenstern \& Nixon (1975).

The test section was overlain by $1.4 \mathrm{~m}$ of gravel fill. The first $0.6 \mathrm{~m}$ of the soil profile was comprised of compressed organic soil, silty clay and pure ice. The base of the pipe was placed in this layer. Icerich clayey silt extended for about $2 \mathrm{~m}$ below the 


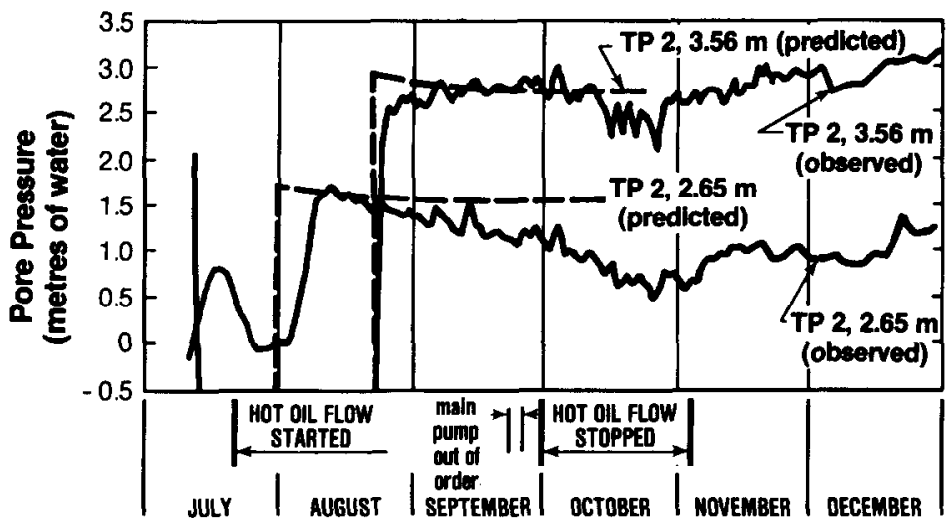

Fig. 49. Comparison between measured and predicted pore pressure; Inuvik test site

pipe and was underlain by a relatively incompressible gravelly till.

The piezometers installed in frozen ground at the site probably provided the first measurements of thaw-induced pore pressures. From a knowledge of the thaw-consolidation ratio $R$ predictions could be made and the comparison with some of the obscrvations is shown in Fig. 49. The values of excess pore pressure predicted at ten locations were about $25 \%$ of the ultimate value of the effective stress at each location. The observed values lay between 15 and $39 \%$ with an average of $24 \%$. This agreement has been extremely encouraging and supports the more routine use of thawconsolidation theory in practice.

Field studies reported by McRoberts (1973) and McRoberts \& Morgenstern (1974a) indicate a widespread propensity for slope instability when fine-grained permafrost is subjected to thaw. Moreover, the gentle inclination of many solifluction slopes has long been paradoxical to the geotechnical engineer.

Thaw-consolidation theory can be introduced into slope stability analysis to account for these features. For example, if infinite slope analysis is extended to consider thawing conditions the factor of safety $F$ of a slope inclined at $\alpha$ to the horizontal becomes

$$
F=\frac{\gamma^{\prime}}{\gamma}\left(1-\frac{1}{1+(1 / 2) R^{2}} \frac{\tan \phi^{\prime}}{\tan \alpha}\right)
$$

where

$\gamma \quad$ denotes the bulk density of the soil

$\gamma^{\prime} \quad$ denotes the submerged density of the soil

$\phi^{\prime} \quad$ denotes the effective angle of shearing resistance

$\boldsymbol{R}$ denotes the thaw-consolidation ratio

Support for the development of excess pore pressures during thawing of slopes in fine-grained soils has been provided by McRoberts, Fletcher \&
Nixon (1978). Two sites adjacent to the Mackenzie River Valley, NWT, that had been exposed to longterm degradation of permafrost, were studied; at both sites, situated on modest slopes, excess pore pressures were measured. It was further shown that the highest excess pore water pressures measured were consistent with predictions from thawconsolidation theory. While not conclusive, due to a variety of site complications, the general correspondence between prediction and measurement is again encouraging. As a result of integrating thawconsolidation with stability analysis it has been possible to evaluate rational stabilization measures for thawing slopes. Pufahl \& Morgenstern (1979) have shown how substantial increases in factor of safety could be obtained if surcharge loading were combined with only modest amounts of insulation to increase the effective stress across a potential slip surface. Skempton \& Weeks (1976) have also found these considerations of value in an analysis of instability of gently inclined fossil periglacial slopes.

Thawing of permafrost is also encountered adjacent to production casing of oil wells and well stability must be evaluated. Experience at Prudhoe Bay (Mitchell \& Goodman, 1978) indicated that thaw occurred under drained conditions in gravelly dense soils and no operational problems have been encountered. However, more recently oil has been discovered offshore in the Beaufort Sea and the possibility exists that wells will be developed through a considerable thickness (approximately $500 \mathrm{~m}$ ) of fine-grained, sub-sea permafrost soils. Under these conditions undrained thaw must be anticipated. Arching of the soil about the well will affect the stresses transferred to the casing tending to make it buckle. As anticipated by Palmer (1972), the existence of high residual stresses will exercise considerable influence on the arching mechanism and attendant stress transfer. However, even if the undrained strength of the thawed soil is very high, strain can still develop in a casing placed in thawing 


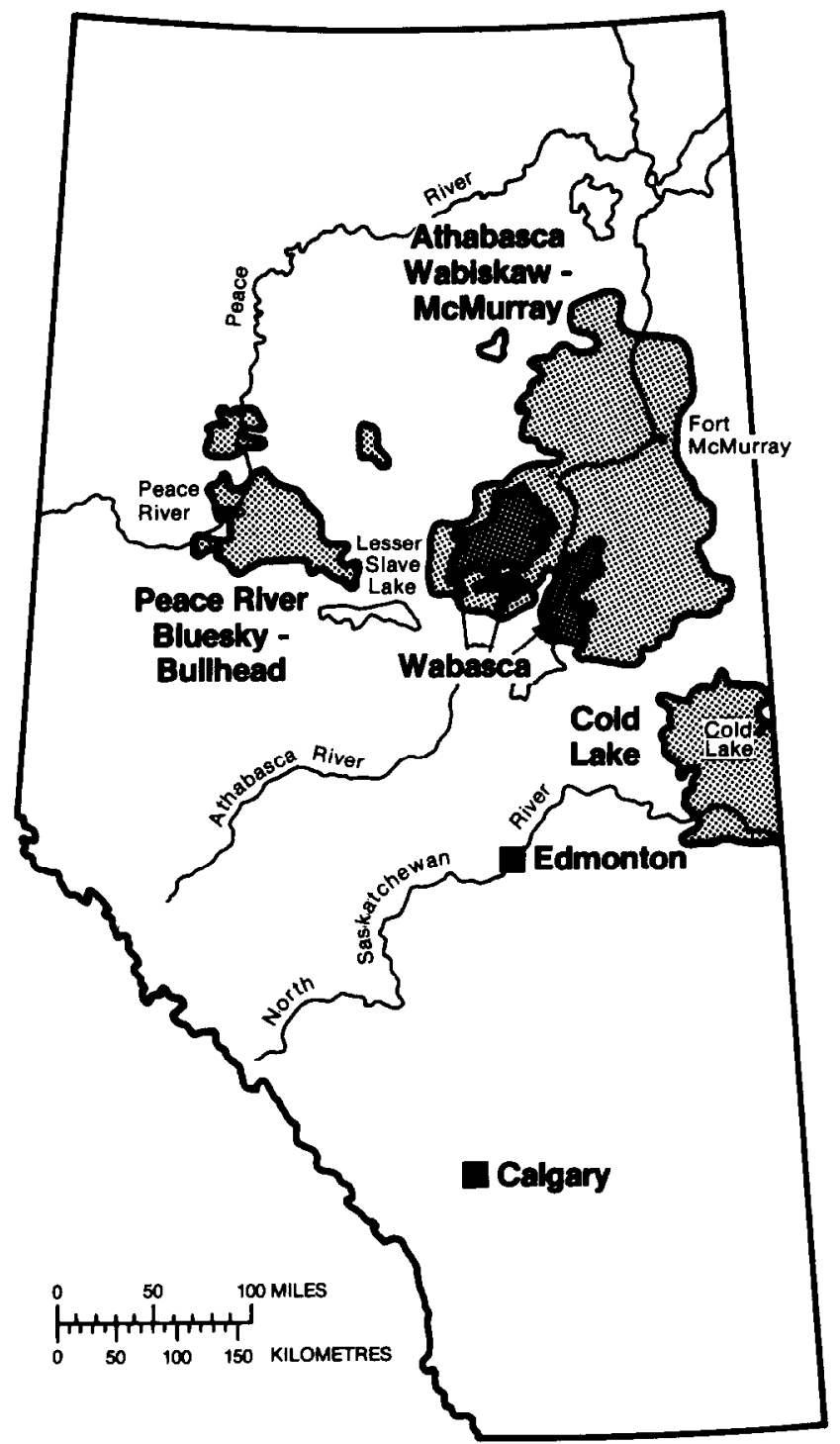

Fig. 50. Location in Alberta of the four major Cretaceous oil sands deposits

permafrost as a result of the volume changes and stiffness changes associated with undrained thaw. Studies of these soil-structure interaction problems are not yet well developed, and testing to obtain the appropriate deformation parameters is in its infancy.

\section{OIL SAND GEOTECHNICS Introduction}

Oil sands may be defined as sands which contain heavy hydrocarbons that are chemically similar to conventional oils but which have higher densities and viscosities. The hydrocarbons range from heavy crudes to natural bitumen. While oil sand deposits are widespread, by far the largest occur in Canada and Venezuela. The Canadian deposits are situated primarily in the Province of Alberta (see Fig. 50). The magnitude of these deposits can be appreciated when one realizes that they are comparable in size, as is the Venezuelan Orinoco Oil Belt, to the in-place volumes of conventional crude oil for the entire Middle East. Demaison (1977) has stated that Alberta's Athabasca deposit is the world's largest known accumulation of hydrocarbons, and is at least four times as large as the largest of all giant oil fields, Ghawar, in Saudi Arabia.

Although abundant, the bitumen has physical 
properties such that it cannot be pumped out like light crude and alternate extraction procedures have had to be developed. The bitumen occurs in beds of sand, and more recently has also been discovered in underlying porous carbonate rocks. The sand grains are usually covered with a film of water, and bitumen occupies most of the remaining pore space, along with minor amounts of fine clay particles, other mineral matter and occasionally some natural gas. Following a long period of research, it was eventually shown that crude bitumen could be separated from the oil sands with hot water. This method eventually became the basis of commercial production in 1967 by the integration of the hot-water extraction process with a mining operation.

\section{Steaming} Without Combustion

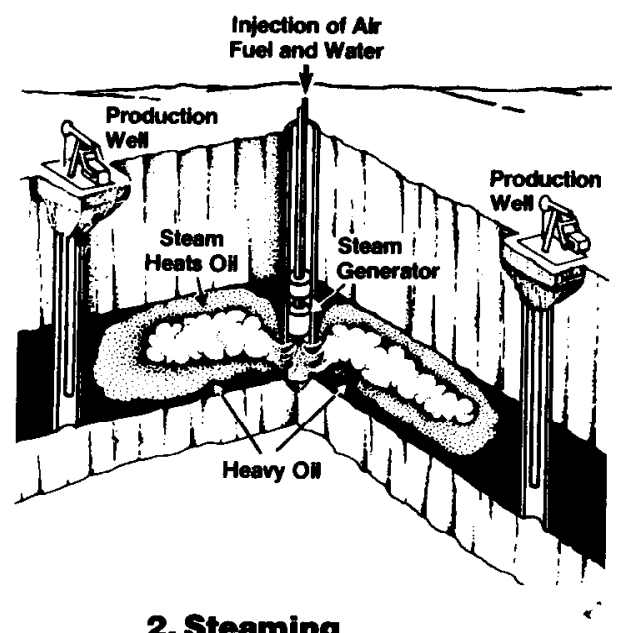

About 0.3 million hectares of the Athabasca deposit is overlain by $50 \mathrm{~m}$ or less of overburden and is potentially capable of being mined from the surface. The remaining 6.7 million hectares of the major Alberta deposits vary considerably in bitumen content and are buried at such depths that the crude bitumen can only be recovered by in situ extraction methods. Generally these methods involve heating the extremely viscous bitumen with steam so that it will flow and can be pumped to the surface. Experience exists for in situ extraction of bitumen where overburden thickness is greater than $150 \mathrm{~m}$ but the extraction techniques for those reserves lying between 50 and $150 \mathrm{~m}$ is uncertain at present. The rapid rise in the cost of conventional light crude since 1973 has made it economic to begin large-scale development of the Alberta oil sands and this has provided a very substantial incentive for resolving the technological problems associated with extraction.

Figure 51 illustrates in a general manner the various ways that have been either adopted or proposed to extract the bitumen. The geology is characteristic in a schematic manner of the Athabasca setting, where the oil sands outcrop in a river valley and dip gently to the west. At shallow depth, open-cast mining provides a means of extracting the oil sand after which it must be delivered to a plant for processing. Where the overburden is deep, steam injection is utilized in a cycle of injection and production to reduce viscosity and recover bitumen. Underground combustion is also under active investigation at the pilot stage. In situ steaming without combustion is more advanced and a commercial-scale operation is currently being designed. At intermediate depths, extraction by mining has been advocated on

\section{With Combustion}
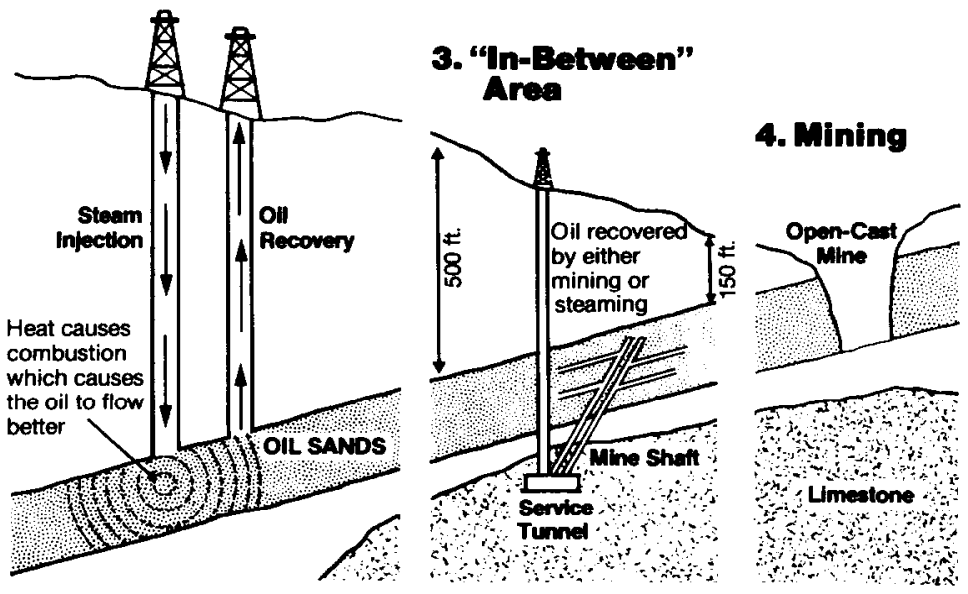

Fig. 51. Extraction of heavy oil 
occasion but economic evaluation is not supportive. However, an interesting hybrid technology is under active investigation. This is mine-assisted in situ processing (MAISP) where an underground mine system is to be developed by means of vertical shafts and tunnels in or adjacent to the oil sands in order to provide access for the installation of horizontal steam injection and recovery wells. This layout is intended to result in more cost-effective production through a higher density of wells per unit cost in the formation. The concept has already been adopted in the USSR to recover bitumen in north-eastern Siberia near Yarega.

In each of the circumstances listed above, extraction by surface mining, extraction by MAISP and extraction by steam injection, novel geotechnical problems arise because of the peculiar properties of the oil sands, the scale of the extractive undertakings, and the pressure-temperature environment of some of the in situ processes.

\section{Mining oil sand}

The mining of oil sand involves earth-moving on a grand scale. The first commercial operation owned by Suncor (Sun Oil Co. Ltd) moves about $25000 \mathrm{~m}^{3}$ of overburden and $60000 \mathrm{~m}^{3}$ of oil sand per day in order to produce $7200 \mathrm{~m}^{3}(45000$ barrels $)$ of oil per day. The leases are covered by organic soil (muskeg) which, following a period of gravity drainage, is removed by front-end loaders and a fleet of dump trucks. This takes place during the winter when the surface is frozen. Both the remaining overburden and the usable oil sand are then mined by means of bucket wheel excavators on a three bench-mining configuration. The overburden wheel has a $12 \mathrm{~m}$ dia. digging head and a theoretical peak digging rate of $13000 \mathrm{t} / \mathrm{h}$. Under normal operations it has achieved a consistent average of $6800 \mathrm{t} / \mathrm{h}$. The bench-mining machines, which have a $10 \mathrm{mdia}$. head, have produced peak quantitics of $9000 \mathrm{t} / \mathrm{h}$ for short periods, but each has an average output closer to $4500 \mathrm{t} / \mathrm{h}$ (Supple, 1980). Bench height has only been about $20 \mathrm{~m}$ and slope instability has not proven to be a particular hazard to the bucket-wheel mining scheme. Trafficability and abrasion of digging teeth have proved troublesome but these difficulties have been reduced with experience.

The outstanding geotechnical challenge of this project has been associated with tailings disposal. As a result of the hot-water separation process about $250000 \mathrm{t}$ of tailings are handled daily including $100000 \mathrm{t}$ of solids. All of this material must be stored permanently in a closed system. Until space was available in mined-out areas, a retention dyke was necessary. For economic reasons it was desirable to construct the dyke from the tailings. However, sufficient fines remain in the tailings to preclude their direct use as a construction material without separation and when sluiced into the pond the fines separate and consolidate very slowly. Mittal \& Hardy (1977) have described the innovative techniques of materials handling, dyke design and construction that have culminated in the building of a dyke from these tailings. The dyke is some $3.4 \mathrm{~km}$ long and has been built by the upstream method of hydraulic construction to a height of over $90 \mathrm{~m}$, being founded in part directly on muskeg and thick normally consolidated alluvial sediments.

The next commercial operation was the Syncrude project which began construction in 1973 with the intent of producing $20700 \mathrm{~m}^{3}(130000$ barrels) per day which entails moving about $250000 \mathrm{~m}^{3}$ of overburden and oil sand every day. After a period of intensive study, this project adopted draglines for primary mining. As reviewed by Adam \& Regensburg (1980), dragline mining appeared to have advantages over bucket-wheel excavation by minimizing the transportation distances for waste disposal even though ore grade oil sands had to be handled twice. Other contributions to the cost advantage were the relatively rapid opening of the mine and the potential for selective mining. Ultimately draglines of $60 \mathrm{~m}^{3}$ bucket capacity and $110 \mathrm{~m}$ boom length were selected, each costing about $\$ 30$ million. Since they were obliged to sit on a steep highwall some $50-60 \mathrm{~m}$ high, confidence in slope stability was central to the approval of the dragline mining scheme.

At the Syncrude site overburden is composed of Holocene, Pleistocene and Cretaceous sediments. The oil-bearing McMurray formation is comprised of both sand-dominated and clay-dominated facies resulting in non-uniform oil saturation. It lies unconformably over Devonian carbonates and is the result of a more or less continuous transgressive sequence. Stable slopes observed in natural outcrops provided a high level of confidence that draglines could be supported safely on oil sand slopes provided weak overburden had been removed. For example, Dusseault \& Morgenstem (1978a) undertook a survey of natural slopes along river valleys where the McMurray formation outcrops and encountered no massive rotational or planar failures. They found that bitumen-rich oil sands may form very steep slopes $\left(50^{\circ}-55^{\circ}\right)$ up to $70 \mathrm{~m}$ in height. Over limited sections, inclinations as steep as $75^{\circ}$ were found. Bitumen-free portions of the McMurray formation were also steep with high slopes indicating substantial natural strengths. These observations were supported by the excavation of a $55 \mathrm{~m}$ deep test pit having a highwall slope of $60^{\circ}$. This trial was extensively instrumented and led to agreement in principle by a Board of Consultants to the application of 


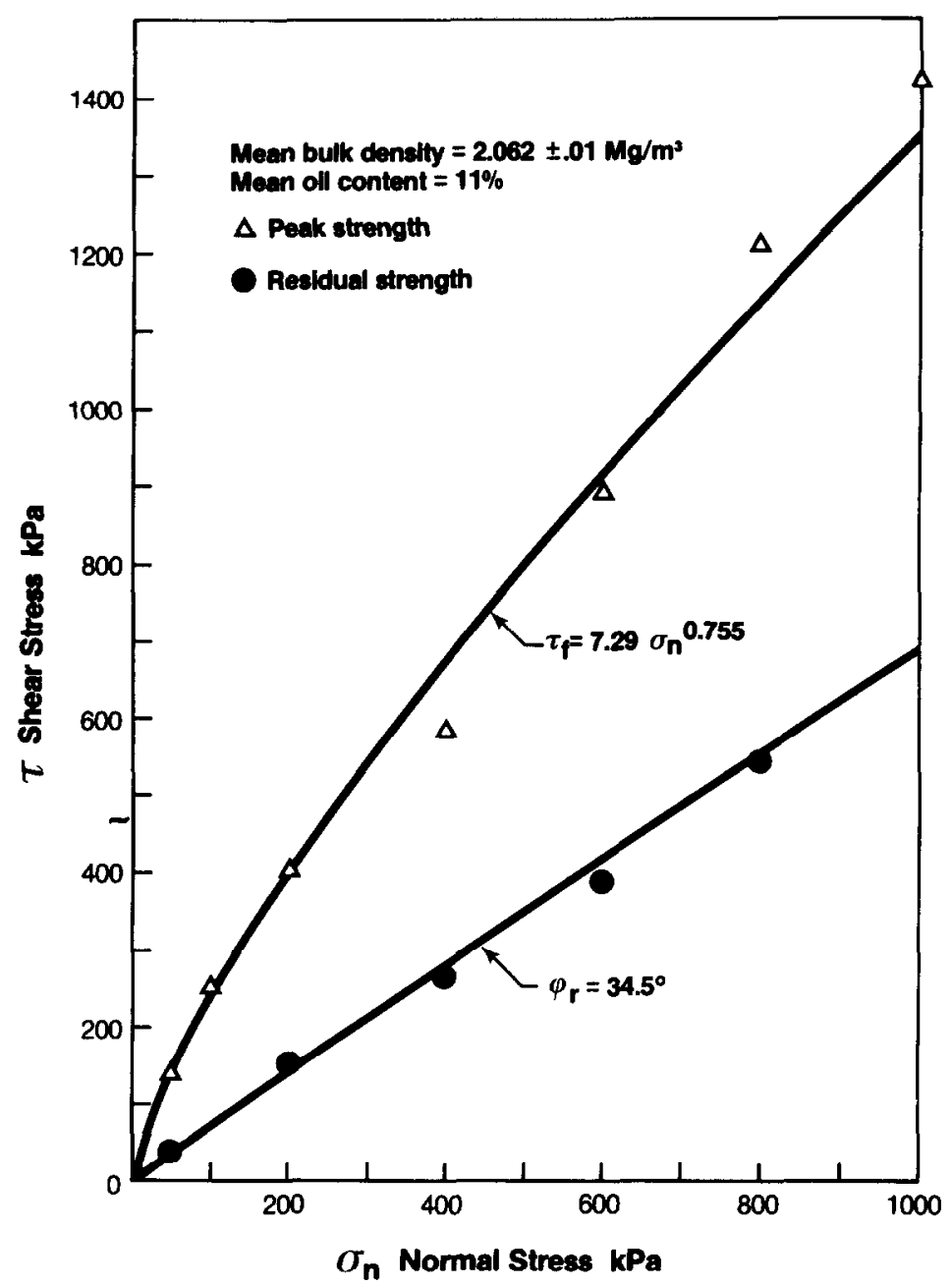

Fig. 52. Failure envelope for oil sands, shear box tests

draglines, subject to certain operating restrictions. It was clear that in practice instability might be controlled by such minor geological details as intraformational lenses of silt and clay, basal clays beneath the oil sands, joints and other defects. Notwithstanding the apparent strength of the oil sand in mass, the stability of the slopes from a conventional geotechnical perspective remained paradoxical.

The evaluation of the shear strength of oil sands is made difficult by the presence of dissolved gas that comes out of solution causing serious sample disturbance due to expansion. The first strength tests performed by Hardy \& Hemstock (1963) gave low values which were correctly attributed to this effect. Brooker (1975) provided the first detailed assessment of the shear strength of the McMurray oil sands, and found dilatant behaviour with an angle of shearing resistance slightly below $45^{\circ}$ and a cohesion intercept of about $80 \mathrm{kPa}$. However, these data were limited in quantity, not yet consistent with field observations, and were based on specimens with void ratios that exceeded typical in situ values.

Fresh oil sand can be remoulded readily in the hand suggesting a lack of cohesion or abnormally high negative pore pressures. Mineral or clay cementation is absent from the greater proportion of most profiles although cemented stringers are encountered. The interstitial bitumen is thought to behave as a fluid and therefore does not contribute directly to the stability of slopes. In addition, the specific surface of oil sand is low, so it is unlikely that interfacial tensions in the quartz-oilwater-gas system contribute to strength in any significant manner. 


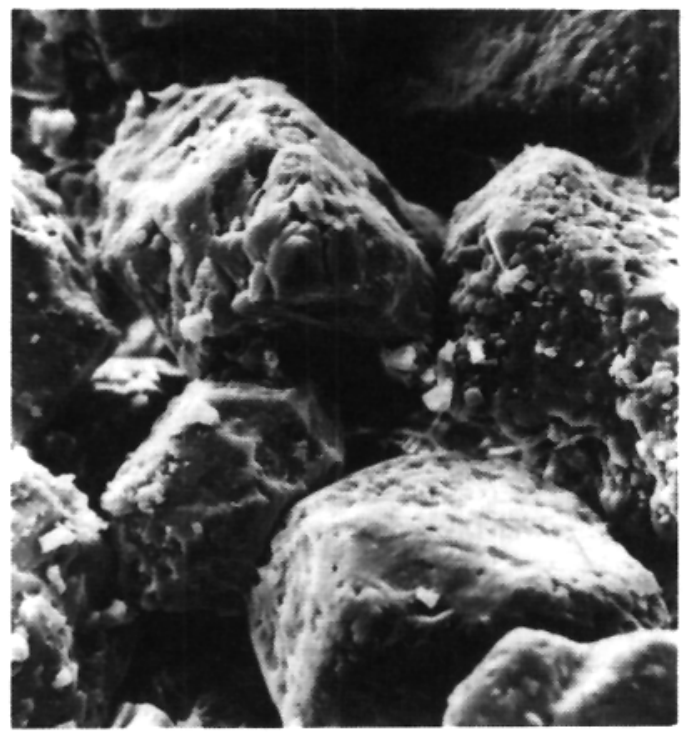

Fig. 53. Locked sand fabric

Dusseault \& Morgenstern (1978b) obtained high quality samples of oil-rich sand by using downhole freezing techniques to inhibit gas expansion. When tested in both triaxial and shear box equipment, these samples produced remarkably high angles of shearing resistance accompanied by high rates of dilatation, particularly at low normal stress. As shown in Fig. 52, the envelope passes through the origin for all practical purposes but is markedly curved as normal stress is increased. The residual strength and the strength of remoulded oil sand is characteristic of values reported elsewhere for quartzose sands and is unexceptional. This suggests that the origin of the remarkable strength of natural oil sands should reside in their structure.

Microscope studies revealed an unusual integranular fabric. Mineral cement is absent, grain-to-grain contact area is large, many contacts are characterized by an interpenetrative structure with grain surfaces displaying a rugose solution-recrystallization texture. An example is given in Fig. 53. The lack of mineral cement is consistent with zero cohesion at zero normal stress. The interpenetrative fabric results in high rates of dilatation at low stresses. As normal stress levels increase, dilatancy is suppressed in favour of grain shear giving rise to the curved Mohr envelope. The rugose surface texture results in a residual friction angle that is somewhat higher than the value observed from testing smooth Ottawa sand.

These observations explained the stability of slopes in oil sands but they are also of more general interest. As a result of this texture, Dusseault \& Morgenstern (1979) suggested that these materials constitute a distinct class of materials separate from loose and dense sands, and that they be called locked sands. Locked sands develop when sands loaded for long periods of time are subjected to diagenetic processes. If the dominant processes are solution and quartz overgrowth formation, the result may be a densified, uncemented aggregate with an interlocked structure. Experience so far indicates that locked sands possess an in situ porosity that is less than the minimum attainable in the laboratory and that they are generally preQuaternary in age. Locked sands are not peculiar to Alberta and are probably widespread. The St Peter sandstone in the Minneapolis region has been shown to be a locked sand and it is likely that many of the soft or friable sandstones referred to in the literature are locked sands. Provided care is taken not to disrupt the fabric, locked sands are strong and capable of supporting substantial loads with only small deformations.

\section{Undergound access to oil sands}

Underground access to oil sand deposits is an integral part of any MAISP scheme. Devenny \& Raisbeck (1980) have illustrated the types of facilities required and indicate that access from underground drilling chambers is being considered because of the following

(a) more of the drilled hole contacts the reservoir

(b) it is probable that horizontal or near horizontal wells can be placed more efficiently with better control of location

(c) with improved location, it will be possible to place wells closer together

(d) with closer well spacing, control of fracture flow paths may become possible, facilitating more rapid and uniform heating and, hence, more efficient extraction

(e) increased resource recovery at lower cost should be possible

The MAISP concept is contingent upon the feasibility of sinking shafts through the oil sands and, in some instances, tunnelling in them at depths of $250-500 \mathrm{~m}$ from the ground surface. They are strong but uncemented sands. However, during unloading, gas comes out of solution. This disrupts the interlocked fabric which leads to both swelling and weakening. Therefore in addition to the more routine considerations of deep shaft and tunnel design, it is necessary to have a clear understanding of the geotechnical behaviour of gas-saturated porous media in order to proceed with design and construction.

Early laboratory tests on oil sand reported by Hardy \& Hemstock (1963) found that contrary to conventional geotechnical experience, the strength in borings decreased with depth. They correctly attributed this to the exsolution of gas upon release 


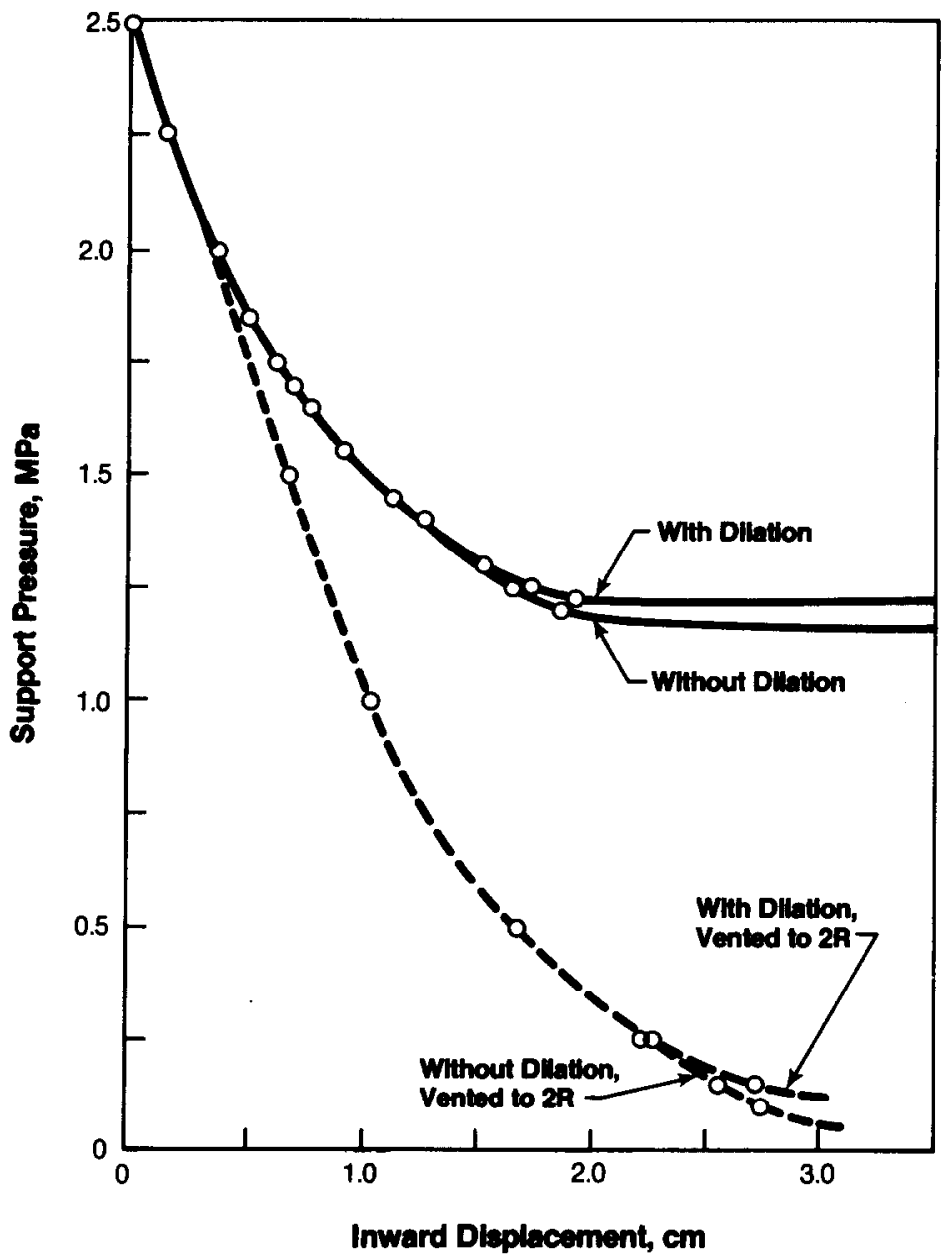

Fig. 54. Convergence of cylindrical shaft in oil sand; radius, $R=2.5 \mathrm{~m}$ (Byrne et al., 1980)

of stress, primarily from the oil phase. In addition, they observed that the gas pressure in the pores will increase with increasing temperature and the oil phase will impede the dissipation of the gas pressure because of its high viscosity. Hence gassaturated oil sand acts in the short term as a relatively impervious material with respect to excess pore gas pressure because of the immobility of the pore fluids.

The geotechnical implications of undrained gas expansion during unloading are multiple. Undrained gas expansion leads to substantial volume increase. This disrupts the interlocked fabric of the oil sand and thereby reduces its shear strength. Until gas drainage occurs by venting, pore pressures during unloading are higher than in a comparable material that is gas-free, and the available shearing resistance is reduced accordingly. For surface works, gas exsolution can result in heave of excavations which will contribute to increased settlement upon reloading. It can also induce weakening of material within slopes and thereby result in shallow instability. Exfoliation of freshly cut slopes is common and is a major factor affecting efficient dragline operations. For underground works, the expansion of the oil sand around a cavity must be considered in both the design of temporary and permanent support systems. The stand-up time of excavation faces will be affected and the production of exsolved gas must be considered when designing ventilation systems. The exsolution of gas constitutes a major impediment to geotechnical design because it makes undisturbed sampling of at least the oil-rich sands virtually impossible. Dusseault (1980) has recently summarized data that show that oil-rich sands have the greatest potential for expansion and that a reduction in bulk density of about $10 \%$ compared with the in situ value determined by geophysical means is not uncommon. 


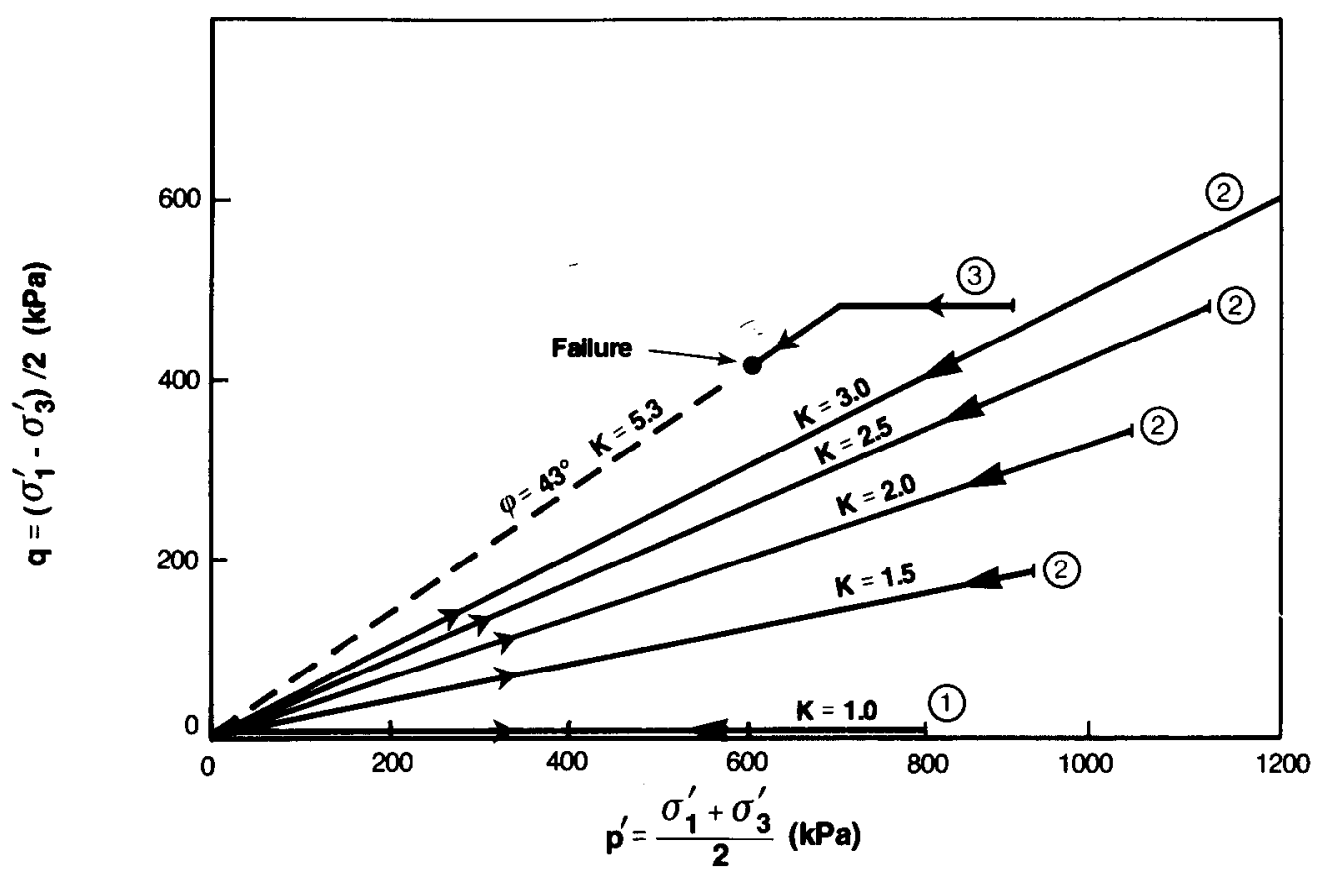

Fig. 55. Stress paths for undrained tests on dense sand with $\mathrm{H}_{2} \mathrm{O} / \mathrm{CO}_{2}$ pore fluid $\left(\mathrm{Sw}_{\mathrm{i}}=100 \%\right)$

Only two underground excavations in the Alberta oil sands have been described so far and both were completed at relatively shallow depths. The first was a test shaft sunk in 1963 which was abandoned at a depth of $23.5 \mathrm{~m}$ because of poor mining methods which did not provide adequate control of seepage. Nevertheless gas was encountered bubbling through the water at the base of the excavation; and below a depth of about $18 \mathrm{~m}$ the walls of the shaft deteriorated by progressive slabbing to a depth of $0.3 \mathrm{~m}$ or more in less than a few hours (Hardy \& Scott, 1978).

The second case was the construction of a short creek diversion tunnel associated with some landslide stabilization works (Chatterji et al., 1979; Harris, Poppen \& Morgenstern, 1979). In this instance a $4.4 \mathrm{~m}$ dia., $107 \mathrm{~m}$ long lined tunnel was constructed through oil-rich sands. While provision was made in the design for considerable swelling of the tunnel face, generally less than $2 \mathrm{~cm}$ swell was encountered. It was possible to excavate the tunnel with a point-attack machine and the stand-up time must be rated in days to weeks. Clearly gas exsolution was not a problem and this is attributed to the proximity of the tunnel location to the valley wall. It appears that during the unloading, natural valley formation was sufficiently slow to permit the gas to drain, probably by diffusion, so that little gas existed during the excavation of the tunnel. It is unlikely that these favourable conditions will be encountered at greater depths.

The development of an analytical framework for dealing with the stresses and deformations of gassaturated oil sand was initiated by Harris \& Sobkowicz. (1977) who formulated the change of pore pressure and volume due to stress and temperature changes when oil sand is unloaded and gas comes out of solution from both the oil and water phases. These considerations have been incorporated in a series of finite element programs in which the skeletal behaviour of the oil sand is modelled with increasing complexity. A recent example, which treats the soil skeleton in a nonlinear manner, includes shear dilation and satisfies strain compatibility between the skeleton and the pore fluid phase (Byrne et al., 1980).

Figure 54 illustrates the application of this analytical capability. A cylindrical shaft in oil sand with radius equal to $2.5 \mathrm{~m}$ is treated as a plane problem. The initial stress was $2.5 \mathrm{MPa}$ and the convergence of the shaft wall as the support pressure is relieved is shown. Soil data are specified in Byrne et al. (1980). The solid line represents the inward displacement predicted when excavation occurs under undrained conditions and gas venting is prevented. Large inward movements occur when the support pressure drops below about $1 \cdot 2 \mathrm{MPa}$. The dashed line indicates the displacements when depressurization due to drainage has occurred to a radius of $5 \mathrm{~m}$ and the pore pressure is zero in this zone. The support may be reduced to about $0 \cdot 2 \mathrm{MPa}$ 


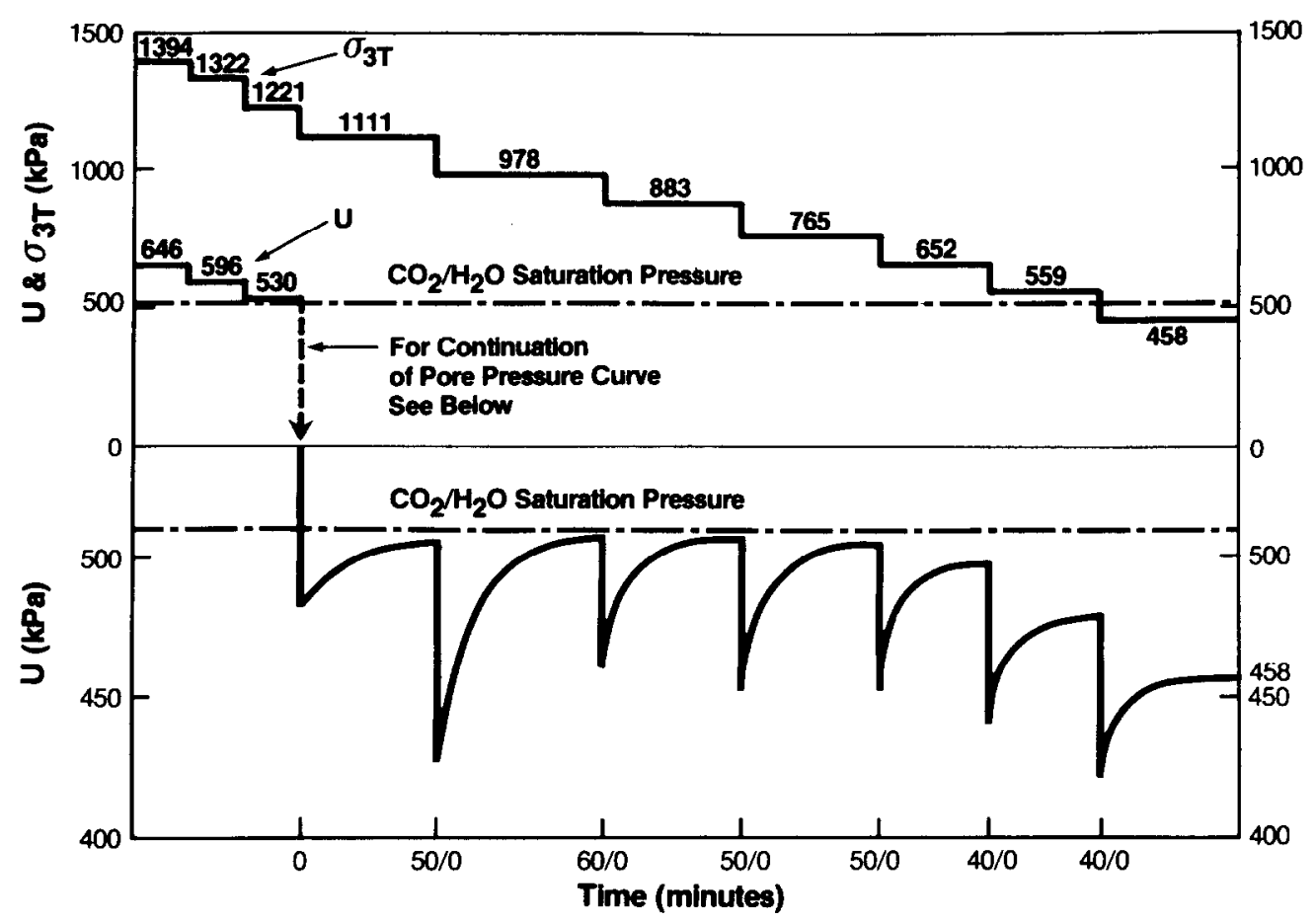

Fig. 56. Isotropic undrained unloading test on dense sand with $\mathrm{H}_{2} \mathrm{O} / \mathrm{CO}_{2}$ pore fluid $\left(S w_{\mathrm{i}}=100 \%\right.$ )

before large inward movements occur.

Little is known experimentally about the influence of alternate stress paths on the behaviour of gas-saturated porous media and the requirements for gas drainage which are of such practical significance. In order to study these effects a test facility has been assembled in which a pore fluid containing dissolved carbon dioxide can be flooded into sand and the sample then subjected to various tests.

Figure 55 illustrates some of the undrained stress paths imposed on samples of very dense Ottawa sand $\left(n=31 \%, \quad M_{v}=2\right.$ to $\left.5 \times 10^{-3} \mathrm{MPa}^{-1}\right)$ containing a water-carbon dioxide mixture as the pore fluid. Initial liquid saturations are $100 \%$, so that the $\mathrm{CO}_{2}$ gas is totally dissolved in the water. The pressure at which gas will just begin to exsolve in the pore fluid is referred to as the liquid-gas saturation pressure. In the tests, time-dependent changes in pore fluid pressure and strain are monitored as total stress changes. Major findings so far are as follows.

(a) For those conditions where the pore fluid pressure remains above the liquid-gas saturation pressure, the soil remains totally liquidsaturated and behaves in a typical undrained fashion. For very dense soils $B$ is slightly less than 1, but for more compressible soils $B=1$. Behaviour is essentially time-independent. (b) As soon as the pore fluid pressure decreases below the liquid-gas saturation pressure, gas starts to exsolve and bubbles form in the pore space. This exsolution process is timedependent and continues until an equilibrium is reached between the liquid and gas pressures and the gas concentrations in the bubble and in the liquid.

(c) The exsolution of gas causes time-dependent pore pressure changes and hence timedependent changes in effective stresses and strain. However, the stress-strain relations for dense cohesionless soils do not appear to be affected significantly by the presence of small amounts of gas, to gas saturations of about $20 \%$.

(d) For tests on dense cohesionless materials containing large amounts of dissolved gas, the exsolution process proceeded in such a way as to maintain, in the long term, pore fluid pressures nearly equal to the initial liquid-gas saturation pressure. This is illustrated in Fig. 56 which shows the results of an isotropic unloading test.

(e) For stress paths with the minor principal stress decreasing to failure, the stress-strain curves for undrained failure with gas in the pore fluid are almost identical with those of a drained sample with no gas in the pore fluid. However, the rate 


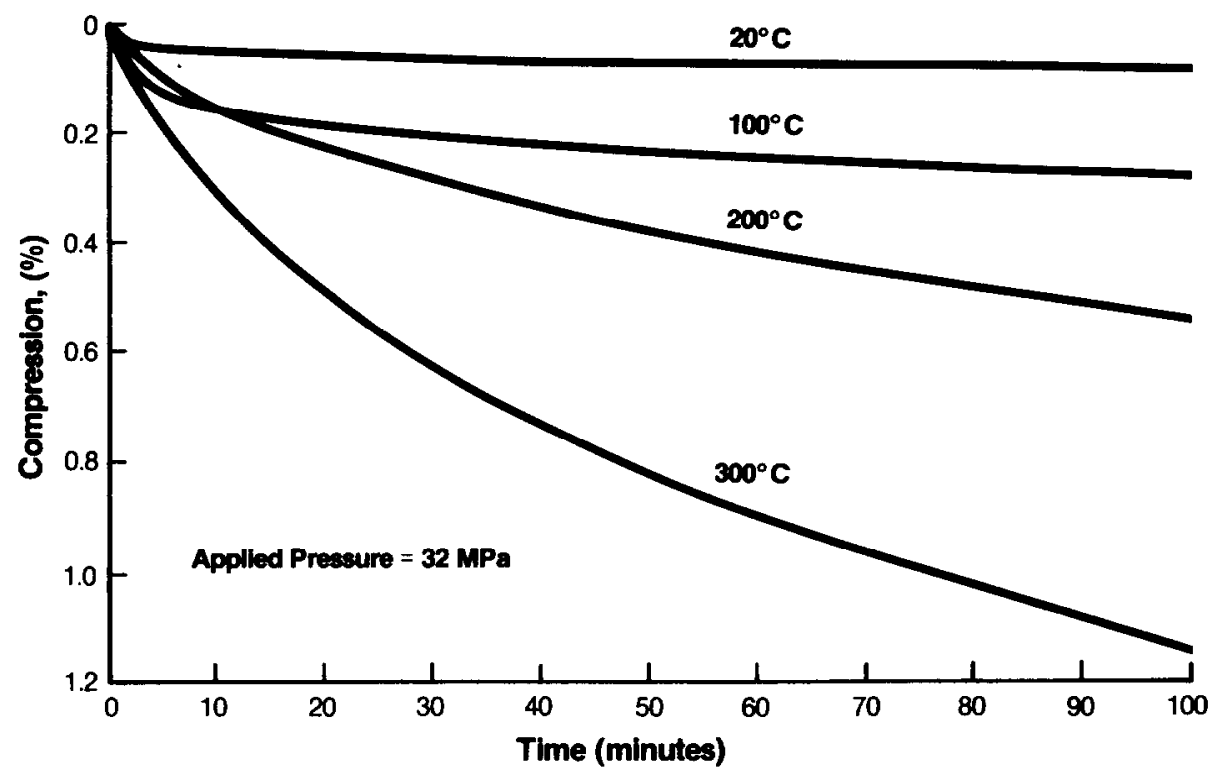

Fig. 57. Compression of Quartz sand under elevated temperature

of failure is governed by the rate of decrease of the minor principal effective stress which is related directly to the rate of gas exsolution.

Interest in the geotechnical behaviour of gassaturated porous media is not restricted to oil sands. In fact, gas-saturated soils are probably more common than is generally recognized. Okumura (1977) has analysed the implications on strength of dissolved air in deep-sea samples and shown that the expansion of the pore fluid upon isothermal stress release greatly influences the effective stress of the sample in the laboratory. As a result, undrained strength measured in the laboratory can be much less than the in situ strength unless compensation is made for the gas expansion effects. Methane-saturated sediments are particularly common in areas of high rates of recent sedimentation.

An interesting example of a gas-saturated soil was encountered in the vicinity of Montalto di Castro, Italy where a nuclear power plant was under construction. ${ }^{5}$ The stratigraphy consists of a $35-40 \mathrm{~m}$ layer of sand and gravel overlying about $30 \mathrm{~m}$ of sandy clay. The clay in turn overlies a layer of silty sand. The deposits are all Pleistocene. Both the clay and underlying sand are virtually saturated with carbon dioxide. Since carbon dioxide is extremely soluble in water considerable volumes of gas can be seen to exsolve upon sampling. The potential existed for undrained gas exsolution in

${ }^{5}$ The geotechnical implications of this clay were investigated by the Author in conjunction with D'Appolonia Consulting Engineers, Inc., Brussels. the clay due to excavation and ground water lowering in the overlying sand layer. Ihis gas exsolution can have an important bearing on the prediction of heave of unloaded areas and subsequent settlement upon reloading.

\section{In situ extraction from oil sands}

Geotechnical considerations enter only in a limited way in conventional hydrocarbon reservoir engineering. Subsidence effects in compressible reservoirs are calculated in terms of changes in effective stress. In situ stresses and rock strength enter into the mechanics of hydraulic fracture propagation. However, most conventional processes concerned with fluid injection and withdrawal in hydrocarbon reservoirs are not intimately dependent on the deformation and strength properties of the reservoir soil or rock. While still speculative, geotechnical considerations may play a more significant role in the in situ extraction processes associated with oil sands because of the weakness and deformability of these materials.

The most common process for in situ recovery involves massive injection of steam in order to reduce the viscosity of the bitumen. The efficiency of subsequent withdrawal is much influenced by the permeability and compressibility induced by the massive injection. In addition, it is important to ensure that the injected steam stays within the stratum intended for stimulation. An understanding of the mechanics of the injection process requires knowledge of how hot pressurized fractures extend in a deformable cohensionless 


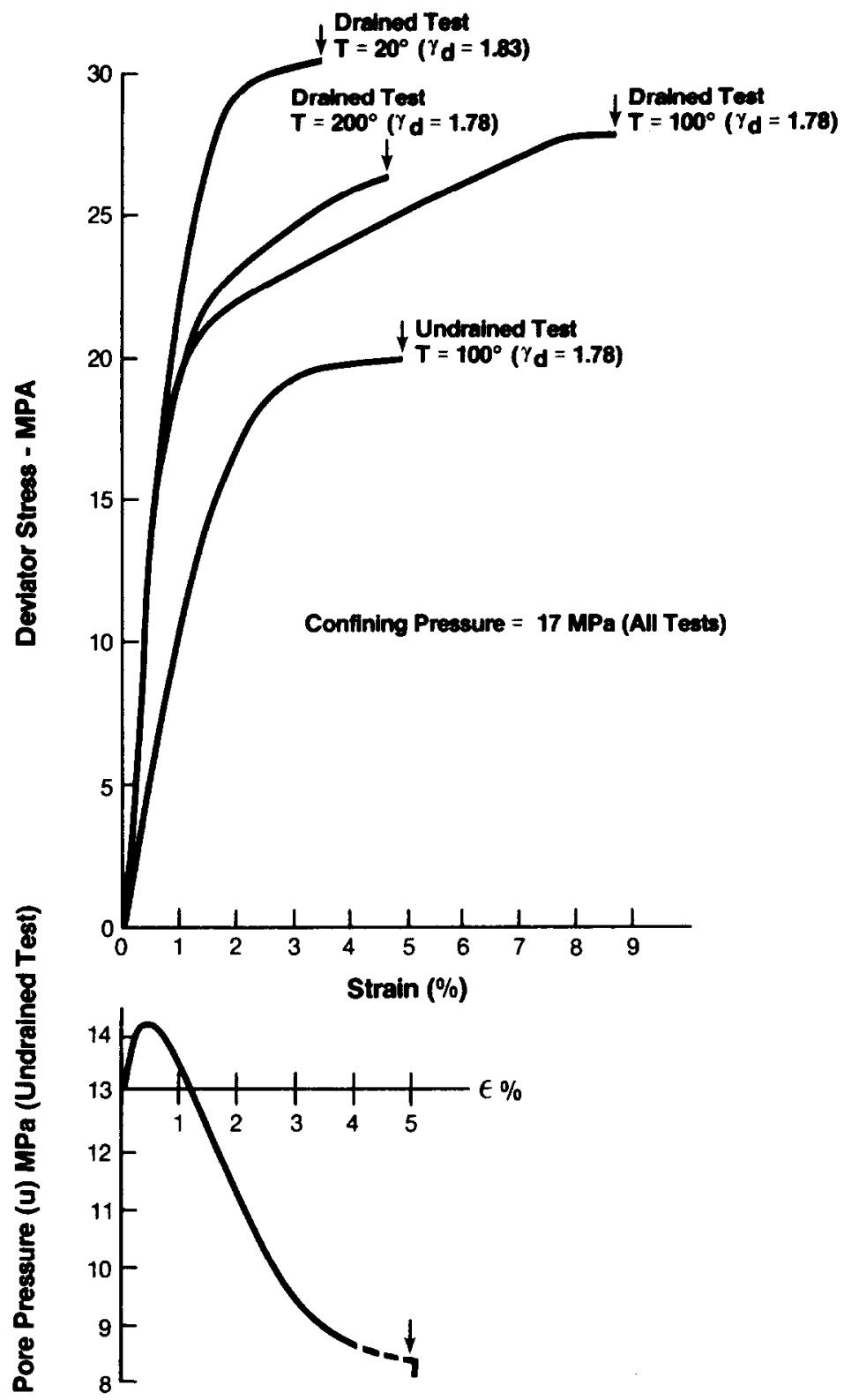

Fig. 58. Temper ature effects on strength of dense sand

medium. Undoubtedly fractures can extend by both parting and by shear. Massive injection can also have surface effects and potential heave could be a factor in movement of surface facilities.

The elastic analysis of pressurized fractures (e.g. Hungr \& Morgenstern, 1980) may provide an adequate basis for the prediction of far field effects. However, these theories or alternate theories derived from linear fracture mechanics constitute an excessive simplification of the actual process of fracture extension. Studies of the mechanics of fracture extension in cohesionless media are needed and these studies will ultimately have to embrace both fluid and heat transfer processes in order to make a realistic contribution to process simulation.

Heating of oil sands due to injection or in situ combustion raises novel geotechnical considerations. The first has to do with the effect of heat on geotechnical properties. The strength and compressibility of oil sands at elevated temperatures 
has a bearing on a variety of both short-term and long-term considerations related to underground access and the mechanics of the in situ recovery processes. In order to investigate these properties a test facility has been assembled capable of performing compressibility, triaxial shear and permeability tests at confining stresses to $27 \mathrm{MPa}$ and temperatures to $320^{\circ} \mathrm{C}$. Steam generation facilities allow injection to be simulated and experiments to be undertaken with liquid or vapour back pressures. Only limited test data have been produced so far.

Even conducting experiments on Ottawa sand has revealed major changes in geotechnical properties at elevated temperatures. Figure 57 illustrates the influence that pressure and temperature have on one-dimensional compressibility. The compressibility at room temperature is similar to other data in the literature. A small amount of comminution occurs at high pressures. Repeating the test at $100^{\circ} \mathrm{C}$ intervals reveals a dramatic change in compressibility and a marked increase in its time dependence. This is due to weakening of the particles as evidenced by reduction in grain size measured after the test. Preliminary shear strength tests on Ottawa sand also show temperature effects, but the effects are not marked for dry sand.

An equally important aspect of heating oil sands is the change in pore pressures that can arise. If heating is rapid, the expansion of the pore fluid may occur under conditions of impeded drainage, and in the limit conditions might even be totally undrained. As a result pore pressures can increase during heating with the consequences of swelling and a reduction in shearing resistance. This class of problems has already been identified by Campanella \& Mitchell (1968), and Mitchell (1976) provides an excellent summary of the interaction between undrained heating and induced pore pressure changes.

Just as the effect of an isothermal total stress change generates a pore pressure reaction expressed in terms of $B$ which is reducible to the amounts and compressibilities of the phases composing the soil, so an undrained temperature change induces a pore pressure change that can be expressed by $B_{r}$. This coefficient is reducible in a similar manner to the stress and temperaturedependent volume changes of the components of the soil. Typical values may be deduced from Mitchell (1976). While the effects on pore pressure changes of removing samples from the ground at $5-10^{\circ} \mathrm{C}$ and placing them in the laboratory at $20^{\circ} \mathrm{C}$ are small, this is probably not the case when the ground is subjected rapidly to temperature changes of $250^{\circ} \mathrm{C}$ by the injection of pressurized steam. Figure 58 presents the Author's first measurements of the pore pressure changes in dense Ottawa sand heated to $100^{\circ} \mathrm{C}$ and then sheared under undrained conditions. It is evident that the pore pressure reaction to heating is substantial $\left(B_{t} \sim 0.77\right)$ and its effect on available shear strength is significant.

In order to assess whether significant pore pressures develop it is necessary to evaluate whether heating occurs in an undrained manner. This introduces the class of problems of heatconsolidation. If heating occurs slowly, there will be time for drainage and the ground can expand due to thermally induced strain alone. Hence the magnitude of the pore pressures that arise at a point during heating will depend upon the relation between the rate of increase of the temperature and the propensity for the pore pressures to dissipate at that point. To determine the pore pressures requires coupling the heat transfer problem and consolidation problem through the thermal pore pressure coefficient $B_{t}$.

Figure 59 presents results from a simple example intended to illustrate rapid heating of oil sands but neglecting the temperature dependence of permeability and any convective effects. For a step temperature applied to the boundary, the governing solution for heat conduction is known. This can be used as input to a moving boundary problem in the theory of consolidation with pore pressure generation due to local temperature changes. Results have been calculated numerically using an explicit procedure. As might be anticipated, the maximum pore pressure that develops depends upon the ratio of the diffusivity of the medium to its coefficient of consolidation. More complex formulations will be needed to simulate in situ conditions realistically. However, this case does serve to draw attention to the major factors influencing thermally induced pore pressure changes.

The Author has been drawn to the investigation of geotechnical behaviour at elevated temperatures through his involvement in oil sand development, but there is increasing interest in high temperature effects for other reasons. In situ retorting of oil shales and in situ gasification of coal will both utilize underground cavities that must remain stable at elevated temperatures. Underground storage of nuclear waste generates heat and the long-term implications on security of containment provides another reason for interest in elevated temperature studies. Both temperature dependence of pore pressures and shearing resistance also have a bearing on the mechanics of faulting. Sibson (1973) has pointed out that the heating of confined water can reduce the effective stress and thereby facilitate fault movement. More recently, Lachenbruch (1980) has analysed in a comprehensive manner the interaction between fault movement and heat consolidation. His study 


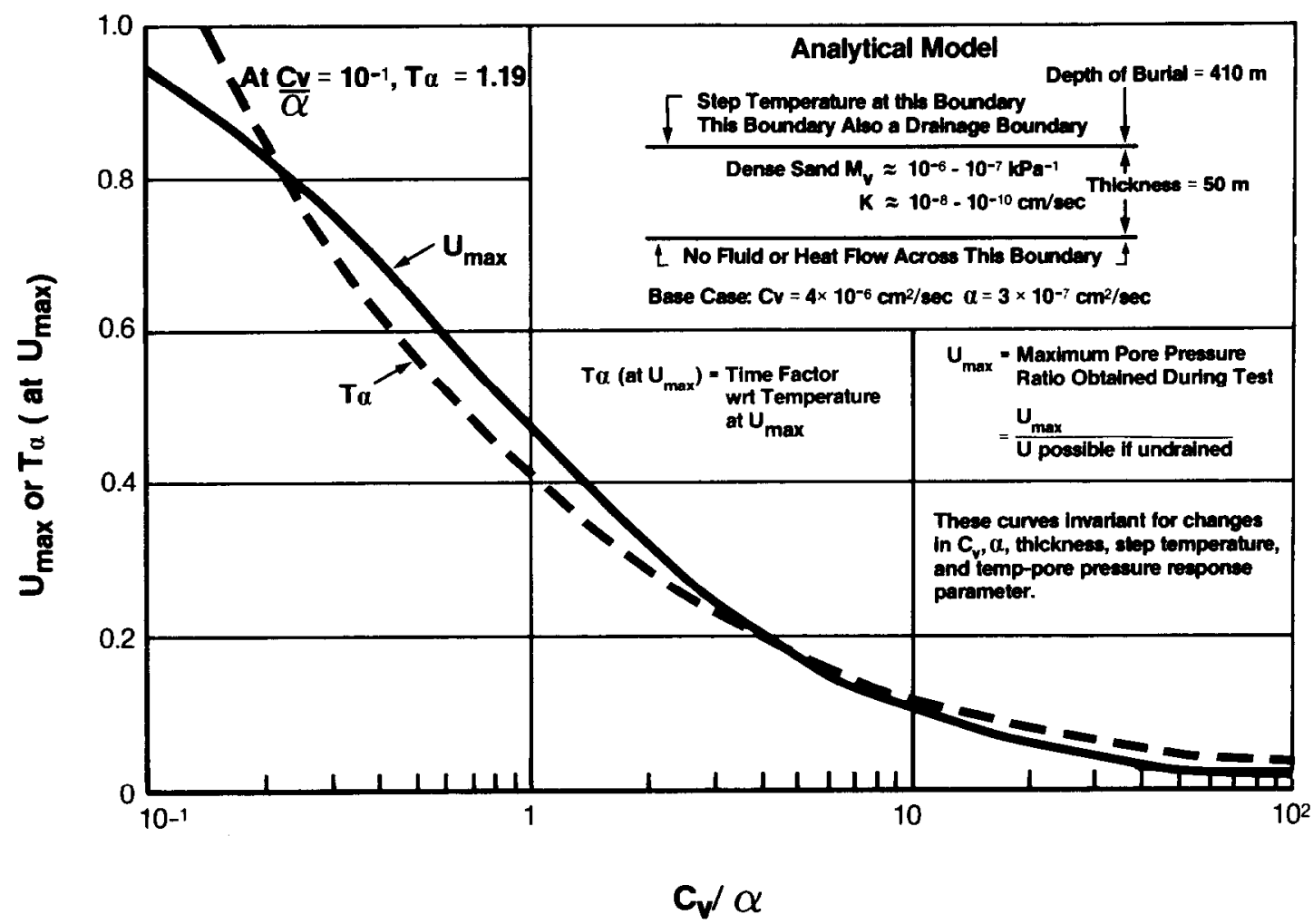

Fig. 59. Heat-consolidation: plot of $U_{\max }$ and $T \alpha$ (at $U_{\max }$ ) against $C_{\mathrm{v}} / \alpha$

reveals that there are several plausible mechanisms that can dramatically affect frictional resistance during an earthquake, but that present knowledge of the controlling parameters makes it difficult to determine which, if any, play a significant role.

\section{SUMMARY}

My selection of examples of geotechnical problems presented by frontier resource development is not intended to be restricted in a geographical sense and I fully recognize that other problems, in particular those associated with recent activities in the North Sea, are equally challenging to the geotechnical community. However, one feature of the problems reviewed that guided my selection is that in each case it has been necessary to reach beyond conventional concepts in order to contribute to their resolution in a rational manner. Moreover, by doing so, the potential of geotechnical engineering is extended to a broader range of activities.

In the case of creep in naturally frozen soils, it is possible to quantify the process occurring in nature in rheological terms, and this is of value both for solving immediate problems in permafrost engineering and for shedding light on the mechanics of some periglacial processes. However, the composite nature of natural permafrost appears to create anomalies when conventional sampling and testing is used to obtain design data, and these procedures need re-evaluation. In the case of frost heave, it has been necessary to absorb certain thermodynamic considerations in order to develop a predictive theory suitable for engineering needs. Both thaw-consolidation and heat-consolidation theories are concerned with the interaction of heat transfer and volume change of soils and both theories have broad application. Concepts from physical chemistry are necessary to account for the behaviour of gas-saturated porous media and the novel problems that they present.

Rankine is honoured in geotechnical engineering primarily for his work on earth pressure theory. However, this was really a very small portion of his contribution to engineering and science and in fact he is far better known for his contributions to thermodynamics and for his studies of the behaviour of gases and fluids. While assembling the material for this lecture it has given me some comfort to believe that illustrating the expanded range of geotechnical concerns draws even more from the work of this great engineer and scientist and therehy enhances his role in gentechnical engineering. We should be encouraged by his 
example to survey the diversity of geotechnical problems around us.

I have in my personal library a volume of Rankine's miscellaneous scientific papers published posthumously (Rankine, 1881). In a memoir of the author within the volume there is a quotation from an article by Clerk-Maxwell on Rankine.

'The scientific career of Rankine was marked by the gradual development of a singular power of bringing the most difficult investigations within the range of elementary methods. In his earlier papers, indeed, he appears as if battling with chaos, as he swims, or sinks, or wades, or creeps, or flies,... but he soon begins to pave a broad and beaten way over the dark abyss ....'

Geotechnical engineering has important contributions to make to many frontier resource developments. The problems are complex, but one hopes that some future commentator will be able to speak of geotechnical engineering in this area of endeavour as Clerk-Maxwell did of Rankine.

\section{ACKNOWLEDGEMENTS}

In assembling the material presented here I have drawn on the efforts of a large number of people not only within the University of Alberta but also associated with us in professional practice. $\mathrm{My}$ colleagues at the University of Alberta have always been supportive in every way and we have enjoyed the collaboration of a remarkably talented group of graduate students. The research on creep of a permafrost slope was undertaken by $\operatorname{Dr} K$. W. Savigny who drew on earlier studies by Dr E. C. McRoberts and Dr W. D. Roggensack. Dr J. F. Nixon, Mr L. B. Smith and Dr Roggensack contributed much of the material on thaw-consolidation behaviour. The investigations into frost heave mechanics have been brought to fruition by Dr J.-M. Konrad. Our research into oil sand behaviour has been conducted mainly by Dr M. B. Dusseault and Mr J. C. Sobkowicz.

I would like to thank my colleague Dr J. D. Scott for providing data from our high-temperature test facility for inclusion and $\mathrm{Mr}$ Sobkowicz for performing the heat-consolidation calculations. Both Dr W. Roggensack and Dr S. Thomson gave valuable assistance by critically reading drafts of the text but they bear no responsibility for the final version.

Finally, I would like to acknowledge the contribution of Dr R. M. Hardy, past-Dean of Engineering at the University of Alberta. Dr Hardy was the first in a Canadian university to initiate research into permafrost engineering and was first to study the geotechnical behaviour of oil sands. His pioneering efforts made it much easier for those who followed.

\section{REFERENCES}

Adam, D. G. \& Regensburg, B. O. (1980). Dragline mining at Syncrude. Proceedings of international mining conference, Calgary, session 1. Calgary: Alberta Chamber of Resources.

Aitken, G. (1974). Reduction of frost heace by surcharge stress. Technical report no. 184. Hanover, New Hampshire: Cold Regions Research and Engineering Laboratory.

Andersland, O. B. \& Anderson, D. M. (1978). Geotechnical enyineering for cold regions. New York: McGraw-Hill.

Anderson, D. M. \& Morgenstern, N. R. (1973). Physics, chemistry and mechanics of frozen ground: a review. In Permafrost: the North American contribution to the 2nd international conference, Yakutsk, 257-288. Washington: National Academy of Sciences.

Biermans, M. K., Dijkema, K. \& de Vries, D. A. (1978). Water movement in porous media towards an ice front. J. Hydrol. 37, 137-148.

Brooker, E. W. (1975). Tar sand mechanics and slope evaluation. Proc. 10th Can. Rock Mech. Symp. 1, $409-446$.

Byrne, P. M., Smith, B. L., Grigg, R. F. \& Stewart. W. P. (1980). A computer model for stress-strain and deformation analysis of oil sands. Proceedings of applied oil sands geoscience conference, Edmonton: University of Alberta. In press.

Campanella, R. G. \& Mitchell, J. K. (1968). Influence of temperature variations on soil behaviour. $J$. Soil Mech. Fdns Div., Am. Soc. Civ. Engrs 94, 709-734.

Chatterji, P. K., Smith, L. B., Insley, A. E. \& Sharma, L. (1979). Construction of saline creek tunnel in Athabasca oil sand. Can. Geotech. $J / 16,90-107$.

Crory, F. E. (1973). Settlement associated with the thawing of permafrost. In Permafrost: the North American contribution to the 2nd international conference, Yakutsk, 599-607. Washington: National Academy of Sciences

Demaison, G. J. (1977). Tar sands and super giant oil fields. In The oil sands of Canada-Venezuela, Redford, D. A. and Winestock, A. G. (eds), 9-16. Special volume 17. Montreal: Canadian Institute of Mining and Metallurgy.

Devenny, D. W. \& Raisbeck, J. M. (1980). Rock mechanics considerations for in-situ development of oil sands. In Underground rock engineering, 90-96. Montreal: Canadian Institute for Mining and Metallurgy.

Dusseault, M. B. (1980). Sample disturbance in Athabasca oil sand. Jl Can. Petrol. Tech. 19, 85-92.

Dusseault, M. B. \& Morgenstern, N. R. (1978a). Characteristics of natural slopes in the Athabasca oil sands. Can. Geotech. Jl 15, 202-215.

Dusseault, M. B. \& Morgenstern, N. R. (1978b). Shear strength of Athabasca oil sands. Can. Geotech. $J / 15$, 216-238.

Dusseault, M. B. \& Morgenstern, N. R. (1979). Locked sands. $Q$. Jl Engng Geol. 12, 117-132.

Hardy, R. M. \& Hemstock, R. A. (1963). Shearing strength characteristics of Athabasca oil sands. In $\mathrm{Karl} A$. Clark Volume, Carrigy, M. A. (ed.), 109-122. Information series no. 45. Edmonton: Research Council of Alberta.

Hardy, R. M. \& Scott, J. D. (1978). The 1963 GCOS test shaft. Proceedings of seminar on underground excat- 
ation in oil sands, paper no. 13. Edmonton: Alberta Oil Sands Technology and Research Authority.

Harris, M. C., Poppen, S. \& Morgenstern, N. R. (1979). Tunnels in oil sand. Jl Can. Petrol. Tech. 18, 1-7.

Harris, M. C. \& Sobkowicz, J. C. (1977). Engineering behaviour of oil sand. In The oil sands of Canada-Venezuela, Redford, D. A., and Winestock, A. G. (eds), 270-281. Special volume 17. Montreal: Canadian Institute of Mining and Metallurgy.

Hoekstra, P. (1969). Water movement and freezing pressures. Proc. Soil Sci. Soc. Am. 33, 512-518.

Hooke, R. L., Dahlin, B. B. \& Kauper, M. T. (1972). Creep of ice containing dispersed fine sand. J. Glaciology 11, 327-336.

Horswill, P. \& Horton, A. (1976). Cambering and valley bulging in the Gwash Valley at Empingham, Rutland. Phil. Trans. R. Soc., series A, 283, 427-451.

Hungr, O. \& Morgenstern, N. R. (1980). A numerical approach to predicting stresses and displacements around a three-dimensional pressurized fracture. Int. Jl Rock Mech. Mining Sci. 17, 333-338.

Jessberger, H. L. (1970). Ground frost: a listing and evaluation of more recent literature dealing with the effect of frost on the soil. Document no. AD 865128. Springfield, Virginia: National Technical Information Service.

Kay, B. D. \& Groenevelt, P. H. (1974). On the interaction of water and heat transport in frozen and unfrozen soils: I. Basic theory; the vapour phase. Proc. Soil Sci. Soc. Am. 38, 395-400.

Konrad, J. M. (1980). Frost heave mechanics. PhD thesis, University of Alberta, Edmonton.

Konrad, J. M. \& Morgenstern, N. R. (1980). A mechanistic theory of ice lens formation in fine grained soils. $\mathrm{Can}$. Geotech. $J l 17,473-483$.

Lachenbruch, A. H. (1970). Some estimates of the thermal effects of a heated pipeline in permafrost. Circular 632. Washington, DC: US Geological Survey.

Lachenbruch, A. H. (1980). Frictional heating, fluid pressure, and the resistance to fault motion. $J$. Geophys. Res. 85, 6097-6112.

Loch, J. P. G. \& Kay, B. D. (1978). Water redistribution in partially frozen, saturated silt under temperature gradients and overburden loads. Proc. Soil Sci. Soc. Am. 42, 400-406.

Mackay, J. R. (1974). Reticulate ice veins in permafrost, northern Canada. Can. Geotech. Jl 11, 230-237.

Mackay, J. R. (1980). The origin of hummocks, western Arctic coast, Canada. Can. Jl Earth Sci. 17, 9961006.

MacPherson, J. G., Watson, G. H. \& Koropatrick, A. (1970). Dykes on permafrost foundations in northern Manitoba. Can. Geotech. Jl 7, 356-364.

McRoberts, E. C. (1973). Stability of slopes in permafrost. PhD thesis, University of Alberta, Edmonton.

McRoberts, E. C. (1975). Some aspects of a simple secondary creep model for deformations in permafrost slopes. Can. Geotech. Jl 12, 98-105.

McRoberts, E. C., Fletcher, E. B. \& Nixon, J. F. (1978). Thaw consolidation effects in degrading permafrost. Proc. 3rd Int. Conf. Permafrost, Edmonton 1, 693-699.

McRoberts, E. C., Law, T. C. \& Murray, T. K. (1978). Creep tests on undisturbed ice-rich silt. Proc. 3rd Int. Conf. Permafrost, Edmonton 1, 539-545.

McRoberts, E. C. \& Morgenstern, N. R. (1974a). The stability of thawing slopes. Can. Geotech. Jl 11,
447-469.

McRoberts, E. C. \& Morgenstern, N. R. (1974b). Stability of slopes in frozen soil, Mackenzie Valley, NWT. Can. Geotech. Jl 11, 554-573.

Mageau, D. \& Morgenstern, N. R. (1979). Observations on moisture migration in frozen soils. Can. Geotech. Jl $17,54-60$.

Miller, R. D. (1972). Freezing and heaving of saturated and unsaturated soils. Highw. Res. Rec., no. 393, 1-11.

Mitchell, J. K. (1976). Fundamentals of soil behaviour. New York: J. Wiley.

Mitchell, R. F. \& Goodman, M. A. (1978). Permafrost thaw-subsidence casing design. J. Petrol. Tech. 30, 455-460.

Mittal, H. K. \& Hardy, R. M. (1977). Geotechnical aspects of a tar sand tailings dyke. Proceedings of conference on geotechnical practice for disposal of solid waste materials, 327-347. New York: American Society of Civil Engineers.

Morgenstern, N. R. (1967). Shear strength of stiff clay. Proceedings of geotechnical conference, Oslo 2, 59-72.

Morgenstern, N. R. \& Nixon, J. F. (1971). Onedimensional consolidation of thawing soils. Can. Geotech. Jl 8, 558-565.

Morgenstern, N. R. \& Nixon, J. F. (1975). An analysis of the performance of a warm-oil pipeline in permafrost, Inuvik, NWT. Can. Geotech. $J l$ 12, 199-208.

Morgenstern, N. R., Roggensack, W. D. \& Weaver, J. S. (1980). The behaviour of friction piles in ice and icerich soils. Can. Geotech. Jl 17, 405 415.

Morgenstern, N. R. \& Smith, L. B. (1973). Thawconsolidation tests on remoulded clays. Can. Geotech. J) 10, 25-40.

Nixon, J. F. (1978). First Canadian geotechnical colloquium: foundation design approaches in permafrost areas. Can. Geotech. Jl 15, 96-112.

Nixon, J. F. \& Ladanyi, B. (1978). Thaw consolidation. In Geotechnical engineering for cold regions, Andersland, O. B. and Anderson M. (eds), chapter 4. New York: McGraw-Hill.

Nixon, J. F. \& Morgenstern, N. R. (1973). The residual stress in thawing soils. Can. Geotech. Jl 10, 571-580.

Nixon, J. F. \& Morgenstern, N. R. (1974). Thawconsolidation tests on undisturbed fine-grained permafrost. Can. Geotech. $J l 11,202-214$.

Northern Engineering Service Ltd, Calgary (1975). Interim report on results from frost effects study. Unpublished.

Okumura, T. (1977). Stress change of soil sample taken from sea floor. Proc. 9 th Int. Conf. Soil Mech., Tokyo. Soil sampling, speciality session 2, 141-146.

Palmer, A. C. (1972). Thawing and differential settlement close to oil wells through permafrost. Division of Engineering report ARPA E-83. Providence, RI: Brown University.

Penner, E. \& Goodrich, L. E. (1980). Location of segregated ice in frost susceptible soil. Proc. 2nd Int. Symp. Ground Freezing, Trondheim, 626-639.

Pufahl, D. (1976). The stability of thawing slopes. PhD thesis, University of Alberta, Edmonton.

Pufahl, D. E. \& Morgenstern, N. R. (1979). Stabilization of planar landslides in permafrost. Can. Geotech. $J / \mathbf{1 6}$, 734-747.

Radd, F. J. \& Oertle, D. H. (1973). Experimental pressure studies of frost heave mechanisms and the growthfusion behaviour of ice. In Permafrost: the North 
American contribution to the 2nd international conference, Yakutsk, 257-288. Washington: National Academy of Sciences.

Rankine, W. J. M. (1881). Miscellaneous scientific papers. London: Charles Griffin.

Roggensack, W. D. (1977). Geotechnical properties of finegrained permafrost soils. PhD thesis, University of Alberta, Edmonton.

Roggensack, W. D. (1979). Techniques for core drilling in frozen soils. Proceedings of symposium on permafrost field methods and permafrost geophysics, technical memorandum no. 124. Ottawa: Associate Committee for Geotechnical Research, National Research Council of Canada.

Savigny, K. W. (1980). In situ analysis of naturally occurring creep in ice-rich permafrost soil. PhD thesis, University of Alberta, Edmonton.

Sego, D. C. (1980). Deformation of ice under low stresses. PhD thesis, University of Alberta, Edmonton.

Sibson, R. H. (1973). Interactions between temperature and pore-fluid pressure during earthquake faulling and a mechanism for partial or total stress relief. Nature, Lond. 243, 66-68.

Skempton, A. W. (1970). The consolidation of clays by gravitational compaction. Q. Jl Geol. Soc. Lond. 125, 373-411.

Skempton, A. W. \& Weeks, A. G. (1976). The Quaternary history of the Lower Greensand escarpment and Weald clay vale near Sevenoaks, Kent. Phil. Trans. $R$. Soc., Series A, 283, 493-525.

Slusarchuk, W., Clark, J., Nixon, J. F., Morgenstern, N. R. \& Gaskin, P. (1978). Field test results of a chilled pipeline buried in unfrozen ground. Proc. 3rd Int. Conf. Permafrost, Edmonton, 878-890.

Slusarchuk, W. A., Watson, G. H. \& Speer, T. L. (1973). Instrumentation around a warm oil pipeline buried in permafrost. Can. Geotech. J., 10, 227-245.

Speer, T. L., Watson, G. H. \& Rowley, R. K. (1973). Effects of ground-ice variability and resulting thaw settlements on buried oil pipelines. In Permafrost: the North American contribution to the 2 nd international conference, Yakutsk, 746-752. Washington: National Academy of Sciences.

Supple, M. A. (1980). Mining with bucket-wheel excavators. Proceedings of international mining conference, Calgary, Session 1. Calgary: Alberta Chamber of Resources.

Tsytovitch, N. A. (1975). The mechanics of frozen ground. New York: McGraw-Hill.

Vaughan, P. R. (1976). The deformations in the Empingham Valley slope. Phil. Trans. R. Soc., Series A, 283, 451-461.

Vignes, M. \& Dijkema, K. (1974). A model for the freezing of water in a dispersed medium. $J$. Colloid Interface Sci., 49, 165-172.

Vyalov, S. S., Dokuchayev, V. V. \& Sheynkman, D. R. (1980). Ground ice and ice-rich ground as structure foundations. Draft translation 737. Hanover, New Hampshire: Cold Regions Research and Engineering Laboratory.
Watson, G. H., Rowley, R. K. \& Slusarchuk, W. A. (1973). Performance of a warm oil pipeline buried in permafrost. In Permafrost: the North American contribution to the 2nd International conference, Yakutsk, 759-766. Washington: National Academy of Sciences.

Zaretskii, Y. K. (1968). Calculations of the settlement of thawing soil. Soil Mech. Fdn. Engng., No. 3, 151-155.

\section{VOTE OF THANKS}

In proposing a vote of thanks to Professor Morgenstern, Dr A. C. Meigh said:

'There are always interfaces in engineering. In our everyday geotechnical problems we have an interface between two disciplines-geology on the one hand, and soil and rock mechanics on the other. We frequently complain that some geologists and engineers are unable or unwilling to cross the boundary. It is clear that we need have no such complaint in the case of Professor Morgenstern. He always views engineering within its geological context.

'Again, tonight, he has put all his work properly into its geological framework. But he has done much more than that; he has straddled other boundaries. To investigate frozen soil problems he has had to consider thermodynamics and heat conduction in soils. In connection with the oil sands he has had to face the problems of dissolved gases and the effects of their coming out of solution.

'I am sure that we have all been impressed by both the scale and complexity of the problems which have been described to us and the practical difficulties which have accompanied their resolution. What is also impressive is that Morgenstern and his colleagues have focussed their attention, and their research efforts, on the major problems confronting the community within which they live, to the benefit not only of that community but others clscwherc. Surely this is the hallmark of a centre of engineering excellence. Furthermore they have tackled these problems in a comprehensive way, and have faced up to the necessity of developing new techniques in the laboratory and in the field, and of developing new analytical concepts.

'We have enjoyed a most stimulating Rankine Lecture. We have been shown dramatically that geotechnical problems cannot always be solved by conventional geotechnics. It is with the greatest of pleasure that I now propose a vote of thanks to Professor Morgenstern.'

The vote of thanks was accorded with acclamation. 